\title{
Technical Progress Report on Application and Development of Appropriate Tools and Technologies for Cost-Effective Carbon Sequestration
}

\author{
Annual Report \\ July 1, 2001 - June 30, 2002 \\ Principal Authors: \\ Bill Stanley \\ Sandra Brown \\ Ellen Hawes \\ Zoe Kant \\ Miguel Calmon \\ Gilberto Tiepolo
}

Date Issued: September 2002

Cooperative Agreement No. DE-FC26-01NT41151

Submitting Organization:

The Nature Conservancy

4245 North Fairfax Drive

Suite 100

Arlington, Virginia 22203

Subrecipients:

Programme for Belize

P.O. Box 749

\#1 Eyre Street

Belize City

Belize

Sociedade de Pesquisa em Vida Selvagem e Educação Ambiental

Rua Gutemberg, 296-Batel

Curitiba - PR - Brasil

CEP 80420-030

Winrock International

1611 North Kent Street

Arlington, VA 22209 


\section{DISCLAIMER}

This report was prepared as an account of work sponsored by an agency of the United States Government. Neither the United States Government nor any agency thereof, nor any of their employees, makes any warranty, express or implied, or assumes any legal liability or responsibility for the accuracy, completeness, or usefulness of any information, apparatus, product, or process disclosed, or represents that its use would not infringe privately owned rights. Reference herein to any specific commercial product, process, or service by trade name, trademark, manufacturer, or otherwise does not necessarily constitute or imply its endorsement, recommendation, or favoring by the United States Government of any agency thereof. The views and opinions of authors expressed herein do not necessarily state of relect hose of the Unied States Government or any agency thereof. 


\begin{abstract}
The Nature Conservancy is participating in a Cooperative Agreement with the Department of Energy (DOE) National Energy Technology Laboratory (NETL) to explore the compatibility of carbon sequestration in terrestrial ecosystems and the conservation of biodiversity. The title of the research projects is "Application and Development of Appropriate Tools and Technologies for Cost-Effective Carbon Sequestration”.

The objectives of the project are to: 1) improve carbon offset estimates produced in both the planning and implementation phases of projects; 2) build valid and standardized approaches to estimate project carbon benefits at a reasonable cost; and 3) lay the groundwork for implementing cost-effective projects, providing new testing ground for biodiversity protection and restoration projects that store additional atmospheric carbon. This Technical Progress Report discusses preliminary results of the six specific tasks that The Nature Conservancy is undertaking to answer research needs while facilitating the development of real projects with measurable greenhouse gas impacts. The specific tasks discussed include:
\end{abstract}

- Task 1: carbon inventory advancements

- Task 2: advanced videography testing

- Task 3: baseline method development

- Task 4: third-party technical advisory panel meetings

- Task 5: new project feasibility studies

- Task 6: development of new project software screening tool 


\section{TABLE OF CONTENTS}

Title Page........................................................................ 1

Disclaimer............................................................................. 2

Abstract........................................................................... 3

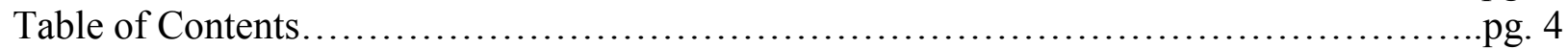

List of Graphical Material......................................................pg. 4

Executive Summary............................................................ 5

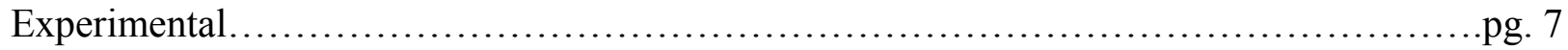

Results and Discussion......................................................... 10

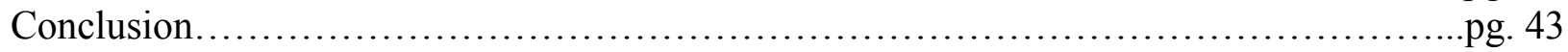

References..................................................................... 44

Appendices

Appendix 1.Measurement Protocol for 2002 Field Work...........................pg. 46

Appendix 2. Belize carbon inventory data...................................pg. 58

Appendix 3. LIBS workshop proposal................................... pg.64

Appendix 4. Belize videography images.................................... 74

Appendix 5. Kankakee Sands soil sampling coordinates......................... pg. 82

\section{LIST OF GRAPHICAL MATERIALS}

Figure 1. Destructive sampling figure........................................... 11

Figure 2. Fern tree graph with updated y axis....................................... 12

Figure 3. GM vegetation map................................................... 15

Figure 4. Areas of interest for potential restoration and protection activities as identified in association with the EDAF analysis..........................pg. 25

Figure 5. Area 3: Example of potential for restoration activities to develop corridors between remaining forest remnants.............................pg. 26

Figure 6. Classification and thematic change legends for previous two figures.............pg. 26

Figure 7. Depiction of the effect of spatial scale of analysis on final results..............pg. 27

Figure 8. Change in Land Cover from 1986-1999 in the Chilean $10^{\text {th }}$ Region................pg. 28

Figure 9. Bottomland Hardwood Restoration opportunities in the Mississippi

Alluvial Plain......................................................pg. 35

Figure 10. Characteristics used to prioritized mined land restoration opportunities in a section of the Clinch River Valley, in southwest Virginia...................pg. 38

Table 1. Expected Results from Feasibility Study ..................................pg. 40

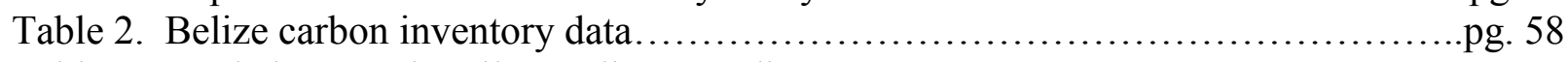

Table 3. Kankakee Sands soil sampling coordinates................................. 82 


\section{EXECUTIVE SUMMARY}

The Nature Conservancy is participating in a Cooperative Agreement with the Department of Energy (DOE) National Energy Technology Laboratory (NETL) to explore the compatibility of carbon sequestration in terrestrial ecosystems and the conservation of biodiversity. The work is being accomplished in close collaboration with NGO partners, government and academic institutions, and U.S. based companies. This research is being conducted on sites where carbon sequestration activities have been underway for several years, and on sites that appear to offer opportunities for carbon sequestration for those interested in taking action to reduce atmospheric greenhouse gas concentrations.

Our objectives are to: 1) improve carbon offset estimates produced in both the planning and implementation phases of projects; 2) build valid and standardized approaches to estimate project carbon benefits at a reasonable cost; and 3) lay the groundwork for implementing cost-effective projects, providing new testing ground for biodiversity protection and restoration projects that store additional atmospheric carbon. The Nature Conservancy is undertaking six specific tasks to answer research needs while facilitating the development of real projects with measurable greenhouse gas impacts. The specific tasks include:

- Task 1: carbon inventory advancements

- Task 2: advanced videography testing

- Task 3: baseline method development

- Task 4: third-party technical advisory panel meetings

- Task 5: new project feasibility studies

- Task 6: development of new project software screening tool

\section{Task 1: Carbon Inventory Advancements}

In Brazil, at projects supported by American Electric Power and General Motors, new regression equations were developed for fern trees (xaxim sp.). The equation shows that height and biomass are closely correlated. Some large trees were also harvested and weighed, and the results showed that there may need to be an adjustment made to the allometric equation that has been used to estimate biomass in trees. A vegetation map was also developed for this area in preparation for inventory work to be accomplished in coordination with advanced videography. Groundwork was also laid for future work for carrying out destructive sampling to be used with the videography, and to explore the use of Laser-induced Breakdown Spectroscopy (LIBS) to measure soil carbon at the sites.

In Belize, destructive sampling was carried out on various vegetation types in the pine savannah. The data will be used to establish correlations between parameters that can be measured using advanced videography (species type, heights, ground areas) and carbon storage.

\section{Task 2: Advanced Videography Testing}

In Brazil, the videography missions have been delayed by a difficulty in obtaining necessary permits. In Belize, the videography mission was flown in a pine savannah. The initial results are 
promising, suggesting that videography can be an effective tool for measuring carbon sequestration in heterogeneous landscapes.

\section{Task 3: Baseline Method Development}

The Conservancy developed a low-cost baseline modeling, called Euclidean Distance for Agriculture to Forest (EDAF) for projecting likely deforestation trends. The approach provides an alternative to the more sophisticated GEOMOD model. While GEOMOD is more flexible and likely more accurate given good data, EDAF is less data-intensive and less cumbersome, and less open to subjectivity. EDAF has been applied to 3 sites in Brazil. EDAF analysis have shown that the scale of the analysis that is used to determine trends has a significant impact on results. Given this finding, The Conservancy is now experimenting with various methods for objectively determining the appropriate spatial scale of analysis. GEOMOD was thoroughly tested at one site in Brazil, but with funding largely outside of that provided under this cooperative agreement. A next step is to test EDAF at the same site in Brazil where GEOMOD has been used to compare the results.

\section{Task 4: Third-Party Technical Advisory Panel Meetings}

Standardizing measurement procedures and methods for carbon monitoring is a major step in the demonstration that land use projects, and emissions avoidance projects in particular, should be credited under a future regulatory mechanism. The Technical Advisory Panel (TAP) gathers a group of experts to evaluate existing methods and to develop standardized carbon offset measurement guidelines for use in all land-use change and forestry projects. Considerable planning was completed for holding the first Technical Advisory Panel (TAP) meeting. The meeting, which has since been held, covered baseline methods and leakage analyses and was attended by representatives of the private sector, U.S. government, and international nongovernmental organizations. Panel members included representatives of the U.S. government, an academic, a private sector entity, and an environmental organization.

\section{Task 5: New Project Feasibility Studies}

Work is underway on feasibility studies in four sites: Mississippi Alluvial Valley, Apache Highlands in Arizona, southwestern Virginia, and Kankakee Sands in Indiana. Considerable amounts of spatial data were collected to identify potential sites for grassland restoration and for reforestation. Preliminary data on carbon sequestration rates have also been identified. Also, soil samples were collected at a grassland restoration site in Indiana, where little research had previously been conducted on the magnitude of sequestration expected given restoration following use as agriculture. The preliminary assessment of the four project ideas suggests that two of the projects will be viable, and two of the projects would not be viable given the amounts that carbon offset purchasers would currently be willing to pay.

\section{Task 6: Development of New Project Software Screening Tool}

Carbon sequestration data that can be used in a screening model have been identified for many forest-based project ideas in the U.S. Data being gathered through the feasibility studies has been used to develop some simple screening models that can be built upon in the future. This task will be proceed slowly until the feasibility studies are completed. 


\section{EXPIRIMENTAL}

\section{Task 1: Carbon Inventory Advancements}

The boundaries of each of the vegetation communities found in the area of interest are identified using imagery from the advanced videography or other available remote sensing data. For this research, the main goal of the sampling in the forest vegetation is to equate what we can identify from the advanced videography imagery (species, crown diameter, and height) with on-theground measurements.

For mosts forests or vegetation types the approach is to develop a relationship between biomass and crown diameter/total height. Since the videography system will provide an aerial shot of the vegetation as well as a measurement of total height, trees or other representative vegetation that cover a range of heights and diameters will be selected. The total height, canopy diameter and $\mathrm{dbh}$ are measured for each representative piece of vegetation selected. These samples then are destructively harvested and weighed to determine biomass and associated carbon storage. With those results we develop a new correlation between diameter and height to predict biomass carbon for the rest of the vegetation in the strata.

To measure the diameter of tree canopies and the total height of trees in the pine/oak and hardwood/riparian forest communities, we use a method developed by Chris Hayward (Winrock International). The steps for the measurements are as follows:

1. Measure the height of the tree: This requires the user to stand far enough away from the tree to view the top of the tree and record two measurements: the distance between the user and the base of the tree (measured with the tape measure or DME), and the angle from the user to the top of the tree (measured with the clinometer).

2. Measure the tree crown radii: This requires the user to stand directly beneath the tree and look up at the crown. Using the clinometer, measure the angle from the main stem to the edge of the crown. On some clinometers, it is required to subtract this measurement from 90 to get the actual angle. Repeat this step, taking the second measurement at a right angle from the first. Repeat until four mesurements are obtained. This will allow the user to record the asymmetry of many tree crowns.

3. Calculating tree height and crown area: This can easily be done in an Excel spreadsheet. Tree height is calculated by multiplying the distance from the user to the tree by the tangent of the angle to the top of the tree $(\mathrm{hgt}=\mathrm{x} * \tan \theta)$. The crown radii are calculated by multiplying the height of the tree by the angle to the edge of the crown $(\mathrm{a}=$ hgt $* \tan \theta)$. The crown area is calculated by multiplying the two crown radii measurements by pi $\left(\right.$ Area $\left.=a^{*} b^{*} \pi\right)$.

More heterogeneous landscapes, such as the pine savannah in Belize, are sampled using clip plots. Clip plots are aluminum sample frames $60 \mathrm{~cm}$ in diameter that are placed on the ground at predetermined locations. All vegetation-herbaceous and other non-tree vegetation - that falls inside the clip plot frames is cut, placed in a sample bag and weighed. Once all the vegetation has been cut and weighed, a sub-sample will be collected for moisture content determination. 


\section{Task 2: Advanced Videography Testing}

Advanced videography utilizes GPS-base mosaicing techniques and off-the-shelf equipment with camera mounts that can be attached to any Cessna aircraft to generate accurate raster-based photomaps. After the videography is flown, 3-dimensional (3D) reconstruction are developed from video that identifies terrain features and vegetation types and measures the height and mass of individual trees. The measurements from the videography are then calibrated with the carbon inventory data and regression equations from Task 1 to estimate carbon remotely.

\section{Task 3: Baseline Method Development}

Baseline analysis is being conducted using two different models. The first model is GEOMOD. GEOMOD was developed by researchers at the State University of New York (SUNY) College of Environmental Science and Forestry with funding from the U.S. Department of Energy, Carbon Dioxide Research Program, Atmospheric and Climatic Change Division. A computerized geographic model, GEOMOD simulates the pattern of land-use change in the tropics from non-developed to developed land. The model is FORTRAN-based and requires a spatially referenced set of equally dimensioned digital grid (raster) maps as inputs. To depict "without-project" scenarios, those areas impacted by clearing or other land cover change between two points in time will be identified. This will allow determination of the rate of deforestation, identification of the location of areas converted, and calculation of the percentage of the total study area deforested, and rates of forestation. Each potential driver or combination of drivers will be assessed to determine which provides the greatest predictive power. Once the rate and the best set of drivers have been selected, the model can be run for a specified timeframe, looking at output every year, 5 years, 10 years, etc.

For each of the proposed study areas, the following inputs, at a minimum, are required:

1. A digital elevation model (DEM) or a digital coverage of elevation contours and maximum/minimum elevation points from which a DEM can be prepared using ARC/INFO's (ESRI) Tin generator. Slope and aspect, which are potentially important drivers, are derived from this.

2. A digital hydrography coverage (streams, lakes). This is used in the analysis as well as in the creation of the DEM.

3. A digital coverage of roads.

4. A coverage of any other transportation routes (rail, air, boat) that give people access to the interior.

5. Classified and geo-referenced land-use maps derived from either aerial photography or satellite imagery for at least two points in time, preferably at the same scale, and no smaller than 1:24,000, with a grid cell resolution no larger than 30 x 30 meters. Existing settlements should be one of the identified land-use classes. Any land guaranteed as "set aside" (i.e. protected) should be indicated.

6. Population data over the same period of time.

7. Climate differences over the project area. If there is a considerable elevation gradient, then both mean annual temperature and precipitation measurements from one or more nearby weather monitoring stations, if available, will be useful. (The elevation and geographic coordinates of that station are required as well.)

Additional useful data include: 
1. Economic data such as crop production, investments, or exports.

2. A digital soil map and accompanying information on such soil characteristics as soil thickness, drainage characteristics, annual flooding, infiltration rate, and percent silt, clay, and loam.

3. Any other climatic data such as PET, daily insolation, cloud cover, etc. could be useful.

4. Carbon storage estimates (See Tasks 1\&2) for digitized vegetation polygons or, if the land use map is classified at a level that supports carbon storage estimates, an accompanying table would be useful.

GEOMOD can produce a time series of land-use maps at a time interval to be chosen over the selected time-frame (i.e. 40 years) for each project. Each digital map is produced as a color print with legend, and the area in each land-use type will be reported in an accompanying table. Additionally, the output and accompanying predicted data can be displayed in a time-series display module called ECOPLOT (RPA, undated). ECOPLOT displays the changing landscape over time as a central image, along with small graphs of important driving variables and program outputs displayed at the image margins (e.g. population growth, GDP, linear miles of roads built, biomass, carbon stored in the vegetation, etc.).

The Conservancy EDAF model is a potentially more cost-effective method that is used early in project implementation to come up with a reasonable baseline estimate. A simplified prediction of future deforestation and other landcover change possibilities is made. Using the baseline landcover trends, the potential future fate of the land cover is quantified. Certain rules are established prior to the modeling (such as distance from existing agriculture) that identify those areas that are relatively more prone to deforestation than are other areas.

In the EDAF method, baseline trends are determined using remote sensing change detection techniques. Landsat TM data, with a resolution of $30 \mathrm{~m}$ and 7 spectral bands, are gathered for the site. Two time periods of Landsat data are gathered. The first data date is generally late 1980's or early 1990's, and the second is as close to the present as possible. Using field data gathered during a visit to the site, the scenes are classified to up to 20-30 landcover classes, including different types and condition of forests. The two landcover maps are then compared and changes from one class to another are noted. Change maps are made to visually display the results, and tables are produced giving percentage, and actual area of change, and anticipated future rate of change from one landcover type to another.

For either of the models, it is necessary to identify potential project boundaries to which the models will be applied. This generally requires a basic analysis of forest conservation and/or reforestation priorities and the development of a basic scenario of what the carbon offset generating activity or activities would be. 


\section{RESULTS AND DISCUSSION}

\section{Task 1: Carbon Inventory Advancements}

\section{Summary of Objectives}

Carbon inventory plans are designed to quantify the amount of carbon stored in key pools on a periodic basis. These inventories are used to estimate the differences between the with- and without-project carbon pools and are the primary basis for determination of project greenhouse gas (GHG) benefits. Through ongoing carbon inventory work in TNC's pilot projects, several aspects of the carbon inventories that could be improved or significantly strengthened were identified. These were allometric regression equations, geo-referenced sample plots, carbon inventory plots and destructive sampling for the calibration of advanced videography measurements, and soil carbon measurement. The following tasks are being carried out through our work under this agreement:

- Establish permanent geo-referenced sample plots for periodic measurements of changes in carbon pools in the project area (2003).

- Measure tree diameters and heights and sample soil, forest floor litter, and understory to estimate carbon storage (2002-2003).

- Use database of tree biomass, and new data from destructive sampling of additional trees to develop and/or refine allometric regression equations (to estimate biomass carbon based on tree measurements) for selected species and forest strata (2002-2003).

- Test and calibrate LIBS for measuring soil carbon in the General Motors and AEP project areas in Brazil (2002-2003).

- Use or develop software to assist in calculation of minimum sample size, assignment of sample unit locations, determination of the minimum spacing for plots, calculation of precision of carbon benefits, calculation of costs of inventorying and monitoring, and optimization of site-specific monitoring plans (2003).

\section{Progress}

\section{Destructive Sampling and Allometric Regression}

Brazil - Atlantic Forest Biome

Destructive Sampling was carried out on trees between 20 and 85 centimeters diameter at breast height (dbh). Specifically, in October, 2001, four trees with dbh $50-84 \mathrm{~cm}$ of different species that are commonly found at the project sites, and one tree with $\mathrm{dbh} 25-50 \mathrm{~cm}$, were measured for dbh, crown diameter, and height at the Guaraqueçaba Climate Action Project in Brazil. They were then harvested and weighed. 
The preliminary results suggested that biomass for trees in the Atlantic Forest fall somewhere between the general wet biomass equation and the general moist biomass equation (Brown, $\mathrm{S}$. 1997), and that the wet equation that we are currently using in the project may be underestimating the total biomass and carbon stock of the project (see Figure 1). Dr. Sandra Brown from Winrock International reviewed the preliminary results, and agreed that more data needs to be collected to verify the accuracy of the equations. The ultimate goal of this research component is to cut 10-15 more trees in the next 1-2 years and generate a more specific and accurate equation for the project areas and Atlantic Forest region.

\section{Figure 1. General Biomass Equations vs. Results}

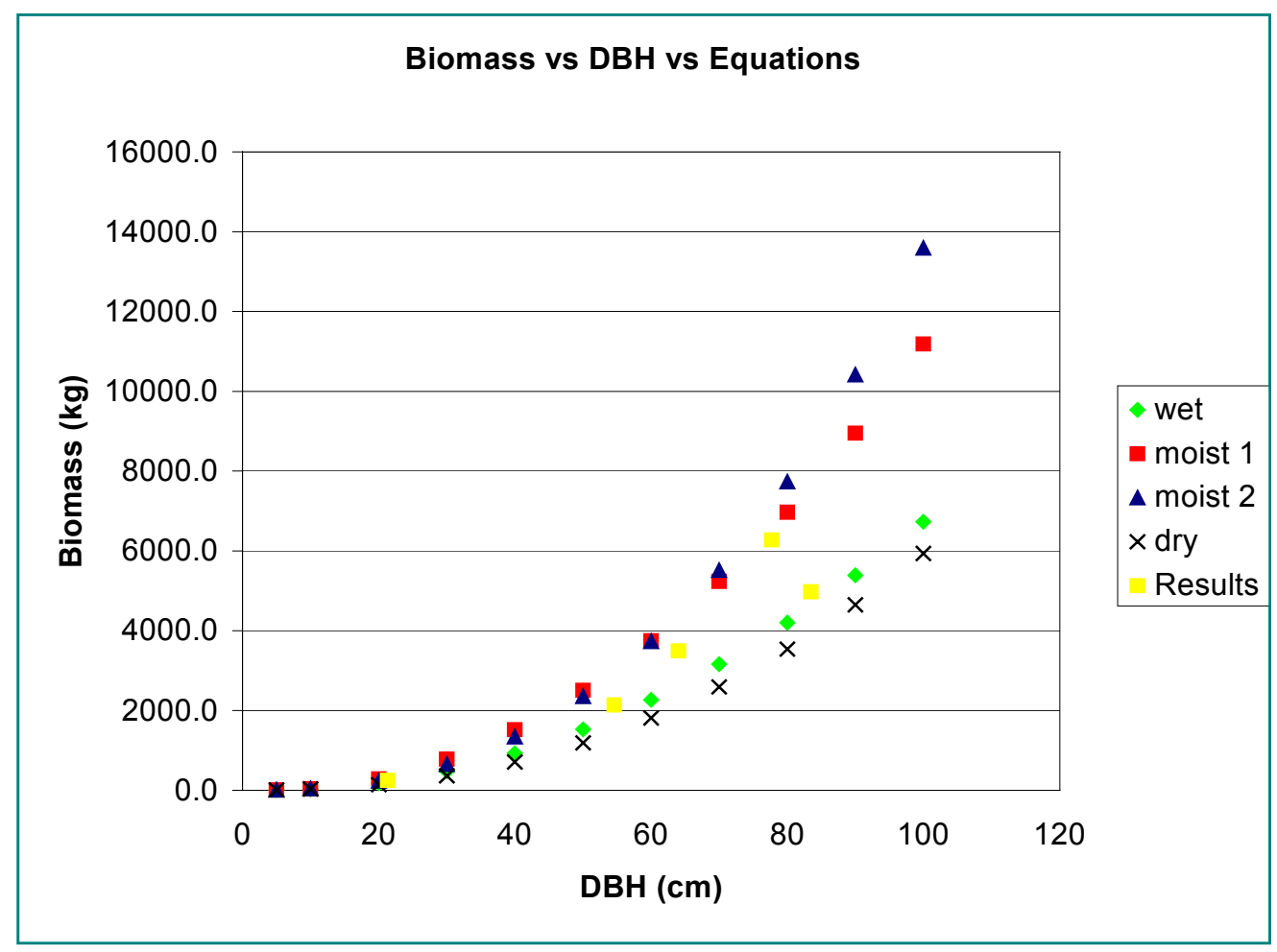

To improve the biomass equation and create more confidence in its use, we will conduct destructive sampling on a few larger and taller trees (e.g. height range $5.0-8.0 \mathrm{~m}$, dbh $>70 \mathrm{~cm}$ ). A request was submitted to the Brazilian Environmental Agency, Instituto Brasileiro do Meio Ambiente e dos Recursos Naturais Renováveis (IBAMA), to get a permit to cut 5 such trees.

To improve the accuracy of estimates for the forest pool composed of trees with height $>1.3 \mathrm{~m}$ and $\mathrm{dbh}<5 \mathrm{~cm}$, another destructive sampling session was conducted. Ten trees were measured, harvested, and weighed within each strata (very young, young, medium and advanced forests) to verify the parameters that have been used to estimate biomass for smaller trees.

During the destructive sampling, tree ferns (xaxim) were also cut, weighed, and analyzed. This represents truly original research as no existing regressions for fern trees are known to us. The fern biomass equation was developed and a total of 22 trees were used to determine the 
relationship between biomass $\mathrm{x}$ height and biomass $\mathrm{x}$ dbh. By looking at the results (Figure 2), the relationship between height and biomass showed a strong correlation, where the dbh $\mathrm{x}$ biomass showed a poor correlation. Therefore, we recommend the use of the relationship height $\mathrm{x}$ biomass when estimating aboveground biomass of ferns in the Atlantic Forest Biome.

\section{Figure 2. Tree Fern Biomass Equations}
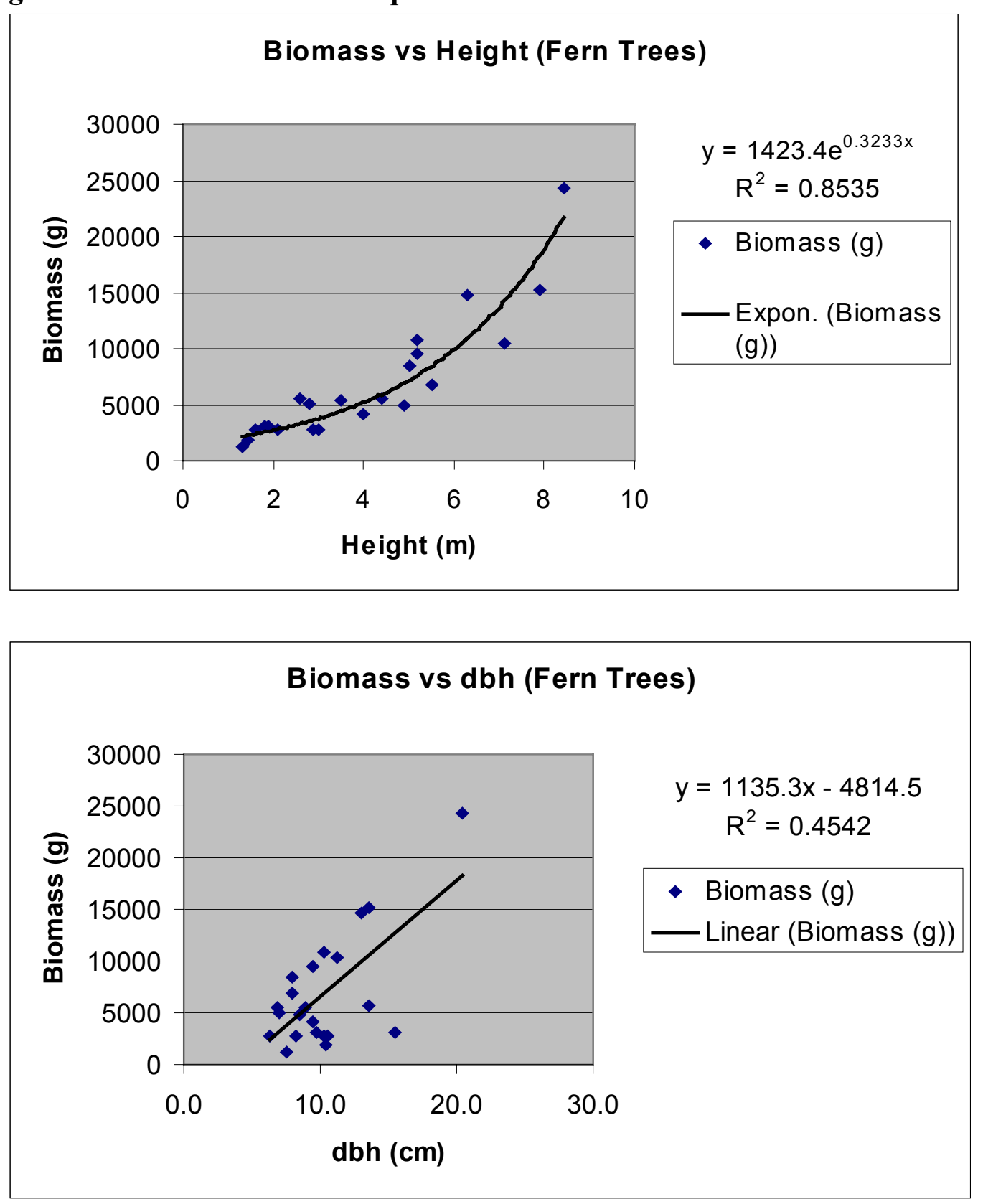

SPVS and TNC have been discussing the possibility of doing destructive sampling to estimate the biomass of roots and improve the ability to estimate total below ground biomass for the different forest strata. Gilberto Tiepolo (SPVS) has already contacted the Federal University of 
Paraná (Forestry Department) to collaborate on this effort and we would be interested in discussing this further with DOE

$\underline{\text { Belize }}$

Winrock International developed a one-page carbon inventory plan for the Pine Savannah, describing appropriate methods to locate trees and collect field data (e.g. tree heights, crown diameters, and diameter at breast height). This plan was used by the Programme for Belize to make field measurements during March $3^{\text {rd }}-8^{\text {th }}$. See attached plan (Appendix 1). This plan is being used as the basis for similar work to be conducted in Brazil in 2003.

Programme for Belize completed field measurements and destructive sampling of Caribbean pine, palmettos, and other vegetation. These data will be used in coordination with the videography measurements below. Since the data is still in raw form and is quite extensive, it is not all included in the report. A table with data from several tree species is included as an attachment in the back of the report (Appendix 2).

\section{Basal Area Correlations To Biomass}

We are working to establish a relationship between basal area and biomass. The purpose of this work was to further explore the correlation between basal area and carbon storage. Given a strong correlation, the basal area assessment will allow for a quick assessment of biomass and correlated carbon storage. This procedure was tested to determine whether it is accurate enough for a preliminary estimate to be used during the preliminary inventory phase of new projects (e.g. preliminary baseline assessment). Therefore, this work contributes to both baseline and inventory tasks.

\section{$\underline{\text { Brazil }}$}

A basal area gauge (Cruiser's Crutch) was used to estimate basal area of all permanent plots found in the Guaraqueçaba Climate Action Project (AEP Project) and to develop a relationship between basal area and biomass. Basal area was estimated on 116 plots within the different strata ( $8 \mathrm{VY}, 14 \mathrm{Y}, 46 \mathrm{M}$, and $48 \mathrm{DM}$ ). Not surprisingly, there is a strong correlation of about 1:1 between the calculated basal area (using dbh) and the Cruiser's Crutch basal area.. The next step is to identify the main variables (forest type, user error, selection of basal area factor, density of understory, etc.) that could affect the reliability of this tool for such an application.

Since there is a correlation between basal area and biomass, this tool could provide a quick and easy preliminary estimate of carbon storage. Even though no additional detailed analysis need to be done, this tool could potentially be used to estimate the variance of the different strata and become part of the preliminary carbon inventory program (ex. Preliminary estimates of the number of plots). This will be particularly useful on new projects or as a part of the field verification in baseline studies. 
$\underline{\text { Belize }}$

A small subset of basal area prism measurements were taken to assess basal area measurements taken with prisms relative to basal area measurements in permanent plots. These data will be added to those taken in Brazil which are presented above.

\section{Vegetation Mapping}

A vegetation map of project areas are needed in order to stratify the project area prior to plot establishment, and for comparisons with advanced videography. SPVS completed the vegetation mapping for the General Motors project area in the Cachoeira River Basin (Figure 3). The first step in the research consisted of identifying, separating, and drawing polygons of the main vegetation patterns on the 8 orthophotos $(1: 10,000)$ and aerial photos $(1: 30,000)$ that cover the GM project area. Additional analysis was carried out on areas that may become part of future expansion of the project. SPVS's GIS laboratory (LABSIG) then edited and labeled the polygons. Finally, the vegetation map was field verified and refined by using other GIS data layers such as soil map and topography.

In order to leverage the benefit of the vegetation map to the research, a soil map was completed for the General Motors project using internal funding. The combination of the vegetation and soil maps will not only allow the team to improve and refine the stratification, but will also give more confidence when estimating future growth rates of the forests within the project area and for soil sample planning in coordination with LIBS. The results of the videography project will be used for additional stratification and further refinement of the vegetation map.

Figure 3. Vegetation map for the Cachoeira River Basin Project (GM) 


\section{Cachoeira River Basin Project (GM)}

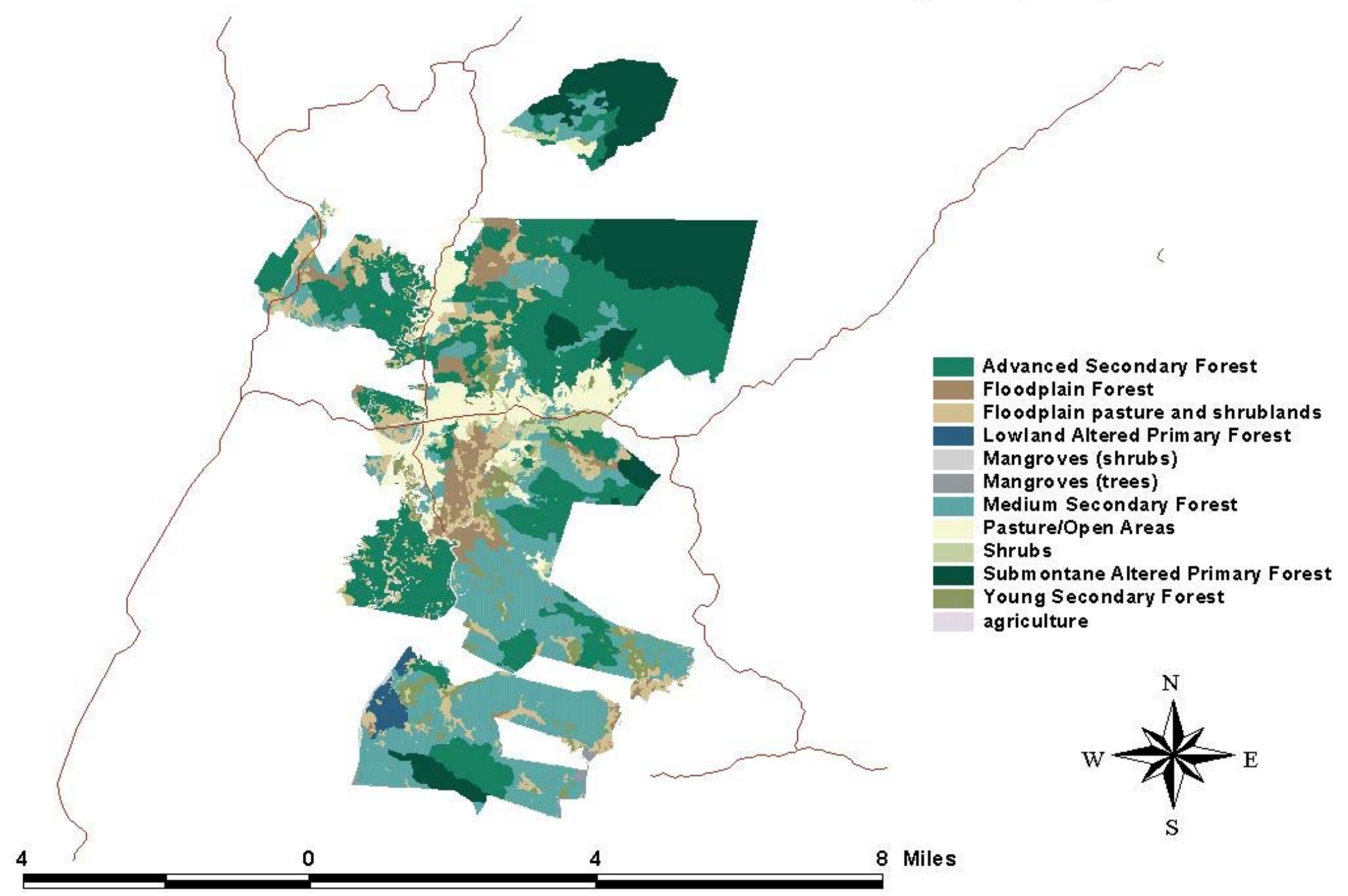




\section{4. $L I B S$}

The Nature Conservancy has identified soil carbon as a key area that could be further measured in order to improve project carbon inventories. Existing technologies have made extensive soil carbon measurement too costly in the past. As part of the Los Alamos National Laboratory (LANL) program on Terrestrial Carbon Sequestration and Management, LANL has developed a method for soil carbon analysis based on laser-induced breakdown spectroscopy (LIBS). The calibration of LIBS for measuring soil carbon on carbon projects in Brazil is a promising way to improve the soil carbon inventories of those projects in a cost-effective manner. The three projects where LIBS will be calibrate are the Guaraqueçaba Climate Action Project/AEP (Serra do Itaqui Natural Reserve), The Atlantic Rainforest Restoration Project/GM (Cachoeira River Basin), and The Antonina Pilot Reforestation Project/Chevron/Texaco (Morro da Minas Reserve).

Mike Ebinger from LANL traveled to Brazil during the week of January $13-19^{\text {th }}$ to gather some initial information about the project sites. He determined that measurements taken by LIBS could include a) comparisons of plots converted from buffalo ranching to forest revegetation at different time intervals and with baseline sites; b) evaluation of different reforestation strategies and different time periods when these strategies have been in place; c) correlation of soil carbon with soil maps of the area; and d) overall carbon inventory from various plots along several different gradients such as vegetation type, moisture regime, and time.

After this initial visit, planning commenced to bring U. S. scientists and LIBS equipment to study areas near Curitiba, Paraná, Brazil to conduct a demonstration workshop in the field. The goal of this workshop will be to familiarize Brazilian soil carbon experts with LIBS, as well as familiarize LANL scientists with advances in soil measurement in Brazil. The workshop will also be an opportunity to calibrate LIBS on the project areas, and discuss its potential and cost vis-à-vis other methods. The workshop proposal is attached (Appendix 3).

TNC discussed obtaining additional funding for the LIBS workshop in Brazil with the DOE Project Officer (John Litynski). The idea of the workshop was well accepted and it was requested that we submit a formal proposal describing the purpose, deliverables and budget. This proposal will be submitted in the first quarter of the next project year.

\section{General}

Several presentations were developed and provided pursuant to this work. In particular, Bill Stanley gave a presentation at the $5^{\text {th }}$ Electric Utilities Environmental Conference on Air Quality and Global Climate Change in Tucson, Arizona titled "Protecting Biodiversity and Improving Offset Measurement Techniques through Pilot Projects". He also gave a presentation at the Regional Partnerships in Terrestrial Carbon Sequestration conference in Lexington, Kentucky in 2001 titled "Carbon Sequestration and Conservation: A Non-Governmental Organization Perspective". Bill Stanley is providing a presentation to the 2002 Convention of the Society of American Foresters, and Zoe Kant, Sandra Brown, and Bill Stanley are scheduled to give presentations on associated research at the 2002 USDA conference on carbon sequestration. 


\section{Problems Encountered}

The three project sites in Brazil are located within a legally designated protected area, the Guaraqueçaba Environmental Protected Area (GEPA). While a Protected Area is not the equivalent of a park or reserve, it brings certain official restrictions, especially on harvesting native tree species. Therefore, it is difficult to get permission from the Brazilian environmental agency, IBAMA, to cut more than a small number of trees at a time for destructive sampling. Therefore, the destructive sampling research cannot be conducted all at once.

\section{Deliverables in next reporting period (July 02 - June 03)}

- LIBS workshop. The workshop and an associated written report will developed.

- Installation of permanent plots, collection and analysis of data. The report will consist of a map showing the locations of the plots and various strata, tables showing the results of the analyses, statistical analyses of precision, and discussion of future needs.

- Further Destructive Sampling, analysis of results, and written reports. Additional equations will be developed and refined. The various methods and equations will be presented in a written report.

\section{Assessment of Future Progress}

We expect to complete the bulk of the inventory work in 2003. The only factor that could delay the work and deliverables described above would be a failure to obtain permission from the appropriate environmental agencies in Brazil to complete the destructive sampling work. 


\section{Task 2: Advanced Videography Testing}

\section{Summary of Objectives}

Reducing carbon inventory costs can help to ensure cost-effective production of offsets in the land-use change and forestry sector. One method of reducing carbon inventory and monitoring costs is through the use of remote-sensing technologies. However, there are distinct limitations to satellite imagery when used in tropical environments to monitor fine scale, or project level land-use change, especially on heterogeneous landscapes. Selective logging, small road development, and appearance of small farm holdings ( $1 / 4$ hectare or less) that indicate colonization of a region or intrusion into a reserve are usually too small to be picked up by the coarse resolution of Landsat or Spot images. Also, the persistent cloud cover in these areas often makes it difficult to obtain satellite coverage on a time scale that is useful for local monitoring.

The Nature Conservancy and its partners are working together with Winrock International to develop low-cost video and digital camera systems to support large-scale aerial surveys of remote regions. Since this research project launched last year, additional applications of advanced videography have been identified and the research objectives have been expanded accordingly. The expanded objectives of this research are to:

- Find out whether measurements of crown diameter or vegetation area and height made from the air can be sufficiently correlated to biomass to accurately calculate the carbon storage in vegetation;.

- Determine how well advanced videography can monitor carbon inventories on heterogeneous landscapes, such as open forest pine savannah or patchy natural regeneration;

- Assess the effectiveness of advanced videography in measuring carbon storage in closed canopy systems; and

- Assess advanced videography as a stratification tool.

Some regression equations for calculating above-ground biomass based on crown diameter measurements and height obtained from videography have already been developed, however, it is necessary to improve these equations in order to better describe the correlation between carbon storage measured through ground sampling and carbon storage calculated using videography. Furthermore, these equations were developed for relatively homogenous landscapes and for a specific type of vegetation, closed forest. This research applies videography to the measurement of carbon in heterogeneous landscapes composed of shrub, tree, palm, hardwood, and conifer mixtures.

In addition to developing and improving regression equations, this research will seek to increase the accuracy with which the flight lines for videography are established. The goal is to be able to fly over a strip whose midpoint is within 2 to 3 meters of the plot center. The application of videography in this proposal will also experiment with the use of videography before ground sampling. A comparison of the results of typical inventory methods and videography will shed light into which of the two techniques gives the most accurate results at the lowest cost. 


\section{Progress}

Videography was conducted in March on the Rio Bravo Climate Action Project in Belize, and we are awaiting the final report. However, we faced several delays in getting permits to conduct the work in Brazil.

\section{$\underline{\text { Brazil }}$}

Sandra Brown of Winrock visited the Brazil project sites in August to advise in the creation a plan for destructive sampling in heterogeneous shrub/grassland areas. The results from the destructive sampling undertaken on these plots (as a part of Task 1) will be correlated with the videography. The sampling plan is under development at this time.

\section{$\underline{\text { Belize }}$}

From March $4^{\text {th }}-8^{\text {th }}$, Bill Stanley joined Matt Delaney and Dana Slaymaker of Winrock in Belize to conduct the advanced videography session of the Rio Bravo pine savannah work. They worked in collaboration with a team from Programme for Belize led by Wilber Sabido and Darryl Novelo. The first step of the session was to modify the videography mounting equipment for use on a local Cessna aircraft, and this was completed successfully. However, to fly a videography mission, skies must be cloud free to a height of around 1,500 feet for the digital video strips and 4,000 feet for the digital photography that can be organized into a mosaic to get $100 \%$ coverage. Unfortunately, the skies were overcast most of the week, allowing flying during a single day when skies where fairly clear. The higher altitude digital photography was not possible.

Even though the time available for data collection was limited due to the weather, Winrock was able to take video of about $40 \%$ of the pine savannah, providing a sample of the area that should be highly representative of the site as a whole. The video was of very high quality and was made available for viewing by field team members the day after it was shot. Tree crowns, individual shrubs, palmettos, and other associations were easy to see. Using 3-D glasses, the team members were able to clearly discern the varying heights of the different vegetative associations.

A presentation from Dr. Sandra Brown of Winrock International, showing images from the Belize videography flyover, is attached. (Appendix 3)

Winrock International is continuing to process and quantify the videography imagery. Programme for Belize has provided Winrock with the destructive sampling data (Task 1) so that they can begin processing it and establishing the biomass and carbon regressions. These regressions will then be used in conjunction with the videography data to develop a carbon storage estimate for the entire pine savannah located within the project area. We estimate that we will receive the final report with the videography imagery and carbon storage estimate from Winrock by December, 2002. 


\section{Problems Encountered}

\section{$\underline{\text { Brazil }}$}

Our local Brazilian partner, Sociedade de Pesquisa em Vida Selvagem e Educação Amiental (SPVS), is leading the process to obtain permits to conduct the videography in Brazil. SPVS received permission from IBAMA (Instituto Brasileiro do Meio Ambiente e dos Recursos Naturais Renováveis) to test videography on the three projects in the Atlantic Forest. IBAMA then informed SPVS that they would need to submit a project plan to CNPq (Conselho Nacional de Desenvolvimento Científico e Tecnológico) for their assessment and final approval. SPVS submitted a proposal to CNPq in February, and kept in close contact with one of the coordinators of $\mathrm{CNPq}$ to follow-up on the status of their decision. By law, $\mathrm{CNPq}$ had 90 days to respond. The proposal was routed through IBAMA first, and was not forwarded on to CNPq and MCT (Ministry of Science Technology) until May, but CNPq was still able to approve the proposal by June.

Unfortunately, even though CNPq/MCT/IBAMA authorized the execution of the videography project, when discussing plane rental with an aerial photography company in Brazil, we were informed that in order gather data from an airplane or satellite, it is necessary to get additional permission from the Brazilian Armed Forces. This would require another lengthy permitting process and additional cost without any guarantee that the authorization would be issued

None of the project partners were fully aware of all of the issues that had to be addressed. Previous videography work in Brazil had been accomplished by other international organizations, in some cases under a broader project agreement where everything was coordinated by Brazilian organizations, and in other cases without obtaining permits. Since those projects appeared to have run quite smoothly, and we are collaborating with a local NGO (SPVS), we did not expect to encounter any major difficulties in this research. Dana Slaymaker, who conducts the videography work for Winrock International, had also done videography research in Brazil previously. He conducted this project with the governmental agency, Brazilian National Institute for Space Research (INPE), and we are looking into collaborating with INPE now. Carrying out this research in strict compliance will Brazilian regulations makes it more costly and time consuming, but we are committed to following all the necessary rules in order to maintain a good working relationship with the Brazilian agencies involved.

Despite the added complications of conducting videography in Brazil relative to those encountered in Belize or other countries, TNC is still committed to testing videography on the projects in Guaraqueçaba. The conditions found on the project sites are unique and may be the best test for the technology. Particularly, the heterogeneity of the sites, along with the vast amount of inventory that has been and continues to be collected, make the site attractive. In addition, the research will be conducted on existing carbon sequestration projects, allowing for a practical application of the technology under real constraints. The fact that the research will be conducted on an actual pilot project is also of great interest to the project investors (Texaco, American Electric Power, and General Motors) and has resulted in match funding from these companies. 
$\underline{\text { Belize }}$

Several technical challenges were encountered while conducting the videography in Belize. First, the weather did not cooperate and we were not able to get full coverage of the pine savannah as had been planned. Second, due to the sparse crowns found in Caribbean pine, videography did not always accurately estimate tree heights. We are strongly considering a return trip to correct the current deficiencies.

\section{Deliverables in next reporting period (July 02 - June 03)}

The videography flyover in Brazilis planned for next spring

Preliminary videography results from Belize will be delivered in January, drawing from both the Task 1 inventory work and the Task 2 videography. These results will provide a final indication of whether or not an additional videography session will be needed.

\section{Assessment of Future Progress}

The team in Brazil is exploring collaboration with INPE. Some drawbacks of this collaboration appear to be that the flying will be considerably more expensive because their plane is much larger than we need, and we will likely have to make some other concessions to meet their criteria, such as providing them with copies of the imagery and subsequent mosaics. However, this collaboration would ultimately give the Brazilian government a greater stake in the results of the research.

After completing the analysis for Belize Winrock will develop a full report. The report will include a CD-ROM with the imagery, along with an assessment of biomass and carbon storage. We anticipate publishing the results of this work in a scientific journal. 


\section{Task 3: Baseline Method Development}

\section{Summary of Objectives}

To quantify the $\mathrm{CO} 2$ emissions reductions resulting from the protection of forests you must be able to quantify the environmental damage that would have occurred had the forest not been protected. This is a challenging task, demanding that the probable future management of a land area be predicted so that changes from the anticipated use can then be measured and the difference between the two quantified.

Emissions avoidance projects preserve carbon stocks (in soils, forests, etc.) in areas that are demonstrably threatened with land conversion or degradation (e.g. high-grading). Methods to estimate the timing and location of deforestation or other management activities that lead to land use are not yet well-developed.

Predicting land-use trends is one of the most challenging components of baseline assessment in forestbased carbon offset projects. An appropriate method for making these assessments is critical for producing accurate and precise carbon estimates. Spatially explicit models are a sound way of projecting baselines. Deforestation or land-use emissions trend models - GIS and software-based analyses that allow a more accurate estimation of the "without-project" baselines - need to be refined and applied to project sites in order to evaluate their effectiveness.

The overall goal of this task is to develop and refine land cover change models and to test them by applying them to a diverse suite of project sites within The Conservancy's portfolio. We originally proposed applying models to five international and three domestic sites where The Conservancy and its partners are developing and implementing projects. Though the sites have changed, we still plan on conducting five international and three domestic baseline studies. The models will asses the risk posed to these forests and analyze expected carbon storage trends.

Two different models are being used: GEOMOD, a computerized geographic model requiring a spatially referenced set of equally dimensioned digital grid (raster) maps as inputs, and The Conservancy's trend model, a simplified prediction of future deforestation and other landcover change possibilities using remote sensing change detection techniques. The models determine rates of deforestation, identify the location of areas converted from forests, calculate the percentage of the total study area deforested, and determine existing forestation rates. At two sites, both approaches will be used in order to compare them. Specific objectives under this task include:

- Identify sites for study by screening their potential contribution to the protection of biological diversity and carbon sequestration.

- Gather information on raster maps, or digital coverage of roads, hydrography, population data, and climate difference over the project area. 
- Determine rates of deforestation, identification of the areas converted, calculation of the percentage of the total study area deforested, and rates of forestation.

- Convert GEOMOD or other output maps and data into time-series display module called ECOPLOT or into summary table format.

\section{Progress}

Baseline studies have commenced in three sites in Brazil, in Chile and in Virginia. TNC staff and several local partners have been trained in the use of GEOMOD.

Though the research is still underway, some early observations have been made when comparing GEOMOD to the TNC approach, which is now being called the Euclidean Distance between Agriculture and Forest (EDAF) method. Both of these methods use geographical information systems to detect and measure the rate of land cover change in a time series of satellite images, and use regression analyses to determine which areas are most likely to be deforested in the future. However, their level of flexibility, objectivity, and portability vary.

EDAF is empirical and standardized, and therefore is objective. It has the potential to provide the first logical and objective method for determining the spatial scale needed to provide an accurate trend projection for a particular area of interest. EDAF stresses data quality over data quantity, using a minimal amount of verified data. It is therefore more portable, and less prone to data error than alternative, more sophisticated, spatial approaches that draw upon a much larger data pool. However, if you assume that the more sophisticated modeling such as GEOMOD is done using high quality data, EDAF will likely lead to a less accurate depiction of the locations of future land use changes.

GEOMOD allows for manipulation and adjustments by the modeler and is more flexible. Therefore, while EDAF is an objective, easily understood, and transferable model for quantifying and projecting land use trends, it is not a replacement for alternative approaches, such as GEOMOD, that allow the modeler to take into account the impacts of potential growth in infrastructure, etc. Since it is nimble, standardized, and empirical, however, it is an attractive approach for establishing baselines and determining general historical trends.

The lack of flexibility in EDAF may be seen by some as an advantage when considering it as an approach for quantifying baseline trends in order to calculate the $\mathrm{CO}_{2}$ impacts of a project. Policy analysts and project critics have cited baseline "gaming" as a major problem. EDAF is a standard approach that can be used and replicated anywhere that satellite images are available, and with the same or very similar results.

\section{GEOMOD training}

When Task 3 was originally conceived, TNC planned to contract Geographic Modeling Systems to run all of the GEOMOD baseline analyses. However, learning to run the model ourselves allows us greater flexibility to adapt it to our needs. With this goal in mind, TNC contracted 
Myrna Hall of Geographic Modeling Systems to conduct a training during the week of December 13 - 19, in Syracuse, NY. Participants included Lynne Brickett (DOE NETL), Sarah Forbes (DOE NETL), Gilberto Tiepolo (SPVS - Brazil), Miguel Calmon (TNC Brazil), Bill Stanley (TNC), Tim Boucher (TNC), Richard Vaca (FAN - Bolivia), Ben Piper (University of Michigan Population and Environment Fellow), and Alejandro Flamenco (Mexico).

The first part of the training provided an overall understanding on how the model works and how much data and effort are necessary to run the model. The second part of the training covered preparation of the data and drivers to run the model. Participants learned about the technique and determined how it may be applied to their work.

Both GEOMOD and EDAF will be used at several sites in order to compare results. We plan to test both approaches on project areas in Brazil and in Chile.

\section{Guaraqueçaba, Brazil}

Both GEOMOD and EDAF are being used on sites in Guaraqueçaba. A large portion of the GEOMOD analyses has already been conducted, but with funding coming primarily from the carbon project sponsors and the U.S. Environmental Protection Agency (EPA) rather than from the DOE under this agreement.

Tim Boucher came to Brazil in October to commence field work in the Guaraqueçaba Environmental Protection Area (GEPA) using EDAF. SPVS worked with Tim to gather all necessary information and data (GIS layers). In addition, a Forester from SPVS traveled with Tim Boucher around the GEPA to do field verification of two landsat satellite images.

Gilberto Tiepolo of SPVS and Miguel Calmon are working with the data layers and analyses developed in collaboration with Geographical Modeling services to continue to refine the GEOMOD baseline for the Guaraqueçaba area of Brazil. During the GEOMOD training, Gilberto and Miguel worked on the data from the area to calibrate and run the model for baseline analysis. After the training, TNC Brazil prepared new vegetation and carbon maps for the Guaraqueçaba Climate Action Project (AEP) project and sent them to Myrna Hall. Myrna has already identified the most important drivers for the environmental protection area and is currently running the model for the first baseline analysis. This is being accomplished as a part of the ongoing project carbon offset estimate work for the three ongoing projects in that region, and contributes to the NETL baseline work.

\section{Santa Catarina, Brazil}

As a part of the EDAF assessment, several regions in the State of Santa Catarina were identified as potential areas for future carbon conservation projects. TNC, led by Miguel Calmon and Tim Boucher, are using EDAF to produce baseline projections for those different regions. They are working in collaboration with APREMAVI, a local NGO, and the Federal University of Santa Catarina. In October, 2001, field verification was completed for four Landsat satellite images (2 different dates). 
Some of the preliminary results from the baseline work done in Santa Catarina were given to APREMAVI (local NGO) to be included in their master plan to protect the Araucaria Forest and biodiversity in Santa Catarina State. Those results will also be part of a carbon feasibility study proposal that was recently approved by FNMA (National Fund for Environment). Tim Boucher and Bill Stanley are also using the results of this work to develop approaches for defining appropriate study scale for study areas on different project sites.

The following figure show some of the results of the work in Santa Catarina.

Figure 4. Areas of interest for potential restoration and protection activities as identified in association with the EDAF analysis. These areas contain remnants of Araucaria forest along with signficant opportunities for restoration

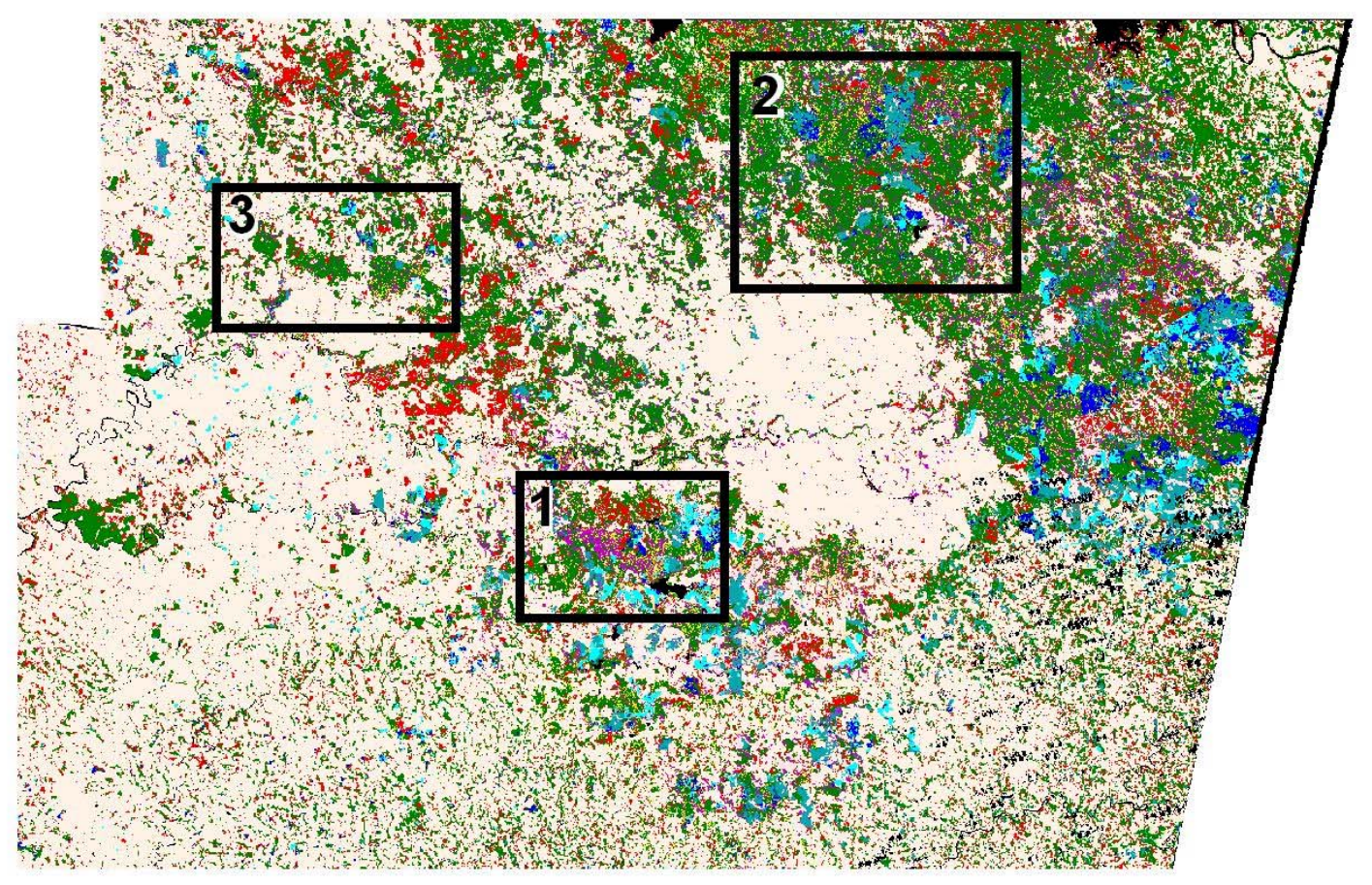


Figure 5. Area 3: Example of potential for restoration activities to develop corridors between remaining forest remnants

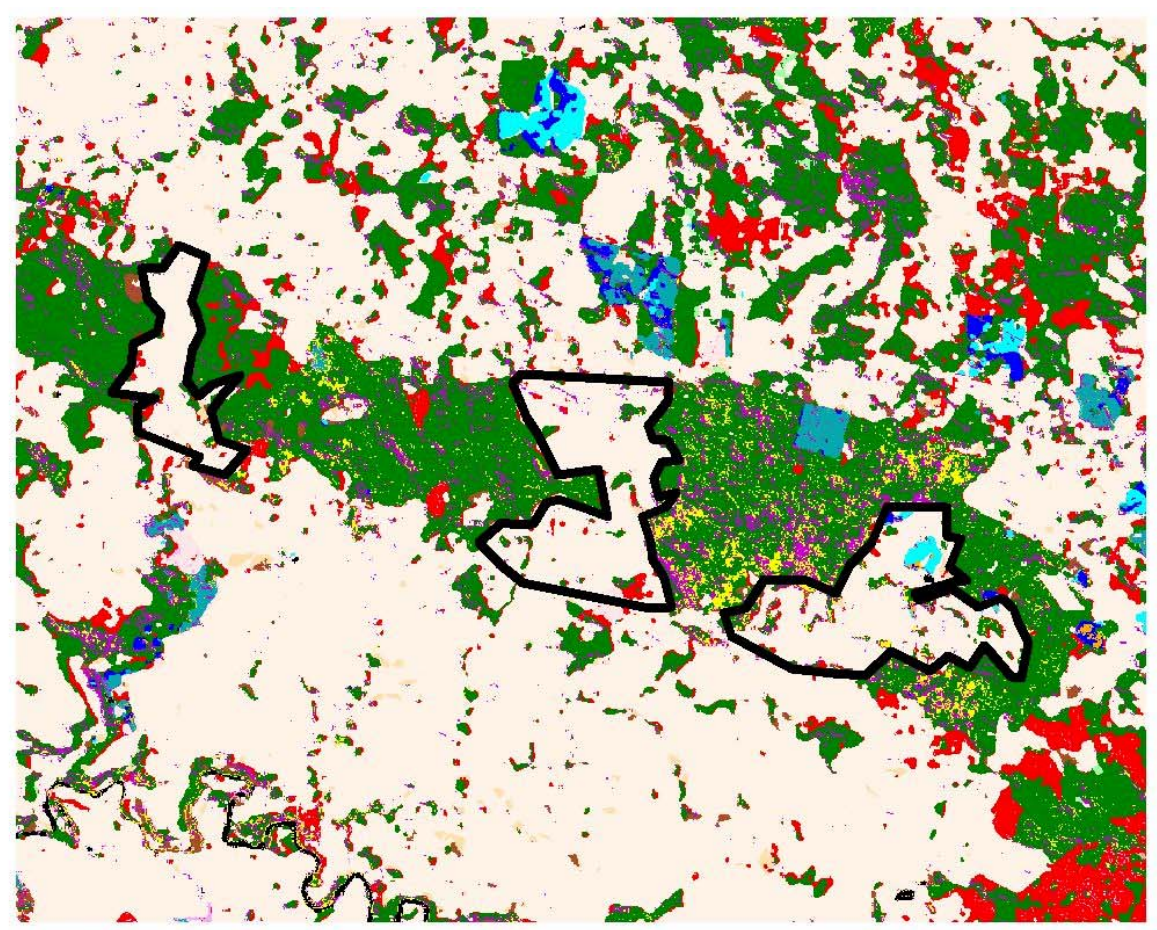

Figure 6. Classification and thematic change legends for previous two figures.

\begin{tabular}{l} 
Classification Legend \\
Water \\
Shadow \\
Araucaria Forest \\
Pine Plantation \\
Old Broadleaf Forest \\
Medium Broadleaf \\
Young Broadleaf \\
Regeneration/Scrub \\
Scrub \\
\hline \\
Agriculture
\end{tabular}

Thematic Change Legend

\begin{tabular}{l} 
Araucaria \\
Was Araucaria, now Pine \\
Was Araucaria, now Degraded Broadleaf \\
Was Araucaria, now Cleared \\
Pine \\
Broadleaf \\
Was Broadleaf, now Pine \\
Was Broadleaf, now Agriculture \\
Was Broadleaf, now Young Broadleaf \\
Young Broadleaf \\
Scrub \\
\hline$\square$ Agriculture/Clearing \\
Was Agriculture/Cleared now Pine
\end{tabular}

\section{Sao Paulo and Rio de Janeiro, Brazil}

Tim Boucher and Miguel Calmon went to the field during the week of May 27-31 to gather data for two feasibility baseline studies in São Paulo State (western part) and Rio de Janeiro (eastern 
part of the state). They worked with two local Conservation NGOs (Mico-Leão-Dourado and IPE), whom are active in those areas.

The preliminary analysis and results for the baseline and field work done in Pontal do Paranapanema (Sao Paulo State) and Cassemiro de Abreu (Rio de Janeiro State) were also completed but are still being written-up; the work of testing new approaches to define the appropriate scale for study areas on different project sites is underway, and an example of a portion of that part the work is provided below. We are assessing what impact the scale of the analysis has on final results.

The results below indicate that spatial scale is very important and that an objective method for determining the appropriate spatial scale to use is a critical issue. The ultimate goal of this work is to develop an objective and systematic method for determining what size the region of the analysis should be to come up with a land use trend that is representative of what would be expected from the site without the project. We are experimenting with several approaches for determining the appropriate scale.

Figure 7. Depiction of the effect of spatial scale of analysis on final results. Percent deforestation over the study time period is on the Y axis. The radius of the study area is found on the $X$ axis. As study are changes, so does the assessed deforestation rate and the assessed mean probability of future deforestation in the site of interest to conservation.

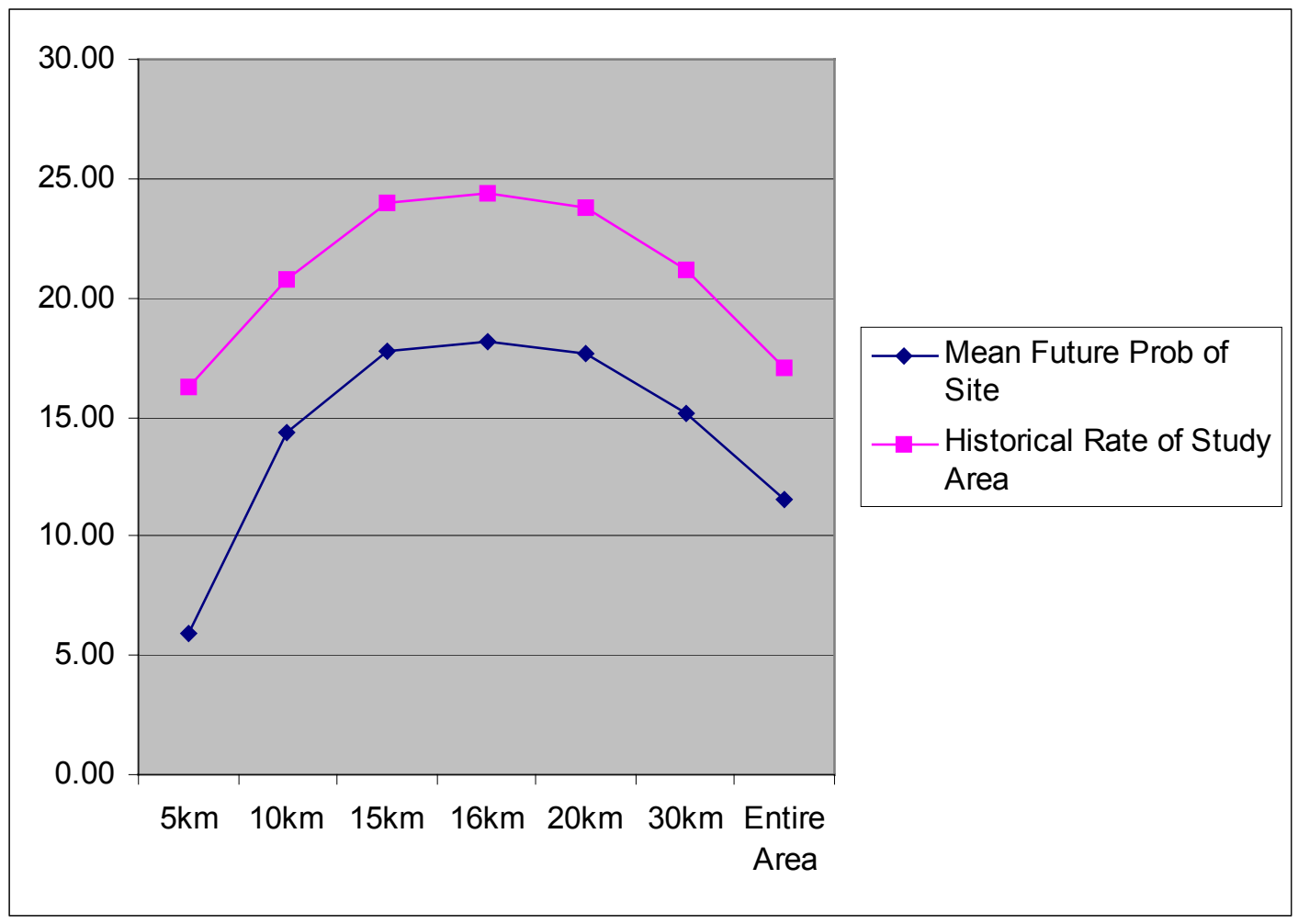


Figure 8. Change in Land Cover from 1986-1999 in the Chilean $10^{\text {th }}$ Region

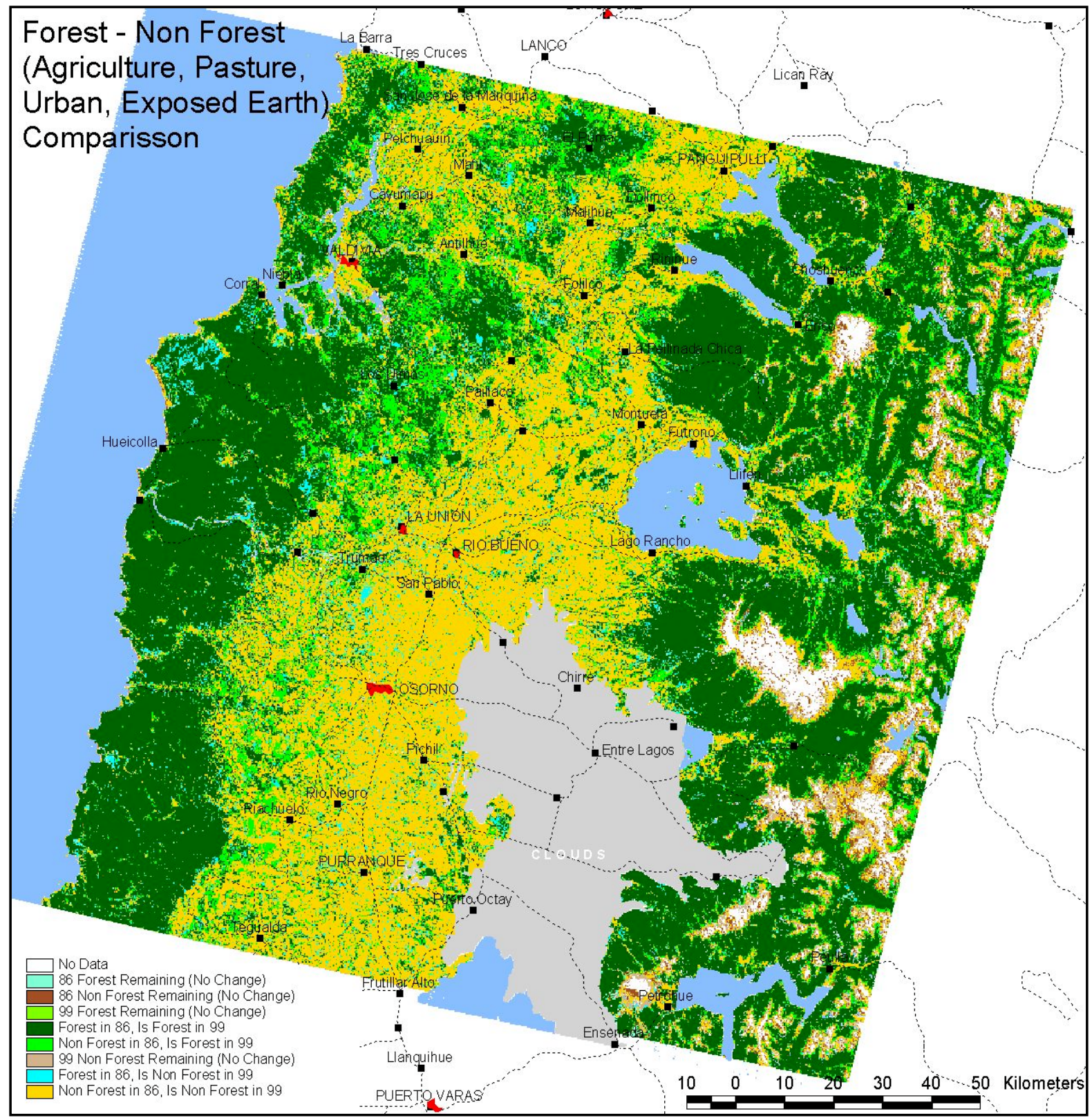

\section{Valdivia, Chile}

Landsat Satelite Imagery was acquired for the pilot analysis area in the Chilean "10th region" corresponding to the area influenced by deforestation threats from the cities of Valdivia and Osorno (Path 233 Row 088). This imagery, dated 10/23/1999 was georeferenced and rectified with Earthsat imagery gathered from 1986. These two data sets (1986 and 1999) were then processed, classified and compared to find approximate changes in land use/land cover to determine a more specific area to perform field verification and/or further carbon sequestration analyses. The results of the preliminary change analysis are shown in Figure 8 above. 
The baseline study in Chile is being conducted in close collaboration with Chilean experts in conservation and carbon sequestration project development. Leonardo Sotomayor, Margo Burnham, and Jay Keller of The Nature Conservancy organized a meeting in April with several experts from universities and conservation groups at the Universidad Austral de Chile campus in Valdivia. The purpose of the meeting was to understand the carbon sequestration project development processes in Chile and to address the question of whether there is an opportunity for a carbon project to be developed in conjunction with conservation of high biodiversity areas.

Key participants in the meeting included Jorge Gayoso from the Forest Science Department, who is currently completing a biomass and carbon survey for many species that should be published soon. Guillermo Trincado, of the Forest Management Institute presented projects specific to GIS and Remote Sensing on topics such as a land cover/use change analysis. Antonio Lara heads the Silviculture Institute, which houses a very complete GIS team and has completed a series of analyses such as a Conservation Priority Setting exercise in collaboration with the Chilean Government, and WRI's Global Forest Watch Frontier Forest project. The Chilean conservation perspective was presented by Cecilia Smith of the Senda Darwin Foundation, who presented a general perspective of Chilean biodiversity based on her foundation's research.

The groups that were present at the meetings (UACH, Senda Darwin, CODEFF, WWF Chile, among others) were very interested in collaborating in the carbon baseline project and being a part of the team that brokers a carbon sequestration project. There are some good opportunities to partner with the Chilean experts at several levels of the baseline development and, hopefully, future carbon sequestration projects. They are experienced, knowledgeable, and have valuable resources such as chemistry labs, GIS labs and biomass data. They provide a good network of local staff, scientists, graduate students and volunteers.

Leonardo Sotomayor and Jay Keller are continuing to talk to local researchers in Chile to determine their proper role in the baseline development. Jay is currently working to formally define and establish the roles of the various institutions that will be involved in the work and to establish formal contracts with them to do the work. The Forest Science Department of the Universidad Austral de Chile has an extensive database of biomass data for the region and TNC will contract with them to gain access to the data. We will also likely collaborate with the Silviculture Institute of the university on GIS analysis.

\section{North Carolina}

Tim Boucher and Bill Stanley have begun discussions with local researchers conducting GIS work in North Carolina to identify opportunities for collaboration in the Roanoke River area. In particular, Ben Poulter of Duke University has offered to assist with data collection as a part of his research at the Nicholas School of the Environment. Specifically, he will help with the following types of spatial data: digital Elevation Model (Lidar derived, $20 \mathrm{~cm}$ vertical and $5 \mathrm{~m}$ horizontal resolution); National Wetlands Inventory classification; Albemarle peninsula peat thickness map; Hydrography (rivers, streams, drainage ditches); Soil types; Flood zone maps; Land ownership (incl. protected areas, state, federal etc.); Pulse vegetation plots (permanent vegetation sampling plots established $\sim 5-10$ yrs ago). 


\section{Virginia}

As a part of the feasibility study, a baseline study is being conducted on abandoned mine lands (AML) in southwest Virginia. This work was just initiated and there is little to report yet, though some of the preliminary work is depicted later in this document, under the descriptions within Task 5.

\section{Problems Encountered}

The primary problems encountered have been 1) finding cloud free images from which to conduct analyses; and 2) identifying and preparing data for use with GEOMOD. We have found that it is extremely difficult to find cloud-free satellite images for some parts of the tropics. This is a serious limitation of any method which depends upon satellite imagery. Also, there are numerous mistakes that can be made in processing data for use in GEOMOD. This has slowed progress.

\section{Deliverables in next reporting period (July 02 - June 03)}

Baseline studies (EDAF) for two sites in Brazil and one site in the U.S. are anticipated to be finished prior to June, 2003. These studies will describe the methods used, identify areas where potential protection and reforestation activities would generate greenhouse gas emissions reductions or removals, and outline future research needs.

\section{Assessment of Future Progress}

Baseline work in Brazil and in Virginia is proceeding steadily. The work in Brazil has already provided some interesting insights into the question of appropriate analytical scale, and we expect to make great progress with two different techniques for determining the correct scale (see Figure 7). This will be the primary research focus of the baseline work over the next period.

Also over the next period, various work descriptions and contracts need to be developed for our Chilean partners. In particular, the Universidad Austral de Chile will be contracted to provide a number of services that will enhance the study, such as GIS imagery and biomass data support. Though the research will be enhanced by involving these organizations, the timing of the work may be delayed some. Also, both EDAF and GEOMOD are being used in Chile. To take advantage of the capabilities of GEOMOD a large amount of data will need to be gathered, and this takes time. 


\section{Task 4: Third-Party Technical Advisory Panel Meetings}

\section{Summary of Objectives}

Standardizing measurement procedures and methods for carbon monitoring and estimation is a major step in the demonstration that land use projects are quantifiable. The Technical Advisory Panel (TAP) meetings gather a group of experts to evaluate existing methods and to develop standardized carbon offset measurement guidelines for use in all land-use change and forestry projects. The goals of the TAP are to: 1) ensure that all projects use the best available science to meet high scientific and technical standards in monitoring carbon offsets and 2) share these standards and methodologies across projects and with a broader scientific and policy audience. This will be accomplished by:

- Opening carbon offset estimation procedures and reports to expert evaluation and critique by third party TAP members;

- Providing opportunities for participants in various projects to meet and share ideas about carbon monitoring and to standardize approaches as appropriate; and

- Disseminating key findings to a wider audience by including outside observers in panel meetings and publishing summaries of primary advances.

Three annual meetings will be held. Comments and recommendations from the TAP on how carbon monitoring protocols, plans, field methods and reports could be improved will be condensed, and an annual report for publication and presentation will be developed.

\section{Progress}

One of the biggest values that the TAP provides is the opportunity to gather experts and project implementers together to discuss advancements, and it is important to ensure the participation of all the key players. Due to scheduling conflicts with potential panelists and key participants, the first annual TAP meeting was postponed until August $1^{\text {st }}$ and $2^{\text {nd }}$ of 2002 . By June, preparations were well underway for the meeting.

It was determined that the topic for the first TAP meeting would be baselines and leakage analysis. These topics were identified during the TAP meeting in 2000 as areas which needed improvement. Since 2000, TNC has continued to develop and analyze how they approach these two issues in project design and implementation. The presentations in this year's TAP will demonstrate the advances in techniques for establishing baselines and innovative approaches to addressing leakage. Both new and old methods will be compared and discussed in the context of all of our international carbon projects, including the Rio Bravo Carbon Sequestration Pilot Project in Belize, the Noel Kempff Climate Action Project in Bolivia, and the Atlantic Forest Carbon Projects in Brazil. 
Four panelists were confirmed: Gregg Marland from Oak Ridge National Laboratory, Marco Boscolo from Harvard University, Jeff Fiedler from Natural Resources Defense Council, and Neil Sampson from The Sampson Group. The selection of panelists will be able to provide us with a variety of technical and economic perspectives.

\section{Problems Encountered}

In any event requiring the participation of so many people, it is difficult to schedule a time that works for everyone. In order to maximize the chances of securing the participation of all the key players, we will need to begin planning for next year's meeting as soon as possible.

\section{Deliverables in next reporting period (July 02 - June 03)}

The TAP meeting occurred on August $1^{\text {st }}$ and $2^{\text {nd }}, 2002$ at The Nature Conservancy's office in Arlington, Virginia, and will be reported on in the next quarterly report.

Proceedings from the meeting will be written up and circulated to TAP members to get further comments and edits during the month of September.

The proceedings will be published in October and distributed to scientific and policy audiences.

Planning for the $2^{\text {nd }}$ TAP meeting will commence, and the meeting itself will take place next summer.

\section{Assessment of Future Progress}

The first TAP meeting occurred after the period covered by this report, but by June $31^{\text {st }}$, planning was well underway to ensure a successful meeting.

The second TAP meeting will assess advancements in our tools and methodologies for carbon measurements, focusing on advanced videography and baseline modeling. Results from our research will be shared, and TAP members and project developers will discuss the accuracy, cost-effectiveness, and applicability of the tools. 


\section{Task 5: New Project Feasibility Studies}

\section{Summary of Objectives}

The feasibility studies will evaluate potential carbon sequestration ideas in terms of sequestration potential, costs, impacts on local social, cultural, or economic needs, and their ability to contribute other benefits such as the protection of biodiversity or improvements to water quality. The studies will also analyze the carbon sequestration ideas in terms of their ability to address technical issues that may impact the carbon benefits of the project, such as leakage and the longterm security of the sequestration. Key tasks include: data collection, carbon estimates, assessment of co-benefits, calculation of project costs, risk analysis, definition of scope, and compilation of the study.

The projects selected for the feasibility studies are-

- Bottomland Hardwood Restoration; Mississippi Alluvial Valley: Mississippi, Louisiana, Arkansas, and small portions of Tennessee, Illinois, and Missouri

- Semi-arid Grassland Restoration; Apache Highlands, Arizona

- Mined Land Forest Restoration; southwestern Virginia

- Native Prairie Restoration; Kankakee Sands, Indiana

- Floodplain Forest Restoration; Pennsylvania

- Longleaf Pine Forest Protection and Restoration; Southeast U.S.: Florida, Georgia, Alabama

- Bottomland Hardwood Restoration; Cache River, Illinois (This site will likely be captured in the Mississippi Alluvial Valley study. Thus we will probably select another site/project idea for the seventh feasibility study.)

\section{Progress}

Work is underway on feasibility studies in four sites: Mississippi Alluvial Valley, Apache Highland, southwestern Virginia, and Kankakee Sands

\section{Bottomland Hardwood Restoration; Mississippi Alluvial Valley: Mississippi, Louisiana, Arkansas, and small portions of Tennessee, Illinois, and Missouri}

Climate action projects in the Mississippi Delta hold particular appeal and promise. First, land values and restoration costs for marginally productive agricultural areas are relatively low compared to other places in the country. Second, because of the Delta's climate and soils carbon sequestration potential is relatively high. Due to the potential for successful projects, TNC sees the feasibility study as an opportunity to conduct a much broader analysis on the carbon sequestration project potential in the region. To this purpose, TNC is collaborating with the Lower Mississippi Valley Joint Venture to engage the key participants in the region and explore how to leverage the DOE feasibility study into a coordinated carbon sequestration program in the valley. 
The Lower Mississippi Valley Joint Venture is a private, state, and federal bird conservation partnership conceived in 1988 in response to the North American Waterfowl Management Plan. Since its inception, the self-directed partnership has broadened its biological scope to include strategic planning and implementation for "all birds in all habitats", and its geographic extent to include the West Gulf Coastal Plain. In response to challenges inherent in landscape scale integrated bird conservation, LMV Joint Venture partners have organized their institutional capabilities and personnel expertise to (1) define a science-based biological foundation, (2) develop a spatially-explicit conservation blueprint of priority sites for restoration and conservation, and (3) orchestrate habitat delivery and management.

Partners in this regional collaboration include:

- Arkansas Game and Fish Commission

- Ducks Unlimited

- US Fish and Wildlife Service

- US Forest Service

- Louisiana Department of Wildlife and Fisheries

- Tennessee Wildlife Resources Agency

- Texas Parks and Wildlife Department

- The Conservation Fund

- The Nature Conservancy

- US Geological Survey

- Business Council for Sustainable Development

- Environmental Synergy, Inc.

- Fields to Forests

- Mississippi Fish and Wildlife Foundation

- Winrock International

Building on the data available, TNC will develop a model for baseline, or business-as-usual land use trends in the LMV. TNC will also explore project costs, carbon yield curves, permanence, additionality, leakage, and socioeconomic issues related to carbon sequestration projects. In the report, standards, including reforestation, monitoring, and verification standards, will be discussed. Priority sites for restoration and conservation, based primarily on biodiversity and hydrological characteristics, will also be identified.

To date we have gathered data, developed carbon sequestration estimates, calculated project costs, developed alternative project financing terms, and created a preliminary map of carbon sequestration opportunities (Figure X).

Because of the broad and collaborative nature of this study, TNC has participated in activities outside the funding of this grant which are relevant to the study. On April 8-10 Zoe Kant and Tia Nelson attended a meeting in Vicksburg, Mississippi hosted by Entergy and Tara Wildlife. The meeting gathered representatives from the energy generation industry, forestry industry, and conservation organizations to discuss ways to standardize measurement and verification for carbon projects in the region and ways to gain credit. Zoe Kant also organized a TNC regionwide meeting to discuss carbon sequestration opportunities in the region, which occurred on July 
$16^{\text {th }}$ and 17th in Memphis, Tennessee. Information generated through the meeting will be incorporated into the study. We believe that these activities will leverage the work being done in the feasibility study, and ultimately lead to a great impact in the Mississippi Alluvial Valley.

Figure 9. Bottomland Hardwood Restoration opportunities in the Mississippi Alluvial Plain

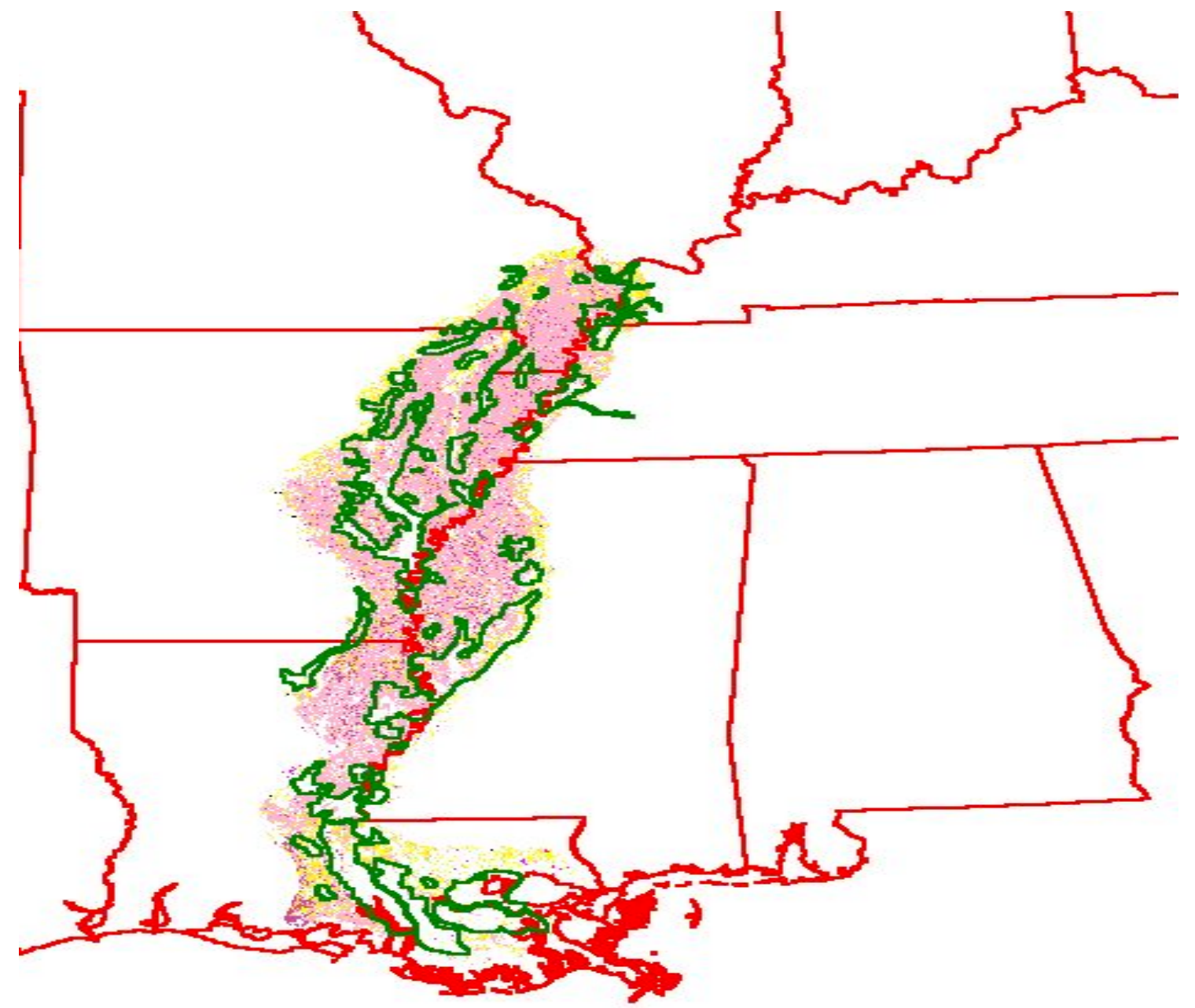

\section{Legend}

Cropland - former bottomland hardwoods

TNC priority conservation areas

State boundaries 


\section{Semi-arid Grassland Restoration; Apache Highlands, Arizona}

Natural grasslands in Arizona are critical as habitat for a diverse array of plants and animals, as open space free of sprawl and attendant air quality problems, and for protection of water resources. Land ownership in the grasslands is a checkerboard of state trust land and private ranchland. Many of these ranches are experiencing intense development pressures.

This feasibility study will explore whether or not carbon values that can be generated from semigrassland restoration are substantial enough to raise the funding necessary to implement carbon sequestration projects. Our hypothesis is that the restoration of natural grasslands in areas that have been heavily grazed or are being encroached by woody shrubs will result in increased carbon storage. If found, increased carbon storage benefits may help to finance the recovery of this important habitat.

The Arizona chapter of The Nature Conservancy is interested in conducting a much more extensive study than was originally planned, and they agreed to match a higher percentage of the total costs. \$30,000 in match funds were raised from the Salt River Project (SRP), and local utility company that is interested in funding a carbon sequestration study in the area.

Given that grasslands in the Apache Highlands cover 2.5 million acres, TNC decided to focus on a limited number of sites within the Apache Highlands that represent the distribution of the grasslands. These 5 sites are:

- Gray Ranch (a TNC preserve)

- Muleshoe Ranch (another TNC preserve)

- Fort Huachuca

- Santa Rita Experimental Range

- Verde Grasslands

The Arizona Nature Conservancy staff have begun to collect data on grasslands to stratify the areas and identify opportunities for restoration work. They are visiting sites throughout the ecoregion and collecting data to establish states of degradation and current management regimes that will essentially serve as the baseline. Zoe Kant also began interviewing restoration scientists at five sites to gather information for the Century model input files. We were interested in specific data for the study - what is the response of semi-arid grassland restoration and management in areas that are facing woody shrub encroachment? Only two of the five representative sites had data on restoration and management response. Thus we limited the study to those two sites (Gray Ranch and Muleshoe Ranch).

Bill Parton, of Colorado State, is finishing up modeling work based on data we gathered for Gray Ranch and Muleshoe Ranch. Parton's modeling work will estimate the carbon sequestration benefits of our semi-arid grassland restoration and management activities in the Apache Highlands.

\section{Mined Land Forest Restoration; southwest Virginia}


Each year, approximately 6,300 acres are mined and reclaimed in southwest Virginia alone. Subsidizing all or a part of these costs through carbon sequestration projects would be a strong incentive for landowners to reforest their sites, and could also provide additional incentives for an operator to remine and reclaim abandoned mine lands that would otherwise not be reclaimed.

This feasibility study will explore opportunities for reclaiming and reforesting abandoned mined lands and reforesting mined lands that have been reclaimed to grassland in southwest Virginia. The Conservancy's interest in mined land reclamation is primarily related to its role in reducing sedimentation of important aquatic habitat, such as the Clinch River. The Clinch River is habitat to the greatest diversity of freshwater mussels found in the world.

In April, TNC staff met with staff from the Department of Mines, Minerals, and Energy (DMME) to determine what data DMME had available. After outlining the steps needed to restore abandoned mined lands and mined lands reclaimed to grassland, Zoe Kant gathered cost information for each step from the DMME. A first version of the carbon sequestration and cost spreadsheet for mined lands forest restoration projects was created.

Brad Kreps, a TNC GIS analyst in our Clinch Valley Program, has delineated abandoned mined lands and mined lands reclaimed to grassland in southwest Virginia. We are creating a reforestation priority system to prioritize reforestation opportunities according to biodiversity benefits. Below is an image showing the characteristics that are being used to prioritize the sites. (Figure 10).

TNC is discussing potential collaboration with the Electric Power Research Institute (EPRI). EPRI is conducting a study on how to combine carbon sequestration values with other environmental assets, such as biodiversity and water quality protection.

Zoe Kant has also had discussions with Dr. Gary Kronrad about a potential collaboration with TNC. Dr. Kronrad is with Stephen F. Austin University and has developed a model for predicting timber harvest and carbon sequestration present value benefits, based on management technique, various site indices, the price of carbon, and various internal rates of return. Zoe Kant has prepared a list of options to model, including carbon payment regimes, value maximization goals, and carbon accounting guidelines. Dr. Kronrad is currently developing a cost estimate for this work. 
Figure 10. Characteristics used to prioritized mined land restoration opportunities in a section of the Clinch River Valley, in southwest Virginia

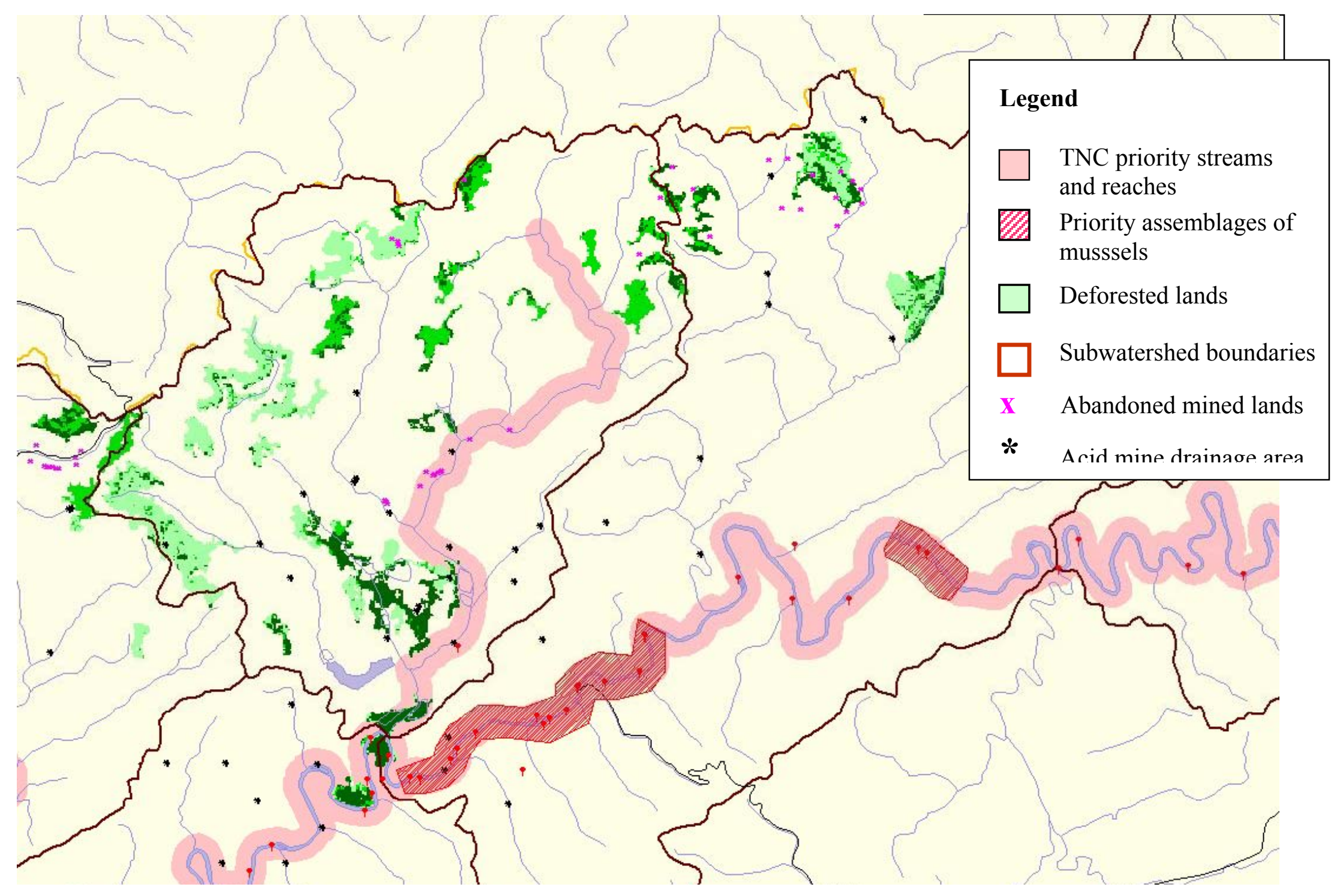




\section{Native Prairie Restoration; Kankakee Sands, Indiana}

We have determined five sites, within and surrounding TNC's Kankakee Sands project area, where we will do modeling and soil sampling work. These five sites will represent different points along a sequestration curve (from cropped lands to restored grasslands). Mike Ebinger at Los Alamos National Laboratory (LANL) has agreed to design a soil sampling study for Kankakee Sands, and to analyze the samples. In late July Zoe Kant, Mike Ebinger, and Kankakee Sands TNC staff took 120 soil samples and shipped them to LANL. Attached is a spreadsheet with coordinates of the soil samples. We are still awaiting analysis. (Attachment E)

Also, Bill Parton is wrapping up modeling work to determine the carbon sequestration potential over 100 years resulting from the restoration work at Kankakee Sands. Preliminary modeling results show that in xeric and mesic areas we would expect very small gain in soil carbon, on the order of 1-2 metric tons of carbon/acre over 100 years. In the wet areas preliminary modeling results suggest that 76 metric tons of carbon/acre would be stored over 100 years. However methane emissions in the wet sites could completely erase the soil carbon greenhouse gas benefits, resulting in net greenhouse gas emissions (versus sequestration) for the restoration area.

\section{Problems Encountered}

There have been few problems encountered in the work under task 5. Our contractors have been delayed in producing deliverables, due to their workloads. However, their work continues to progress.

\section{Deliverables in next reporting period (July 02 - June 03)}

We plan to complete the four feasibility studies that were commenced this project year by the end of the next project year. The Native Prairie Restoration study will be completed by December 2002. The Mined Land Forest Restoration study will completed by December 2002.

The Semi-arid Grassland Restoration study and the Bottomland Hardwood Restoration study will be completed by March 2003.

We will commence two other studies in the next reporting period: Floodplain Forest Restoration (Pennsylvania) and Longleaf Pine Forest Protection and Restoration (Florida, Georgia, Alabama).

In August we started the Longleaf Pine Forest Protection and Restoration study. Zoe Kant attended a TNC Southeast Division forestry initiative meeting in early September, in which forest protection, restoration, and threats were discussed. We have gathered information on carbon sequestration potential in longleaf pine forest and developed estimates for restoration on cropland and restoration on loblolly pine plantation lands. 
We are currently screening TNC's portfolio of priority conservation areas for longleaf pine restoration/carbon sequestration potential.

\section{Assessment of Future Progress}

We have gathered and analyzed much of the information needed for four feasibility studies. Written reports will follow shortly. Also we have started gathering information for a fifth study. In some cases we will likely discover that some of our habitat protection and restoration project ideas do not lead to carbon sequestration. In other cases we will discover that the project ideas make credible, viable carbon sequestration projects. From these studies we will learn what paths to follow and what paths to avoid when creating carbon sequestration projects that are designed for habitat protection and restoration.

Based on the information we have currently, we expect the following results:

Table 1. Expected Results from Feasibility Studies

\begin{tabular}{lll}
\hline Feasibility Study & $\begin{array}{l}\text { Carbon } \\
\text { sequestration } \\
\text { potential }\end{array}$ & $\begin{array}{l}\text { Viable project } \\
\text { (factoring in } \\
\text { project costs) }\end{array}$ \\
\hline $\begin{array}{l}\text { Bottomland Hardwood Restoration; Mississippi } \\
\text { Alluvial Valley }\end{array}$ & Positive & Yes \\
\hline $\begin{array}{l}\text { Semi-arid Grassland Restoration; Apache } \\
\text { Highlands, Arizona }\end{array}$ & Negative & No \\
\hline $\begin{array}{l}\text { Mined Land Forest Restoration; southwestern } \\
\text { Virginia }\end{array}$ & Positive & Yes \\
\hline $\begin{array}{l}\text { Native Prairie Restoration; Kankakee Sands, } \\
\text { Indiana }\end{array}$ & Negligible & No \\
\hline $\begin{array}{l}\text { Longleaf Pine Forest Protection and Restoration; } \\
\text { Southeast U.S. }\end{array}$ & Positive & Unsure \\
\hline Floodplain Forest Restoration; Pennsylvania & Not started & Not started \\
\hline $\begin{array}{l}\text { Bottomland Hardwood Restoration; Cache River, } \\
\text { Illinois }\end{array}$ & Not started & Not started \\
\hline
\end{tabular}




\section{Task 6: Development of New Project Software Screening Tool}

\section{Summary of Objectives}

There is currently a great interest in carbon offsets across the United States, but little knowledge by many organizations and private landowners with access to land about what is required to make a project an attractive one. Easy-to-use tools are needed for quick screening of specific carbon sequestration project ideas. We are developing an Excelbased screening tool to provide an initial estimate of both the costs, and the carbon emissions avoidance or removals, represented by different project ideas. The model will allow the user to explore carbon offset potential in a variety of ecosystem types and baseline conditions found across the United States.

Some of the attractive features of this type of tool are the following: (1) they require few inputs that are easy to generate; (2) they are easy to modify and adaptable to local or regional conditions; (3) once they are calibrated, they are user friendly and can be used by people coming from a variety of backgrounds; and (4) they provide key information needed to determine whether or not a project idea would be feasible.

In order to develop the screening tools, four main objectives were identified:

- Data collection and calibration by gathering information across the U.S. on:

1. Carbon inventories and sequestration rates

2. Land purchase or acquisition costs

3. The costs of monitoring carbon storage over time

4. Other implementation and management costs

- Incorporation of data into the model

- Development of guide

- Dissemination of model

\section{Progress}

Bill Stanley has identified a strong data set, based on the United States Forest Inventory and Analysis, that can be input to the model. He has also been discussing a model for estimating carbon inventory costs that could be developed with the help of Winrock. Finally, all of the feasibility study work will be fed into the model development process. TNC has also been in contact with Winrock about overlaps between this work and work being funded by the Electric Power Research Institute (EPRI). There is a potential collaboration possible that would enable both Winrock and TNC to increase both the scope of the work and the confidence in modeling, as well as ensure that efforts are not duplicated. 
Bill, Zoe, and members of The Nature Conservancy's Innovative Conservation Finance team met with representatives from Conservation International and the Wildlife Conservation Society to discuss the development of tools to aid in mobilizing carbon sequestration funding for biodiversity conservation. The three organizations agreed to cooperate in the development of a screening tool. It was discussed that The Nature Conservancy will be the lead on overall tool development, but will seek reviews from others, in particular Conservation International, on the financial components.

A draft screening tool was forwarded to NETL. This tool will serve as a model for the final product, but, as it stands, is highly specific to the Atlantic Forest Region of Brazil where it was developed. It needs to be modified for broader use. We suspect that the model may also need to be further simplified to make it more adaptable to other site conditions, or that various versions may be needed in order to keep it simple. For example, separate components are likely to be needed for reforestation, forest protection, and grassland restoration.

\section{Problems Encountered}

The challenge will be to develop a relatively accurate tool that requires few inputs and is simple to use, but is flexible enough to apply to a variety of project types, sizes, and geographical locations. The Nature Conservancy is considering partnering with a software development firm to work through some of these issues.

\section{Deliverables in next reporting period (July 02 - June 03)}

While additional biomass and growth data that could be input into the model is being collected, we have made few updates to the model itself. Realistically, little progress will be made on the tool until data that will support its development is collected through the feasibility studies.

\section{Assessment of Future Progress}

The biomass and growth data that is being collected as part of the 7 domestic feasibility studies will directly contribute to the development of this tool. We have already developed several simpler verions of the model for use in the feasibility studies, and will be building upon these, along with the model developed in Brazil. 


\section{CONCLUSION}

Since initiating this work one year ago, The Nature Conservancy and collaborators have made great strides in achieving the research goals of this cooperative agreement. To review, these goals are to: 1) improve carbon offset estimates produced in both the planning and implementation phases of projects; 2) build valid and standardized approaches to estimate project carbon benefits at a reasonable cost; and 3) lay the groundwork for implementing more projects to provide new test ground for increasing knowledge on how to sequester significant amounts of carbon from the atmosphere.

The new allometric regression equations and advanced videography work accomplished in Brazil and Belize have helped to improve carbon offset estimates by improving the accuracy of the inventories. The planned work with LIBS will further advance the goal of improving carbon offset estimates, as will the ongoing work with advanced videography.

The TAP meeting, planned for during the period that this report covers, provided an excellent forum for discussing and standardizing approaches. A standardized, and costeffective approach to estimating the offsets produced through forest protection projects is being identified through the EDAF research. Future work focussed on reducing costs while improving the accuracy of offset estimates will focus on the use of advanced videography, and the refinement of baseline techniques.

The feasibility studies are bearing out the fact that there are additional cost-effective project ideas throughout the U.S. that could sequester greenhouse gases while achieving biodiversity benefits. Standard tools to aid project development still need to be developed, and this will be a priority in the future work. 


\section{REFERENCES}

Brown, S. 1997. Estimating Biomass and Biomass Change of Tropical Forests: a Primer. FAO Forestry Paper 134, Rome, Italy.

Brown, S., L. R. Iverson, and A. E. Lugo, 1994. Use of GIS for estimating potential and actual forest biomass for continental South and Southeast Asia, pp. 67-116 in V. H. Dale (Ed.), The effect of land-use change on atmospheric $\mathrm{CO}_{2}$ concentrations, SpringerVerlag, New York.

Dale, V H., R. V. O’Neill, M. Pedlowski, and F. Southworth. 1993. Causes and effects of land-use change in central Rondonia, Brazil. Photogrammetric Engineering and Remote Sensing 59:997-1005.

Hall, C. A. S., H. Tian, Y. Qi, G. Pontius, J. Cornell and J. Uhlig, 1995a. Spatially explicit models of land use change and their application to the tropics. DOE Research Summary, No. 31. (Ed. by CDIAC, Oak Ridge National Lab); and Hall, C. A. S., H. Tian, Y. Qi, G. Pontius, J. Cornell and J. Uhlig, 1995b. Modeling spatial and temporal patterns of tropical land use change. Journal of Biogeography 22: 753-757.

Kaimowitz, D. And A. Angelsen. 1998. Economic models of tropical deforestation: a review. Center for International Forestry Research, Bogor, Indonesia.

Pontius, G. 1994. Modeling tropical land use change and assessing policies to reduce carbon dioxide release from Africa. Ph.D. dissertation, State University of New York, Syracuse, New York; Tian, H. 1995. Spatial and temporal patterns of carbon flux and land use/cover at scales from landscape to the biosphere: an empirical study with observation and modeling. Ph.D. dissertation, State University of New York, Syracuse, New York; andQi, Y. 1994. Human-induced biospheric change and the global carbon cycle: a spatial modeling approach and its application to tropical Asia. Ph.D. dissertation, State University of New York, Syracuse, New York.

RPA (Resources Planning Associates, Inc.) ECOPLOT software, Ithaca, NY

Slaymaker, D.M., K.M.L. Jones, C.R. Griffin \& J.T. Finn. (1996) Mapping deciduous forests in southern New England using aerial videography and hyperclustered multitemporal Landsat TM imagery. Pages 87-101 in Gap Analysis: A Lanscape Approach to Biodiversity Planning, ASPRS, Bethesda, MD, USA

Schriever, J.R. \& R.G. Congalton. (1995) Evaluating seasonal variability as an aid to cover-type mapping from Landsat Thematic Mapper data in the Northeast. Photogrammetric Engineering and Remote Sensing 61 (3):321-327.

Spanner, M.A., L.L. Pierce, D.L. Petersen \& S.W. Running. (1990) Remote sensing of temperate coniferous forest leaf area index: The influence of canopy closure, understory 
vegetation and background reflectance. International Journal of Remote Sensing 11(1)95-111 


\title{
Appendix 1
}

\section{Measurement Protocol for 2002 Field Work}

\author{
Rio Bravo, Belize
}

\author{
March 2002 \\ Prepared by: \\ Matt Delaney \\ Sandra Brown
}




\subsection{Introduction}

The two main activities that will take place during the 2002 field work in Rio Bravo are: 1) sampling the pine-savannah strata and 2) re-measurement of some of the permanent plots in the Original and Expansion area properties.

\subsection{Pine savannah field activities}

For the pine-savannah work our objective is to use dual-camera videography in conjunction with on the ground measurements to develop an index to estimate carbon. The videography system is a combination of digital cameras, high-resolution video, GPS, and a laser profiler that is mounted on a platform and attached to an airplane. The Original and Expansion area properties will be flown using this system and a highresolution map will be produced. We will use this map to identify specific vegetation communities within the pine savannah strata and develop an index that we can use to estimate carbon content on the ground. It is uncertain at this time what that index will be but possible measurements of crown diameter, dbh, total height of vegetation, or some combination of the three will be used.

Pine savannah is a heterogeneous type of vegetation. It consists of a mixture of trees, grasslands, shrubs, and palmetto vegetation. To estimate the carbon content of such a complex vegetation community would require the installation of dozens of permanent plots because the carbon content is likely to be highly variable. Using the dual camera videography system we hope to decrease the need for extensive ground measurements while creating better carbon estimates in a more accurate and cost effective manner.

\subsection{Field verification of permanent plots}

A second key priority to be fulfilled in this years field work is verification of the nested plots in the Original and Expansion properties. Given the large differences in the estimated carbon stocks based on the original 1995 inventory, and the 2000/2001 inventories, it is critical that the field measurements in at least $25 \%$ of all plots be field verified. Original field sheets from the 1995 and field sheets from the 2001 inventories should be in hand during the verification.

The following section of this report will describe the methods and procedures planned for both activities and describe the methods and procedures that will be used in the pine savannah and plot verification work.

\subsection{Methods}

After discussions with personnel at $\mathrm{PfB}$ there appears to be four main vegetation communities in the Pine Savannah strata. Their names and approximate percent of total strata area are:

1) Pine/Oak (50\%) 
2) Hardwood/Riparian forests (5\%)

3) Savannah-Palmetto $(15 \%)$

4) Savannah-Shrubs (15\%)

5) Savannah-pure grasses $(15 \%)$

Sampling the pine savannah strata, particularly the shrubs, will be difficult. According to PfB some of the shrubs are relatively small and low $(<1 \mathrm{~m}$ in height $)$ but others are taller (2-3 $\mathrm{m}$ in height) and are very dense and hard to get into. The smaller shrubs can most likely be sampled using clip plots as outlined below (section 2.1.2), but for the larger shrubs other methods will have to be used.

\subsection{Field measurements}

The first step in the sampling will be to identify the boundaries of each of the vegetation communities using the videography imagery. After examination of the imagery, we will identify regions for ground measurements. The idea is to identify candidates for measurements that cover a broad range of sizes, heights, and types of vegetation.

\subsubsection{Pine/Oak and Hardwood/Riparian forests}

The main goal of the sampling in the forest vegetation is to equate what we can identify from the imagery (species, crown diameter, and height) with on the ground measurements. For the Pine/oak and Hardwood/riparian forests the approach will be to develop a relationship between crown diameter and total height to biomass. Since the videography system will provide an aerial shot of the vegetation as well as a measurement of total height we will select 30 trees in each forest type that covers a range of heights and canopy diameters. We will then measure those candidate trees during ground measurements. Each candidate tree will have its total height, canopy diameter and dbh measured. Using the dbh measurement we will plug that into a general biomass equation to get an estimate of tree biomass carbon. With those results we will try to develop a new correlation between canopy diameter and total tree height to predict biomass carbon for the rest of the trees in the forest strata.

\subsubsection{Savannah-Palmetto}

For the savannah-palmetto (and all the other savannah associations) we will attempt to develop a similar relationship as for trees. The basic idea is to try and develop some index obtained from the videography imagery that we can correlate with a measurement on the ground. We will first identify areas of savannah-palmetto from the imagery and select areas that cover a range of density and sizes. Based on the range and diversity of the association we will select areas for measurement. Palmettos are fairly easy to cut although they have sharp fronds and placing them in sample bags could be problematic. Field crews should therefore have plenty of extra bags for the sampling.

The savannah-palmetto association will be sampled using clip plots. Clip plots are aluminum sample frames $60 \mathrm{~cm}$ in diameter that are placed on the ground at predetermined locations (which will be selected from the videography imagery). The following steps will be used after the sampling location is identified. 
1) Place the clip plot frame on the ground. All vegetation-herbaceous and other nontree vegetation - that falls inside the clip plot frames should be cut, placed in a sample bag and weighed. It is important to cut the vegetation at a constant level for all clip plots. Do not cut the vegetation right down to the ground, instead use the clip plot frame as a guide and cut the vegetation down to the top of the clip plot frame.

2) If small woody vegetation falls within the clip plot and they are shorter than breast height $(1.3 \mathrm{~m})$, cut and place in sample bag. If woody vegetation is taller than breast height $(1.3 \mathrm{~m})$, measure its $\mathrm{dbh}$ and record on the data sheet. Palmettos regardless of size should be cut and placed in the sample bag.

3) Once all the vegetation has been cut and weighed, a sub-sample will be collected for moisture content determination. Collect a representative sub-sample (approximately 80-100 g), measure its fresh weight, and place in a sample bag. Write the plot number on the bag; label it as containing herbaceous vegetation.

\subsubsection{Savannah-Shrubs}

The goal of the savannah-shrubs sampling is the same as the other pine-savannah vegetation, we are trying to correlate the aerial imagery with on the ground measurements. What the index or variable that will be used (density of shrubs, diamter of individuals, height, diamter, etc) is unclear at this time but sampling in savannah shrubs will likely be the most difficult part of the field work. For small shrubs $(<1 \mathrm{~m}$ in height) clip plots will be used as outlined above, but in cases where the shrubs are taller (2-3 $\mathrm{m}$ in height) and in thicker clumps a different method will have to be used. One option is to place the clip plot in an area of tall shrubs and destructively sample all of the vegetation within the ring. A second option is to measure the height and diameter of individual shrub crowns and select 20 individuals for destructive sampling and apply an average value per shrub to the rest of the area. Since we have not sampled these areas before, the sampling scheme will have to be somewhat flexible until we can get into the field and decide on the best approach.

\subsubsection{Savannah-pure grasslands}

The savannah grasslands will be measured using clip plots as outlined in section 2.1.2. At this point, we are not sure how many plots we will need, grassland carbon is fairly uniform and low, so sampling this vegetation does not have as high a priority as the forest or shrub vegetation. If the savannah-grasslands areas are homogeneous perhaps 10-15 plots are all that are required, but this will have to be decided in the field.

\subsubsection{Saplings}

The goal for measuring saplings will be the same as the other vegetation types found in the pine-savannah strata. We are attempting to correlate the videography imagery with a ground measurement to develop a way of estimating carbon. At this point it is unclear 
what the videography imagery will be able to detect when it comes to saplings, but the goal is to develop a relationship between canopy diameter and total height to carbon. Approximately 30 saplings will be selected covering a range of diameters and heights to develop this relationship.

Saplings are defined as having a measurable $\mathrm{dbh}$ at $1.3 \mathrm{~m}$ of at least $2.5 \mathrm{~cm}$. The upper diameter range of saplings is unclear but is likely to be in the range of 5-8 cm, but that will be dependent on what the videography imagery can detect and measure. The saplings to be sampled will be most likely in transition zones between the pure grasslands and the forest associations. Ground measurements will include dbh and total height. The sapling will be cut into pieces and the fresh weight recorded, then mixed well and a subsample collected for dry weight to wet weight ratio determination.

\subsubsection{Tree crown and height measurements}

To measure the diameter of tree canopies and the total height of trees in the pine/oak and hardwood/riparian forest communities, we will use a method developed by Chris Hayward (Winrock International). The steps for the measurements are as follows:

4. Measure the height of the tree: This requires the user to stand far enough away from the tree to view the top of the tree and record two measurements: the distance between the user and the base of the tree (measured with the tape measure or DME), and the angle from the user to the top of the tree (measured with the clinometer).

5. Measure the tree crown radii: This requires the user to stand directly beneath the tree and look up at the crown. Using the clinometer, measure the angle from the main stem to the edge of the crown. On some clinometers, it is required to subtract this measurement from 90 to get the actual angle. Repeat this step, taking the second measurement at a right angle from the first. Repeat until four mesurements are obtained. This will allow the user to record the asymmetry of many tree crowns.

6. Calculating tree height and crown area: This can easily be done in an Excel spreadsheet. Tree height is calculated by multiplying the distance from the user to the tree by the tangent of the angle to the top of the tree $\left(\right.$ hgt $\left.=x^{*} \tan \theta\right)$. The crown radii are calculated by multiplying the height of the tree by the angle to the edge of the crown $\left(\mathrm{a}=\mathrm{hgt}^{*} \tan \theta\right)$. The crown area is calculated by multiplying the two crown radii measurements by pi (Area $=a * b * \pi)$.

7. Precautions: The crown area measurement is dependent on the height measurement. When measuring trees with crowns that taper at the top, the main tree height can't be used. Instead a second tree height measurement should be taken at the point where the tree crown is widest. This measurement should then be used to calculate crown radii.

\subsection{Permanent plot measurements}

In addition to the work in the pine savannah strata, $25 \%$ of the permanent plots in the original and expansion areas will be re-measured. The purpose of this re-measurement is 
to verify that the data that collected by PfB in 2001 were collected correctly. In addition, this field work will enable us to examine if there has been any significant impact from the 1999 and 2000 hurricanes on tree biomass and regrowth.

Since the beginning of the Rio Bravo project, a total of 154 permanent plots have been installed (94 in the Original and 60 in the Expansion area properties), of which 39 were chosen at random for re-measurement (Table 1).

Table 1. Permanent plots in the Original and Expansion properties that will be remeasured during 2002 field work.

\begin{tabular}{|llll|}
\hline Plot & Property & Plot & Property \\
1A1007 & Original & $1 \mathrm{~A} 3105$ & Expansion \\
1A3021 & Original & $1 \mathrm{~A} 3129$ & Expansion \\
1A4011 & Original & $1 \mathrm{~A} 3133$ & Expansion \\
1A4015 & Original & $1 \mathrm{~A} 4142$ & Expansion \\
1A4101 & Original & $1 \mathrm{~A} 5128$ & Expansion \\
1A4113 & Original & $1 \mathrm{~A} 5155$ & Expansion \\
1A4704 & Original & $1 \mathrm{~A} 7108$ & Expansion \\
1A4804 & Original & $1 \mathrm{~A} 7116$ & Expansion \\
1A4904 & Original & $1 \mathrm{~A} 7126$ & Expansion \\
1A6024 & Original & $1 \mathrm{~A} 7146$ & Expansion \\
1A6113 & Original & $1 \mathrm{~A} 7159$ & Expansion \\
1A7002 & Original & $1 \mathrm{~A} 9113$ & Expansion \\
1A7006 & Original & $1 \mathrm{~A} 9137$ & Expansion \\
1A7010 & Original & $1 \mathrm{~A} 9150$ & Expansion \\
1A7303 & Original & & \\
1A7401 & Original & & \\
1A7501 & Original & & \\
1A7601 & Original & & \\
1A8008 & Original & & \\
1A9002 & Original & & \\
1A9006 & Original & & \\
1A9010 & Original & & \\
1A9014 & Original & & \\
1A9018 & Original & & \\
1A9202 & Original & & \\
\hline & & & \\
\hline
\end{tabular}

The plots will be re-measured according to the same methodology used during initial plot installation. Re-measurements will include live and standing dead trees only (no lying dead wood or understory vegetation will be sampled).

\subsection{Planning and equipment}

It is unlikely that all of the field work outlined above will be completed during the first week. After week one, PfB will be leading the effort for collecting samples, drying, and data entry. Winrock will bring tape measures, dbh tapes, clinometers, and field sheets for 
use during the first week but PfB will need these items to complete the field work. One goal of the first week's activities will be to examine the equipment that PfB has on site and make recommendations.

Other issues that should be considered for field work are:

1) Dana Slaymaker will only be in the field for a couple of days and a copy of the videography imagery will have to be left behind so that the PfB field crew can use it to locate the pine savannah sampling locations. If computers are available at Hill Bank it would be best if a copy could be left there. If not, a copy will have to be left at PfB offices in Belize City.

2) As indicated during previous discussions between Winrock and PfB, the videography equipment will require two 12 -volt batteries to function. Time will be short during the field work and it is essential that the imagery be collected promptly since it will guide the ground sampling in the pine savannah. It might be a good idea to have an extra 12-volt battery on hand for back-up purposes.

3) A lot of sample bags will be needed for field work $(>100)$. Winrock will bring down as many as possible, but PfB should consider having extras on hand.

Lunch-sized paper bags will do for sampling the grasslands but larger ones will be needed for sapling, palmetto, and shrub sampling.

\subsection{Field notes for Pine Savannah sampling}

\section{Measure a total of 30 trees of Caribbean Pine}

- Minimum dbh of approximately $8-10 \mathrm{~cm}$

- Maximum dbh to be determined (likely around $50 \mathrm{~cm}$ ?)

- Total height using clinometer

- 4 measurements of crown $(\mathrm{N}, \mathrm{E}, \mathrm{S}, \mathrm{W})$ or edge of canopy

\section{Measure a total of 30 trees of Oak}

- Minimum dbh of approximately $8-10 \mathrm{~cm}$

- Maximum dbh to be determined (likely around $30 \mathrm{~cm}$ ?)

- 4 measurements of crown $(\mathrm{N}, \mathrm{E}, \mathrm{S}, \mathrm{W})$ or edge of canopy

- Total height using clinometer

\section{Measure 20-25, 2 meter by 2 meter Palmetto associations}

- Establish a $2 \mathrm{~m} \times 2 \mathrm{~m}$ square with a metric tape around a clump of palmettos

- Measure Maximum height, Average height, and \% coverage (density)

- Cut down Palmetto

- Pile stems and fronds separately

- Weigh using $20 \mathrm{~kg}$ scale using a tarp.

- Take a sub-sample and record fresh weight

- Label bag Palmetto 1, 2, 3, etc 
- Measure approximately 8 Palmetto associations of $<1$ meters in height

- Measure approximately 8 Palmetto associations of 1-1.9 meters in height

- Measure approximately 8 Palmetto associations $>2$ meters in height

\section{Measure 20-25, 2 meter by 2 meter Shrub associations. Possibly 3 shrub} associations (Tea Box, Myrtaceae, others? If time/resources allow do 20-25 for each)

- Establish a $2 \mathrm{~m} \times 2 \mathrm{~m}$ square with a metric tape around a clump of shrubs

- Measure Maximum height, Average height, and \% coverage (density)

- Cut down Shrubs

- Weigh using $20 \mathrm{~kg}$ scale using a tarp

- Take a sub-sample and record fresh weight

- Label bag Shrub 1, 2, 3, etc

- Measure approximately 12 shrub associations of 1-2.9 meters in height

- Measure approximately 12 shrub associations $>3$ meters in height

\section{Measure 15 shrubs with clip plots}

- Place clip plot around single shrub $(<1$ meter in height $)$

- Measure height, two measurements of crown, and \% coverage (density)

- Cut down Shrub

- Weigh

- Take a sub-sample and record fresh weight

- Label bag Small Shrub 1, 2, 3, etc

Measure 20-25 Pine saplings using clip plot (maybe 20-25 of Oak as well)

- Place clip plot around single sapling

- No minimum dbh, but minimum height of $0.5 \mathrm{~m}$

- Maximum dbh (not clear) but approximately $8 \mathrm{~cm}$

- Measure height, two measurements of crown (when possible), and \% coverage (density)

- Cut down sapling

- Weigh

- Take a sub-sample and record fresh weight

- Label bag Pine Sapling 1, 2, 3, etc

\section{Destructively sample approximately 30 Calabash}

- Select samples from a range of approximately $5-15 \mathrm{~cm}$ (if $15 \mathrm{~cm}$ is maximum dbh)

- Measure dbh

- Measure crown diameter (using the metric tape)

- Cut down

- Measure height

- Weigh

- Take a sub-sample and record fresh weight

- Label bag Calabash 1, 2, 3, etc

\section{Lower Priority (if time allows):}


1) Using the clip plot, sample 10 pure grassland areas. Cut and weigh, collect subsample, and dry

2) Measure approximately 30 Gallery (Riparian) forest trees, across a range of height and dbh's (just like for Pine and Oak).

3) Destructive sampling of Caribbean Pine (will check and get back to PfB on this point)

\subsection{Data sheets}

It is important that the field crews have a copy of the data sheets from last year's inventory with them when the re-measurements take place. Winrock will bring hard copies of the Excel sheets that contain the plot data but PfB should have a hard copy of the original data sheets on hand as well. The data sheets in this section do not include those that will be used for re-measuring the permanent plots. 
FIELD DATA SHEET FOR DESTRUCTIVE SAMPLING OF SAPLINGS

Crew Chief:

Tree Species:

Start time

\begin{tabular}{|c|c|c|c|c|c|c|}
\hline $\begin{array}{c}\text { Tree } \\
\text { number }\end{array}$ & Species & $\begin{array}{l}\mathrm{DBH} \\
(\mathbf{c m})\end{array}$ & $\begin{array}{c}\text { Total } \\
\text { height } \\
\text { (m) }\end{array}$ & $\begin{array}{c}\text { Fresh } \\
\text { weight } \\
\text { (kg) }\end{array}$ & $\begin{array}{c}\text { Sub- } \\
\text { sample } \\
\text { number }\end{array}$ & $\begin{array}{c}\text { Sub- } \\
\text { sample } \\
\text { fresh } \\
\text { weight } \\
\text { (g) }\end{array}$ \\
\hline & & & & & & \\
\hline & & & & & & \\
\hline & & & & & & \\
\hline & & & & & & \\
\hline & & & & & & \\
\hline & & & & & & \\
\hline & & & & & & \\
\hline & & & & & & \\
\hline & & & & & & \\
\hline & & & & & & \\
\hline & & & & & & \\
\hline & & & & & & \\
\hline & & & & & & \\
\hline & & & & & & \\
\hline & & & & & & \\
\hline & & & & & & \\
\hline & & & & & & \\
\hline & & & & & & \\
\hline & & & & & & \\
\hline & & & & & & \\
\hline & & & & & & \\
\hline & & & & & & \\
\hline & & & & & & \\
\hline & & & & & & \\
\hline
\end{tabular}




\section{FIELD DATA SHEET FOR AREA \\ PLOT MEASUREMENTS}

Location: Rio Bravo, Belize

Strata type: Pine Savannah

Start time:

Crew chief:

End time:

Number of people in crew:

Date:

Total time:

Type of Plot: $\quad \square 2 \mathrm{~m} \times 2 \mathrm{~m}$ or $\square$ Ring

Type of Vegetation:

Plot number:

\begin{tabular}{|l|c|c|}
\hline Total fresh weight (g) & $\begin{array}{c}\text { Sub-sample fresh } \\
\text { weight }(\mathrm{g})\end{array}$ & $\begin{array}{c}\text { Sub-sample dry weight } \\
(\mathrm{g})\end{array}$ \\
\hline & & \\
\hline
\end{tabular}

Average height (m):

Maximum height (m):

Density ( $\%$ of coverage in plot) :

\section{If Ring}

Crown diameter $(\mathrm{cm})$ : Crown 1 Crown 2 
FIELD SHEET FOR MEASURING TREE HEIGHT AND CROWN DIAMETER

Tree Species:

Crew chief:

Start time:

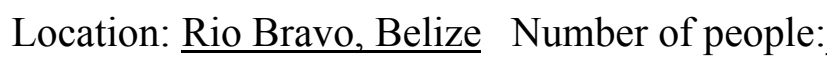

Date:

Total time:

\begin{tabular}{|c|c|c|c|c|c|c|}
\hline $\begin{array}{c}\text { Tree } \\
\text { number }\end{array}$ & Species & $\begin{array}{l}\mathrm{DB} \\
\mathrm{H} \\
\text { (cm) }\end{array}$ & $\begin{array}{c}\text { Distance } \\
\text { to tree } \\
\text { (m) }\end{array}$ & $\begin{array}{c}\text { Clinometer } \\
\text { reading } \\
\text { (bottom/top) } \\
\%\end{array}$ & $\begin{array}{c}\text { Crown } \\
\text { reading } \\
(\mathrm{N} / \mathrm{E}) \\
\text { Degrees }\end{array}$ & $\begin{array}{c}\text { Crown } \\
\text { reading } \\
(\mathrm{S} / \mathrm{W}) \\
\text { Degrees }\end{array}$ \\
\hline 1 & & & & & & \\
\hline 2 & & & & & & \\
\hline 3 & & & & & & \\
\hline 4 & & & & & & \\
\hline 5 & & & & & & \\
\hline 6 & & & & & & \\
\hline 7 & & & & & & \\
\hline 8 & & & & & & \\
\hline 9 & & & & & & \\
\hline 10 & & & & & & \\
\hline 11 & & & & & & \\
\hline 12 & & & & & & \\
\hline 13 & & & & & & \\
\hline 14 & & & & & & \\
\hline 15 & & & & & & \\
\hline 16 & & & & & & \\
\hline 17 & & & & & & \\
\hline 18 & & & & & & \\
\hline 19 & & & & & & \\
\hline 20 & & & & & & \\
\hline 21 & & & & & & \\
\hline 22 & & & & & & \\
\hline 23 & & & & & & \\
\hline 24 & & & & & & \\
\hline 25 & & & & & & \\
\hline 26 & & & & & & \\
\hline 27 & & & & & & \\
\hline 28 & & & & & & \\
\hline 29 & & & & & & \\
\hline 30 & & & & & & \\
\hline
\end{tabular}





\section{Appendix 2}

\section{Belize Carbon Inventory Data}

\section{Gallery Trees}

\begin{tabular}{|c|c|c|c|c|c|c|c|c|c|c|}
\hline \multirow[b]{2}{*}{ No. } & \multirow[b]{2}{*}{ Species } & \multirow[b]{2}{*}{$\mathrm{dbh}$} & \multirow[b]{2}{*}{ ht } & \multirow[b]{2}{*}{$\begin{array}{l}\text { dist. From } \\
\text { tree }\end{array}$} & \multirow[b]{2}{*}{ Top } & \multicolumn{2}{|c|}{ tree ht.(clin deg) } & \multicolumn{2}{|c|}{ crown diam(m) } & \multirow[b]{2}{*}{ W } \\
\hline & & & & & & bottom & $\mathrm{N}$ & $E$ & S & \\
\hline 1 & yemeri & 40 & & 20 & 72 & 12 & 4 & 3 & 7 & 6 \\
\hline 2 & yemeri & 21.8 & & 20 & 55 & 11 & 2.3 & 2 & 1.8 & 2.3 \\
\hline 3 & nargusta & 36.9 & & 20 & 52 & 12 & 7.4 & 4 & 7 & 6 \\
\hline 4 & $\begin{array}{l}\text { R. } \\
\text { gumbolimbo }\end{array}$ & 24.6 & & 20 & 65 & 13 & 3 & 3 & 2.5 & 2.8 \\
\hline 5 & boyjob & 25.2 & & 20 & 96 & 14 & 5 & 4 & 3.5 & 2 \\
\hline 6 & bullettree & 39.8 & & 20 & 90 & 12 & 4.2 & 5 & 4 & 4.3 \\
\hline 7 & negrito & 22.1 & & 20 & 72 & 12 & 1.5 & 2 & 1.6 & 2.1 \\
\hline 8 & $\begin{array}{l}\text { Bl. } \\
\text { Poisonwood }\end{array}$ & 23.8 & & 20 & 65 & 7 & 2 & 2.3 & 3 & 4.5 \\
\hline 9 & ballseed & 23.8 & & 20 & 64 & 12 & 3.1 & 3.8 & 1.4 & 1.8 \\
\hline 10 & red mylady & 25.1 & & 20 & 88 & 2 & 2 & 2.3 & 2.1 & 1.8 \\
\hline 11 & sabal palm & & 6.3 & & & & 1.5 & 1.5 & 1.4 & 1.2 \\
\hline 12 & $\begin{array}{l}\text { R. } \\
\text { gumbolimbo }\end{array}$ & 27 & & 10 & 150 & 18 & 3 & 3.4 & 2.5 & 2.1 \\
\hline 13 & $\begin{array}{l}\text { Bl. } \\
\text { Poisonwood }\end{array}$ & 30.2 & & 20 & 43 & 14 & 1.89 & 1.6 & 2 & 1.8 \\
\hline 14 & Wild craboo & 21 & & 10 & 86 & 20 & 2 & 2.8 & 1.8 & 2.4 \\
\hline 15 & Santa maria & 59.7 & & 20 & 108 & 12 & 6 & 6.2 & 4.5 & 4.6 \\
\hline 16 & Provision bark & 21.5 & & 10 & 122 & 28 & 3.4 & 1.6 & 2 & 1.5 \\
\hline 17 & $\begin{array}{l}\text { R. } \\
\text { gumbolimbo }\end{array}$ & 23.9 & & 10 & 170 & 23 & 4 & 3.3 & 2 & 2.2 \\
\hline
\end{tabular}




\begin{tabular}{|c|c|c|c|c|c|c|c|c|c|}
\hline 18 & Santa maria & 28.4 & 20 & 70 & 19 & 3 & 3.8 & 3.5 & 4 \\
\hline 19 & Tzalam & 28.8 & 20 & 76 & 15 & 1.8 & 1.6 & 1.4 & 1.7 \\
\hline 20 & bullettree & 30.9 & 20 & 62 & 11 & 6 & 6.3 & 2 & 3.2 \\
\hline 21 & Provision bark & 22.1 & 20 & 66 & 14 & 2 & 1.8 & 2.7 & 2.1 \\
\hline 22 & mahogany & 11.2 & 10 & 82 & 18 & 1.3 & 1.1 & 1.1 & 1.4 \\
\hline 23 & $\begin{array}{l}\text { Myrtaceae } \\
\text { spp. }\end{array}$ & 22.4 & 20 & 63 & 10 & 2 & 1.4 & 1.8 & 2 \\
\hline 24 & $\begin{array}{l}\text { Red cabb. } \\
\text { Bark }\end{array}$ & 13.6 & 20 & 57 & 9 & 1 & 1.3 & 1 & 1.3 \\
\hline 25 & $\begin{array}{l}\text { Red cabb. } \\
\text { Bark }\end{array}$ & 13.9 & 20 & 55 & 10 & 1.7 & 1.2 & 2 & 1.6 \\
\hline 26 & $\begin{array}{l}\text { Bl. } \\
\text { Poisonwood }\end{array}$ & 10.4 & 10 & 90 & 11 & 1 & 1.3 & 1 & 1 \\
\hline 27 & $\begin{array}{l}\text { bastard } \\
\text { rosewood }\end{array}$ & 36.1 & 20 & 72 & 7 & 4.6 & 4.1 & 2.3 & 3 \\
\hline 28 & bullettree & 20.4 & 10 & 160 & 16 & 3.1 & 3.2 & 1.6 & 1.2 \\
\hline 29 & $\begin{array}{l}\text { R. } \\
\text { gumbolimbo }\end{array}$ & 27.2 & 20 & 66 & 7 & 3.3 & 4.2 & 2 & 1.5 \\
\hline 30 & bullettree & 21.3 & 20 & 66 & 10 & 2.3 & 3.8 & 5.3 & 2 \\
\hline
\end{tabular}

\section{Shrub assoc. $(2 \times 2)$}

No. Specie Tot wt. Max ht. Avg. ht. crown coverage( diam1

$\%)$

\begin{tabular}{|c|c|c|c|c|c|c|c|}
\hline Teabox & 2750 & 1.5 & 0.7 & 30 & 1.2 & 0.9 & 111 \\
\hline Teabox & 2120 & 1.65 & 1.5 & 35 & 0.75 & 0.8 & 100 \\
\hline Teabox & 4700 & 1.66 & 1.54 & 45 & 0.9 & 0.8 & 110 \\
\hline
\end{tabular}




$\begin{array}{cccccccccc}4 & \text { Teabox } & 2960 & 1.65 & 1.1 & 35 & 1.1 & 1.3 & 120 & 55.7 \\ 5 & \text { Teabox } & 3150 & 1.5 & 0.85 & 40 & 0.85 & 0.9 & 110 & 47.2 \\ 6 & \text { Teabox } & 10500 & 2.7 & 2 & 75 & 1.7 & 1.5 & 110 & 64.4 \\ 7 & \text { Teabox } & 13400 & 3.1 & 3 & 45 & 2.85 & 2 & 150 & 83.3 \\ 8 & \text { Teabox } & 34500 & 3.4 & 2.57 & 100 & 2.45 & 2.2 & 150 & 72.6 \\ 9 & \text { Teabox } & 12600 & 3.28 & 2.18 & 40 & 2.6 & 2.8 & 100 & 49.8 \\ 10 & \text { Teabox } & 11000 & 3.1 & 2.7 & 60 & 2.5 & 2.7 & 120 & 46.5 \\ 11 & \text { craboo } & 11200 & 3 & 2.52 & 60 & 1.9 & 2 & 120 & 45.4 \\ 12 & \text { craboo } & 12600 & 2.05 & 1.7 & 75 & 1.6 & 1.35 & 150 & 59.1 \\ 13 & \text { craboo } & 18100 & 2.35 & 1.5 & 90 & 1.34 & 1.6 & 200 & 67.4 \\ 14 & \text { craboo } & 4000 & 1.45 & 1.15 & 45 & 1.05 & 0.85 & 160 & 69.8 \\ 15 & \text { craboo } & 6750 & 1.52 & 1.3 & 90 & 1.3 & 1.3 & 180 & 64.9 \\ 16 & \text { Yaha } & 8250 & 2.6 & 1.8 & 35 & 1.1 & 0.8 & 102 & 45.8 \\ 17 & \text { Yaha } & 16750 & 3.1 & 2.4 & 90 & 2.1 & 2.3 & 110 & 44.9 \\ 18 & \text { craboo } & 13000 & 2.4 & 2 & 90 & 2.8 & 2.3 & 129 & 52.4 \\ 19 & \text { craboo } & 15750 & 2.4 & 2.1 & 80 & 1.8 & 2.1 & 140 & 51.9 \\ 20 & \text { craboo } & 8750 & 1.8 & 1.4 & 60 & 1.7 & 1.55 & 105 & 38\end{array}$

\begin{tabular}{|c|c|c|c|c|c|c|c|c|c|c|}
\hline \multirow[b]{2}{*}{ No. } & & Calabash & $e r(\mathrm{~cm})$ & \multicolumn{2}{|c|}{$\begin{array}{l}\text { Crown } \\
\text { diam }\end{array}$} & \multicolumn{2}{|l|}{ wt(g)) } & \multicolumn{3}{|c|}{ Sample wt(g) } \\
\hline & $\begin{array}{l}\text { Tot. } \\
\text { ht. }\end{array}$ & $\begin{array}{c}\text { at breast } \\
\text { ht. }\end{array}$ & $\begin{array}{c}\text { below 1st } \\
\text { branch }\end{array}$ & $\mathrm{d} 1$ & $\mathrm{~d} 2$ & $\begin{array}{c}<5 \\
\text { branch/lv }\end{array}$ & $\begin{array}{c}>5 \\
\text { branch }\end{array}$ & $\begin{array}{l}\text { bole } \\
\text { wt.(g) }\end{array}$ & wet & dry \\
\hline 1 & 2.55 & & $6.8 / 0.55 \mathrm{~m}$ & 1.4 & 1.1 & 8700 & & & 110 & 45.6 \\
\hline 2 & 3.4 & 7.5 & & 2.8 & 2.6 & 17250 & & & 140 & 64.5 \\
\hline 3 & 3.6 & & 13.8/0.6 & 6 & 4.55 & 48450 & 65350 & & 200 & 86.5 \\
\hline 4 & 3.4 & & $9.2 / 0.7$ & 2.1 & 2.3 & 20550 & & & 110 & 45.3 \\
\hline 5 & 3.65 & & $7.2 / 0.9$ & 3.5 & 2 & 8500 & 14200 & & 125 & 52 \\
\hline 6 & 2.78 & & $10.8 / 1$ & 2.75 & 2.4 & 24300 & 8300 & & 129 & 62.1 \\
\hline 7 & 3.85 & & $10.9 / 0.9$ & 4.2 & 3.1 & 10000 & 23200 & & 110 & 42.2 \\
\hline
\end{tabular}




\begin{tabular}{c|c|cc|cr|cc||ccc}
8 & 3.1 & & $13.9 / 0.4$ & 3.9 & 4.6 & 13300 & 28600 & & 132 & 65.6 \\
9 & 2.57 & 5.7 & & 1.2 & 1.05 & 4000 & 5500 & & 116 & 49.4 \\
10 & 3.6 & & $21.1 / 0.9$ & 6.45 & 5.7 & 28794 & 95691 & 52607 & 124 & 56 \\
11 & 3.9 & 6.6 & & 3.8 & 1.3 & 5500 & & 10000 & 163 & 79 \\
12 & 2.8 & & $15.3 / 0.4$ & 3.4 & 2.7 & 22222 & & 29024 & 120 & 59.6 \\
13 & 5.1 & & $25.1 / 0.45$ & 6.6 & 3.8 & 50793 & 117913 & 42176 & 150 & 68.5 \\
14 & 2.7 & & $10.9 / 0.7$ & 1.78 & 1.7 & 5300 & 13400 & & 115 & 51 \\
15 & 4.2 & 27.2 & & 5.8 & 3.2 & 18594 & 63492 & 124263 & 200 & 106.8 \\
16 & 2.2 & & $10.6 / 0.7$ & 1.9 & 2.25 & 6750 & 5600 & 6200 & 100 & 45.2 \\
17 & 3 & & $18.4 / 0.5$ & 5.3 & 4.1 & 34920 & 41723 & 20861 & 145 & 66.9 \\
18 & 4.2 & & $8.4 / 0.95$ & 2.95 & 2.8 & 8616 & 12244 & & 110 & 52.4 \\
19 & 3.4 & & $9.7 / 1$ & 1.26 & 2.75 & 6802 & 9523 & 8163 & 102 & 45.9 \\
20 & 3.75 & 11.2 & & 1.95 & 2.6 & 9070 & 10430 & 20408 & 170 & 67.7 \\
21 & 4.9 & 14.3 & & 4 & 3.45 & 11337 & 32199 & 49433 & 150 & 75.9 \\
22 & 3.9 & & $10.8 / 1.1$ & 3.2 & 2.2 & 10884 & 15419 & 17687 & 180 & 83.8 \\
23 & 2.35 & & $8.2 / 0.66$ & 2.5 & 2.3 & 3174 & 8150 & & 205 & 98.1 \\
24 & 4.6 & & $17.9 / 0.9$ & 2.95 & 3.38 & 13605 & 42176 & 19954 & 110 & 44 \\
25 & 3.9 & 11 & & 3.6 & 3.7 & 14965 & 16780 & 23129 & 200 & 86.3 \\
26 & 3 & & $8.6 / 0.8$ & 1.85 & 1.7 & 4535 & 4535 & 4988 & 150 & 70 \\
27 & 3.83 & & $26.2 / 0.55$ & 5.3 & 5.2 & 47619 & 67120 & 43537 & 198 & 96 \\
28 & 3 & & $9.1 / 1.15$ & 4.4 & 4.9 & 9070 & 5895 & 10430 & 170 & 85.5 \\
29 & 2.85 & & $13.5 / 0.6$ & 3.4 & 3.3 & 23582 & 20861 & 10430 & 190 & 96.5 \\
30 & 2.71 & & $9.9 / 0.8$ & 3.65 & 3.12 & 14512 & 9070 & 9070 & 180 & 88.1
\end{tabular}

\section{Palmetto Sampling(2x2 m)}

\begin{tabular}{|c|l|l|l|l|l|l|l|l|}
\hline Smple \# & $\begin{array}{l}\text { Bulk Wt } \\
(\mathrm{g})\end{array}$ & $\begin{array}{l}\text { Samp Fresh Wt } \\
(\mathrm{g})\end{array}$ & $\begin{array}{l}\text { Samp Dry Wt } \\
(\mathrm{g})\end{array}$ & $\begin{array}{l}\text { Avg Height } \\
(\mathrm{m})\end{array}$ & $\begin{array}{l}\text { Max Height } \\
(\mathrm{m})\end{array}$ & $\begin{array}{l}\text { Density } \\
\%\end{array}$ & $\begin{array}{l}\text { Crown Diam } \\
1(\mathrm{~cm})\end{array}$ & $\begin{array}{l}\text { Crown Diam 2 } \\
(\mathrm{cm})\end{array}$ \\
\hline 1 & 22,700 & 275 & 132.6 & 2 & 3.5 & 58 & 1 & 1.2 \\
\hline 2 & 12,000 & 130 & 54.1 & 1.3 & 1.6 & 75 & 100 & 113 \\
\hline
\end{tabular}




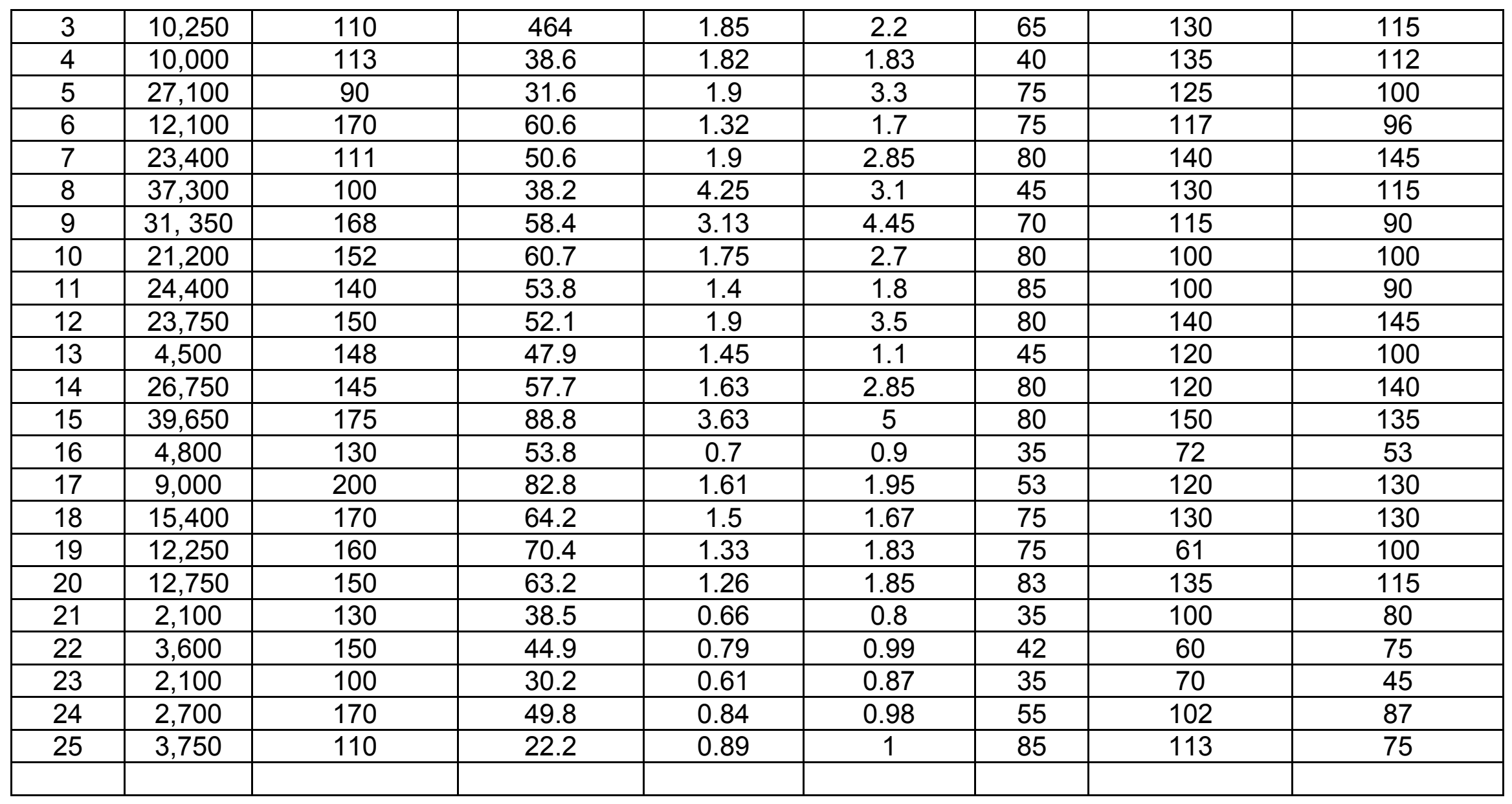




\section{Appendix 3}

\section{LIBS Workshop Proposal}

\section{Proposal to the National Energy Technology Laboratory to Enhance Cooperative Agreement DE-FC26-01NT411511}

\section{Workshop: LIBS Applications for Carbon Measurement on Brazil Carbon Project Lands}

July 17,2002

\section{Background}

As part of the Los Alamos program on Terrestrial Carbon Sequestration and Management, LANL has developed a method for soil carbon analysis based on laserinduced breakdown spectroscopy (LIBS). After initial calibration and testing, it was clear that the LIBS method is a potentially powerful tool for improving soil carbon measurements. The Nature Conservancy (TNC) has expressed interest in using LIBS on two carbon sequestration projects in Brazil being implemented by Sociedade de Pesquisa em Vida Selvagem e Eduacação Ambiental (SPVS), in partnership with TNC and funded by American Electric Power and General Motors. This proposal is for funding to bring U. S. scientists and LIBS equipment to study areas near Curitiba, Paraná, Brazil to conduct a demonstration workshop in the field. Below we detail the goals, objectives, and deliverables from the workshop as well as list the potential participants. The workshop is a direct outgrowth of individual and collaborative project activities at Los Alamos and TNC funded by NETL to evaluate the measurement of carbon in soils and application of soil measurements to carbon sequestration strategies.

\section{Carbon Inventory work under Cooperative Agreement DE-FC26-01NT411511}

Through ongoing carbon inventory work, TNC has identified several aspects of the inventories that could be improved or significantly strengthened. Measurement of soil carbon is one area that needs to be more fully developed. TNC received funding from NETL through a cooperative agreement to undertake research into more accurate and cost-effective inventory methods for measuring carbon and for developing new project ideas. The calibration of Laser-Induced Breakdown Spectroscopy (LIBS) for measuring soil carbon on the Guaraqueçaba Climate Action Project (Serra do Itaqui Natural Reserve) and The Atlantic Rainforest Retoration Project (Cachoeira River Basin) carbon projects in Brazil is already planned for under this agreement. 
We believe that a demonstration workshop would greatly increase the visibility and effectiveness of this new technology. A major result of the site visits and extensive exchange of ideas from the proposed workshop would be to develop a proposal for longer-term joint studies between Brazilian and U.S. scientists. We will be able to use the local expertise of Brazilian scientists to build the project into a significant contribution in understanding the role of terrestrial systems in global change. In addition, by familiarizing the Los Alamos scientists with the research needs of the carbon projects sponsored by TNC and its local Brazilian partner SPVS, this will provide a strong basis for planning future use of LIBS on TNC's project sites in Brazil.

\section{Goals}

The goals of the proposed workshop are 1) to show the effectiveness of LIBS technology in the field; 2) to collaborate with Brazilian experts to measure carbon in soils, estimate carbon inventories in select sites of interest, and ultimately establish baselines for soil carbon; and 3) to develop a joint proposal for additional work by the Brazilian and American scientists, either in the United States, Brazil, or both, that relates to carbon sequestration efforts important to the governments of both countries.

The focus of the workshop is to demonstrate the effectiveness of LIBS analyses in the field and to apply the LIBS method to challenges that involve measuring soil and biomass carbon in Brazil, including the Atlantic Forest and other biomes. By way of the proposed workshop, we will demonstrate the field use of laser-induced breakdown spectroscopy (LIBS) to measure soil carbon as well as develop potential applications of LIBS measurements to various soil carbon/terrestrial carbon inventory concerns presented by Brazilian scientists. The workshop and associated field campaign will provide the information needed to develop a sound proposal for using LIBS measurement for terrestrial carbon inventories for projects similar to those initiated by The Nature Conservancy and SPVS with funding provided by General Motors, American Electric Power, and Texaco/Chevron.

\section{Objectives}

The proposed Workshop will include a joint meeting between the Los Alamos Terrestrial Carbon Project and invited Brazilian soil scientists as well as a 1-day sampling trip to sites within the TNC/SPVS Carbon Project in the Atlantic Forest. The following are the main objectives of the proposed workshop:

- demonstrate the effectiveness of LIBS in the field to influential U.S. and Brazilian scientists;

- familiarize the Los Alamos team with research needs for the Carbon Project sponsored by TNC/SPVS;

- develop the sampling methodology for a proposal to use LIBS in the Carbon Project (or related projects) in Brazil or the United States;

- develop a proposal to use LIBS on carbon inventory measurements and establishment of baseline that will be conducted jointly by Brazilian and U. S. scientists; 
- provide a proceedings report on the various technical and policy implications of conventional and advanced soil carbon measurement.

The proposed workshop will be a forum to familiarize the Los Alamos scientists with efforts underway in Brazil, terrestrial carbon issues that might be addressed through application of LIBS analysis of soil carbon, to demonstrate the use of LIBS, and begin comparisons of the cost effectiveness of LIBS and conventional methods. We will develop a detailed proposal as a product of the workshop that will be submitted for funding consideration to an as yet unspecified funder. The proposal will focus on using LIBS analysis in work planned by SPVS and TNC for the three ongoing carbon sequestration projects in the Atlantic Forest Region of Brazil, as well as testing and refining the LIBS analysis protocols. Five potential topics that will be addressed in future application of LIBS analyses to carbon measurement problems include:

1. Calibrate LIBS for soil carbon analysis in tropical soils.

2. Extend soil carbon measurements into the top 1 to $2 \mathrm{~m}$ of the soil depth at sites of interest.

3. Explore whether the cost of measurement of soil carbon by LIBS and/or conventional analysis is less than the value of sequestration, and compare cost effectiveness of LIBS analysis vs. conventional methods.

4. Evaluate correlations between soil carbon analyses and other remotely-measured indices of soil properties.

5. Select sites that will provide representative estimates of soil carbon, provide estimates of "baseline" carbon in soils from LIBS measurements, and identify and quantify the uncertainties in those estimates.

The Los Alamos scientists, with the collaboration of scientists from TNC, SPVS and other national and international collaborators, will be able to develop the proposal for longer-term studies as a result of site visits and extensive exchange of ideas from the proposed workshop. In addition, we will be able to demonstrate the new method of analysis in the field and use the local expertise of Brazilian scientists to build the project into a significant contribution in understanding the role of terrestrial systems in global change.

\section{Proposed Dates and Location}

The proposed dates of the workshop are mid-February, 2003, or mid-March, 2003. Vehicle-portable LIBS is ready for deployment and has been successfully tested in this mode at three remotes sites in the United States. Capabilities for total core analysis and discreet sample analysis are in place and will be part of the LIBS instrument available for this workshop. Los Alamos personnel will be responsible for shipping the instrument, all import and export authorities needed, and safety procedures required for safe operation of the instrument during the workshop.

The workshop will be conducted at the Hotel Mata Atlântica, located close to Morretes, the project areas, and 1.5 hours from Curitiba. This provides adequate facilities for the talks that will be held as part of the workshop, as well as facilities for demonstrating the 
LIBS instrument before and during the field campaign. TNC personnel will be responsible for planning and hosting the workshop. Field sites will be located approximately 1 hour from Morretes at SPVS/TNC facilities in the field. The field facilities will be used to house the LIBS instrument and for sample handling during the campaign.

\section{Deliverables}

In addition to the proposal mentioned above to support joint measurement efforts by Brazilian and U. S. scientists, we will produce a proceedings report of the workshop events and outcomes. While a more detailed outline of the proceedings report will be developed as the workshop participants are confirmed, the main ideas are listed below:

- Address broad but pertinent questions about soil carbon measurement in Brazil and the United States:

What are the needs for advanced carbon measurement systems in Brazil?

What is the conceptual model for an integrated, joint measurement system between Brazil and the U. S.?

What are potential impacts for carbon management, land use, and climate change research from advanced carbon measurement systems and from the workshop?

What policy impacts are likely/unlikely from the workshop?

- Technical Reports

What is the current state of the art with regard to carbon measurement in soils (without LIBS)?

What are time estimates to obtain carbon data for various projects to date?

Cost effectiveness: How does carbon analysis by LIBS compare to dry combustion analysis and carbon measurement by other methods?

How are carbon baselines established?

What is the sampling design and intensity needed?

Where does current accuracy and precision of carbon measurements leave us?

How do we test carbon inventories against baseline values so that the comparisons are statistically valid?

What sort of research designs are needed to support baseline measurements, carbon management policy (e.g., sequestration and permanence), and carbon trading?

- Where next? How can we apply the new carbon measurement technologies?

Technical issues: Improvements of bulk density measurements and inventory estimates-new technology needed?

Policy issues: how could measurements of increased accuracy affect carbon management and carbon trading issues?

The joint proposal that will be developed as part of the workshop will be used to fund future collaboration between the Brazilian and U. S. scientists involved with carbon 
measurements. The proposal will likely be of high impact in future monitoring efforts regarding soil carbon and global change. As yet, we have not identified potential sponsors of such a proposal.

\section{Potential Participants}

The following table lists the scientists who should be invited to participate in the proposed workshop.

Table listing potential participants in LIBS Workshop

\begin{tabular}{|c|c|c|c|}
\hline Name & Organization & Workshop Role & Country \\
\hline Michael Ebinger & $\begin{array}{l}\text { Los Alamos National } \\
\text { Laboratory }\end{array}$ & $\begin{array}{l}\text { Workshop Organizer. } \\
\text { Principal Investigator, } \\
\text { Soil Carbon Measurement }\end{array}$ & $\begin{array}{l}\text { United } \\
\text { States }\end{array}$ \\
\hline Miguel Calmon & TNC-Brazil & $\begin{array}{l}\text { Workshop Organizer. } \\
\text { Principal Investigator, } \\
\text { Carbon Monitoring/Brazil } \\
\text { Ecosystems }\end{array}$ & Brazil \\
\hline David Cremers & $\begin{array}{l}\text { Los Alamos National } \\
\text { Laboratory }\end{array}$ & $\begin{array}{l}\text { Principal Investigator, } \\
\text { LIBS Instrumentation }\end{array}$ & $\begin{array}{l}\text { United } \\
\text { States }\end{array}$ \\
\hline David Breshears & $\begin{array}{l}\text { Los Alamos National } \\
\text { Laboratory }\end{array}$ & $\begin{array}{l}\text { Principal Investigator, } \\
\text { Ecosystem Dynamics }\end{array}$ & $\begin{array}{l}\text { United } \\
\text { States }\end{array}$ \\
\hline Monty Ferris & $\begin{array}{l}\text { Los Alamos National } \\
\text { Laboratory }\end{array}$ & $\begin{array}{l}\text { Lead LIBS instrument } \\
\text { technician }\end{array}$ & $\begin{array}{l}\text { United } \\
\text { States }\end{array}$ \\
\hline Clif Meyer & $\begin{array}{l}\text { Los Alamos National } \\
\text { Laboratory }\end{array}$ & $\begin{array}{l}\text { Lead Ecosystems } \\
\text { technician }\end{array}$ & $\begin{array}{l}\text { United } \\
\text { States }\end{array}$ \\
\hline Pat Unkefer & $\begin{array}{l}\text { Los Alamos National } \\
\text { Laboratory }\end{array}$ & $\begin{array}{l}\text { Principal Investigator for } \\
\text { Plant Systems }\end{array}$ & $\begin{array}{l}\text { United } \\
\text { States }\end{array}$ \\
\hline Dick Benson & $\begin{array}{l}\text { Los Alamos National } \\
\text { Laboratory }\end{array}$ & Project Manager & $\begin{array}{l}\text { United } \\
\text { States }\end{array}$ \\
\hline Bill Stanley & $\mathrm{TNC}$ & $\begin{array}{l}\text { Workshop Organizer. } \\
\text { Principal Investigator, } \\
\text { Forest and Carbon } \\
\text { Specialist }\end{array}$ & $\begin{array}{l}\text { United } \\
\text { States }\end{array}$ \\
\hline Lee Norfleet & USDA-NRCS & & $\begin{array}{l}\text { United } \\
\text { States }\end{array}$ \\
\hline Rattan Lal & $\begin{array}{l}\text { Ohio State } \\
\text { University }\end{array}$ & & $\begin{array}{l}\text { United } \\
\text { States }\end{array}$ \\
\hline John Litynski & DOE-NETL & Project Manager & $\begin{array}{l}\text { United } \\
\text { States }\end{array}$ \\
\hline Gary Kaster & $\begin{array}{l}\text { American Electric } \\
\text { Power }\end{array}$ & & $\begin{array}{l}\text { United } \\
\text { States }\end{array}$ \\
\hline 1 Representative & General Motors & & \\
\hline Sandra Brown & $\begin{array}{l}\text { Winrock } \\
\text { International }\end{array}$ & & $\begin{array}{l}\text { United } \\
\text { States }\end{array}$ \\
\hline Bill Parton & Colorado State & & \\
\hline
\end{tabular}




\begin{tabular}{|c|c|c|c|}
\hline & University & & \\
\hline Pedro Machado & Embrapa Soils & & Brazil \\
\hline Celso Manzatto & Embrapa Soils & & Brazil \\
\hline Carlos Cerri & $\begin{array}{l}\text { State University of } \\
\text { SP - USP/CENA }\end{array}$ & & Brazil \\
\hline Warwick Manfrinato & $\begin{array}{l}\text { State University of } \\
\text { SP - USP/CENA }\end{array}$ & & Brazil \\
\hline Reynaldo Victoria & $\begin{array}{l}\text { State University of } \\
\text { SP - USP/CENA }\end{array}$ & & Brazil \\
\hline Rosana Higa & $\begin{array}{l}\text { Embrapa Forestry } \\
\text { Center }\end{array}$ & & Brazil \\
\hline Gustavo Curcio & $\begin{array}{l}\text { Embrapa Forestry } \\
\text { Center }\end{array}$ & & Brazil \\
\hline Gilberto Tiepolo & SPVS & $\begin{array}{l}\text { Area specialist/Carbon } \\
\text { Monitoring }\end{array}$ & Brazil \\
\hline Ricardo Britez & SPVS & $\begin{array}{l}\text { Area specialist/Forest and } \\
\text { Soils }\end{array}$ & Brazil \\
\hline Dirley Schimidlin & SPVS & Area specialist/Soils & Brazil \\
\hline $\begin{array}{l}2 \text { from the Federal } \\
\text { University of Parana }\end{array}$ & Federal University & & Brazil \\
\hline $\begin{array}{l}1 \text { from } \mathrm{ABC} \\
\text { Foundation }\end{array}$ & ABC Foundation & & Brazil \\
\hline $\begin{array}{l}1 \text { from Embrapa } \\
\text { Cerrados Center }\end{array}$ & Embrapa & & Brazil \\
\hline Paulo Gabriel & $\begin{array}{l}\text { Federal University of } \\
\text { Bahia }\end{array}$ & & Brazil \\
\hline $\begin{array}{l}1 \text { from the Federal } \\
\text { University of Vicosa } \\
\text { - Minas Gerais }\end{array}$ & $\begin{array}{l}\text { Federal University of } \\
\text { Viçosa }\end{array}$ & & Brazil \\
\hline 1 representative & $\begin{array}{l}\text { LBA } \\
\text { Project/Amazon }\end{array}$ & & Brazil \\
\hline 1 representative & $\begin{array}{l}\text { INPA/Amazon } \\
\text { region }\end{array}$ & & Brazil \\
\hline $\begin{array}{l}2 \text { representatives } \\
\text { from the private } \\
\text { sector (potential } \\
\text { users of the } \\
\text { technology) }\end{array}$ & & & Brazil \\
\hline
\end{tabular}

\section{Budget}

All funding for the workshop will be provided from NETL through their cooperative agreement (DE-FC26-01NT411511) with TNC, with the exception of FTE time for Los 
Alamos personnel, which will be covered internally through Los Alamos programmatic funds. Additional project time may be needed for Mike Ebinger to prepare the proceedings for the workshop and develop the proposal. A request for resources for this work is not included in this proposal.

\section{A. - LANL}

\begin{tabular}{|l|l|l|l|}
\hline \multicolumn{1}{|c|}{ LANL Staff } & $\begin{array}{c}\text { Travel \& Lodging (each, } \\
\text { estimates) }\end{array}$ & \multicolumn{1}{|c|}{ Per diem $^{\mathbf{1}}$} & \multicolumn{1}{|c|}{ Total (each) $^{-1}$} \\
\hline Ebinger, Cremers, Ferris & $\$ 2,500.00$ & $\$ 525.00$ & $\$ 3,025.00$ \\
\hline & & Total Travel & $\mathbf{\$ 9 , 0 7 5 . 0 0}$ \\
\hline
\end{tabular}

1. Per diem based on DOE estimate, and based on 7-day stay.

\section{B. - TNC}

The proposed budget includes travel and lodging expenses for TNC staff and the Brazilian scientists. It also includes catering expenses for the workshop, and food and transportation for the field trip. Salary time for Calmon ( 2 weeks preparation, 1 week workshop, 1 week to prepare proceedings and develop proposal, plus fringe benefits) and Stanley (1 week preparation, 1 week workshop, 3 days to prepare proceedings and proposal, plus fringe benefits) was included. The travel line item includes foreign air travel ( 5 trips between the U.S. and Brazil, and 10 in-country trips, all for workshop participants). The workshop budget is based on 32 participants.

\begin{tabular}{|c|c|}
\hline EXPENDITURES & AMOUNT \\
\hline a. PERSONNEL & $\$ 7187.27$ \\
\hline b. FRINGE BENEFITS & $\$ 3559.10$ \\
\hline \multicolumn{2}{|l|}{ c. TRAVEL } \\
\hline -Air Tickets & $\$ 8510.64$ \\
\hline -Hotel & $\$ 2553.19$ \\
\hline -Van Transportation & $\$ 1072.34$ \\
\hline d. EQUIPMENT & $\$ 0.00$ \\
\hline e. SUPPLIES & $\$ 0.00$ \\
\hline f. CONTRACTUAL & $\$ 0.00$ \\
\hline g. COMMUNICATIONS & $\$ 0.00$ \\
\hline \multicolumn{2}{|l|}{ h. OTHER } \\
\hline -Catering Expenses & $\$ 2140.43$ \\
\hline -LDC Projector & $\$ 187.23$ \\
\hline Total TNC Costs & $\$ 25210.20$ \\
\hline
\end{tabular}

\section{Total Budget}

\section{EXPENDITURES}

AMOUNT 


\begin{tabular}{|l|r|}
\hline & \\
\hline a. PERSONNEL & $\$ 7,187.27$ \\
\hline b. FRINGE BENEFITS & $\$ 3,559.10$ \\
\hline c. TRAVEL & $\$ 21,211.17$ \\
\hline d. EQUIPMENT & $\$ 0.00$ \\
\hline e. SUPPLIES & $\$ 0.00$ \\
\hline f. CONTRACTUAL & $\$ 0.00$ \\
\hline g. COMMUNICATIONS & $\$ 0.00$ \\
\hline $\begin{array}{l}\text { h. OTHER- FEES, } \\
\text { CHARGES }\end{array}$ & $\$ 2,327.66$ \\
\hline & \\
\hline Total Allowable Direct & $\$ 34,285.20$ \\
\hline Costs & \\
\hline Indirect Costs, at 22\% & $\$ 7,542.74$ \\
\hline & \\
\hline TOTAL PROJECT COSTS & $\mathbf{\$ 4 1 , 8 2 7 . 9 4}$ \\
\hline & \\
\hline Federal Share & $\mathbf{\$ 3 3 , 4 6 2 . 3 5}$ \\
\hline & \\
\hline Non-Federal Match & $\mathbf{\$ 8 , 3 6 5 . 5 9}$ \\
\hline
\end{tabular}

${ }^{1}$ Food provided for meetings is classified under TNC's budget category "Other - Fees, Charges", which includes training and meeting expenses. 


\section{Preliminary Agenda}

Monday - Preparation: Meeting between LANL/TNC/SPVS to discuss logistics, agenda, and details of the workshop. This will also been an opportunity to check and test the equipment and go over the list of equipment necessary for the field trip.

Participants leave Curitiba and go to Hotel Mata Atlântica.

Tuesday - Day 1 of Workshop: Introduction, presentation of the objectives of the workshop, several presentations and group discussions to address some key issues. Present field test design for workshop: 1) measure soil carbon from a site grazed with buffalo and site or sites reclaimed from buffalo grazing ( 1 or 2 sites; if more than 1, then we should look at time without buffalo as a factor); 2) measure soil carbon in a forest and/or old forest and new forest.

Day 1 of Workshop be presented at the Hotel Mata Atlântica.

Presentations:

Los Alamos - description of LIBS - from development stage to its application in the field on the different areas (contaminants, soil carbon, precision ag, etc), what has been done in the US and Brazil, preliminary results of calibration, description of the equipment.

SPVS - Presentation on the projects and results of the soil mapping

$T N C$ - The possibilities of using this technology in Brazil for soil carbon monitoring and inventory in carbon sequestration projects and how can it be used more broadly.

Embrapa Soils - Presentation on the status of soil carbon measurements in Brazil and common methodologies, some research results and potential of using LIBS in Brazil.

State University of São Paulo - Presentation of some projects that have been using different techniques to measure soil carbon and its spatial variability.

$U S D A / N R S C$ - What has been going on in the US regarding soil carbon measurement in agriculture and forestry areas.

Wednesday - Day 2 of Workshop: Field Trip (get cores and samples, test LIBS, visit soil pits, scan them with LIBS, and analyze data). Prepare tables of carbon data measured from LIBS, also other methods if data exist. Begin discussions of data collection and integration into carbon inventories.

Go back to the hotel at the end of the day and have dinner.

Thursday - Day 3 of Workshop: 1) Finish data analysis, present results in workshop; 2) Design sampling schemes and monitoring strategies for the project area; 3) Discuss the potential of using LIBS in Brazil and priorities and strategies for future work and collaboration. Wrap-up. 
Head back to Curitiba.

Friday - Wrap-up and Departure: Participants return home-Calmon, Ebinger, Stanley finalize any proceedings. 

Appendix 4

March 2002 Aerial Survey

Belize Videography Images

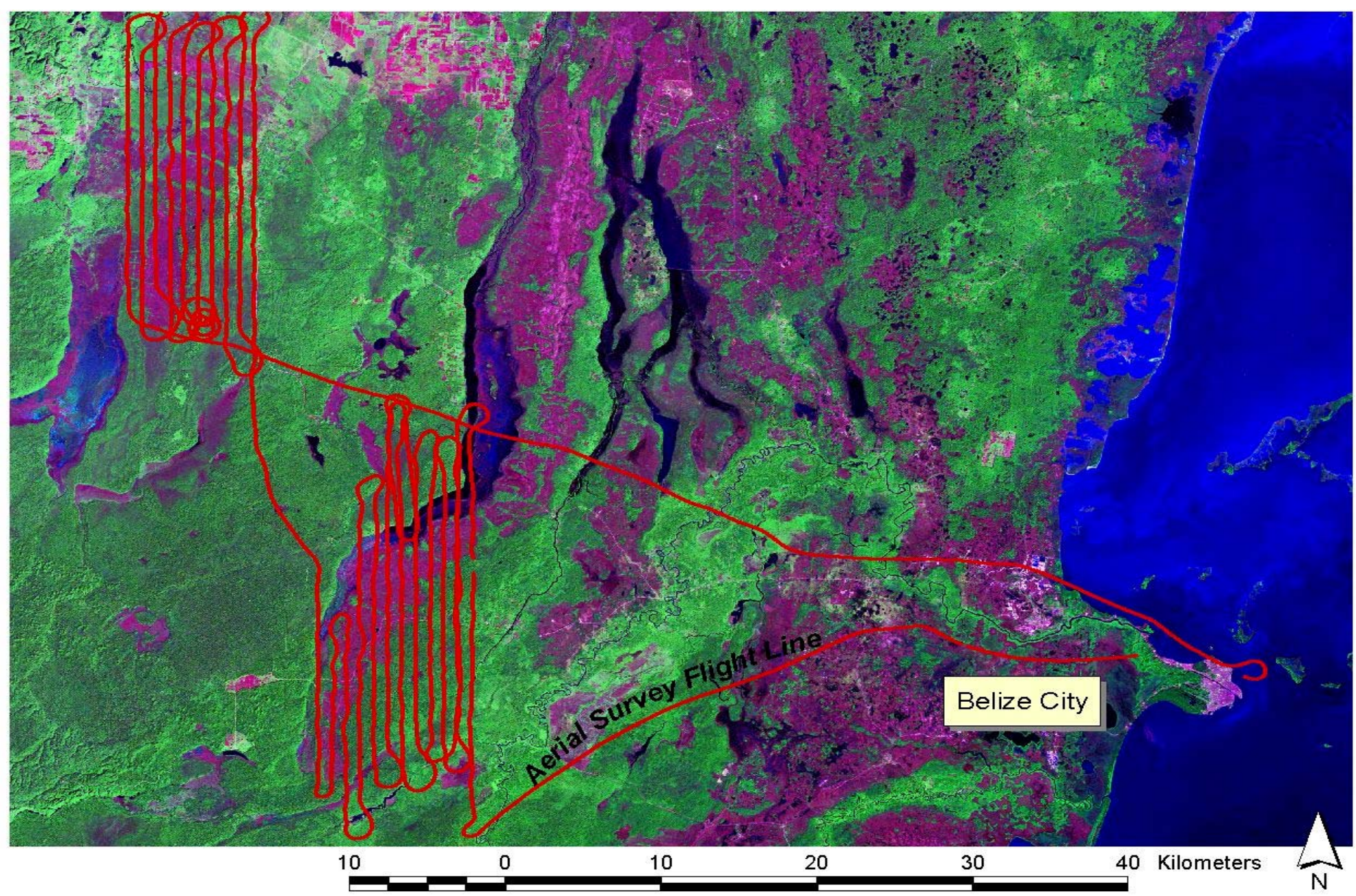


Aerial Digital Images Vs. Satellite Image

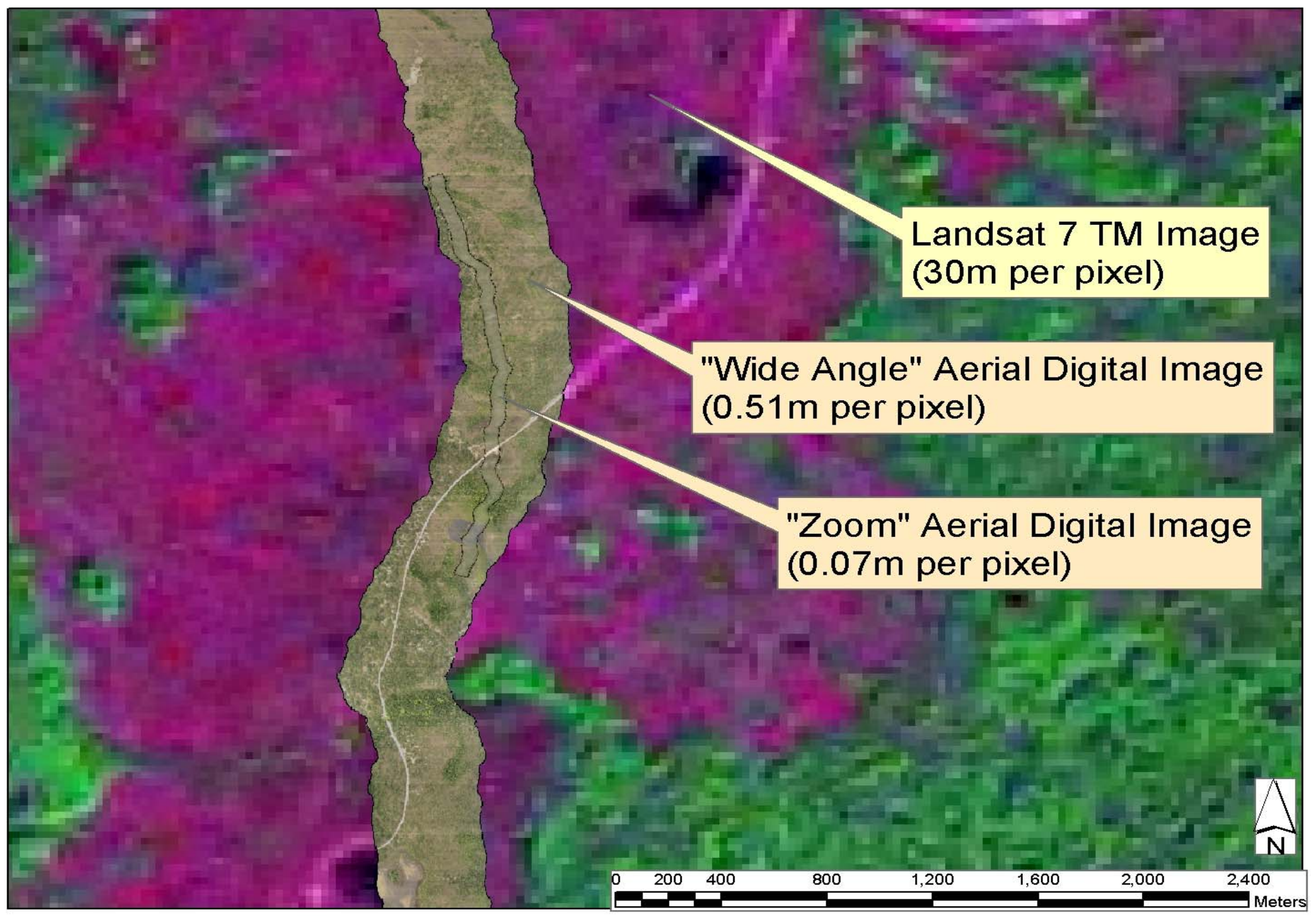


Aerial Digital Images Vs. Satellite Image

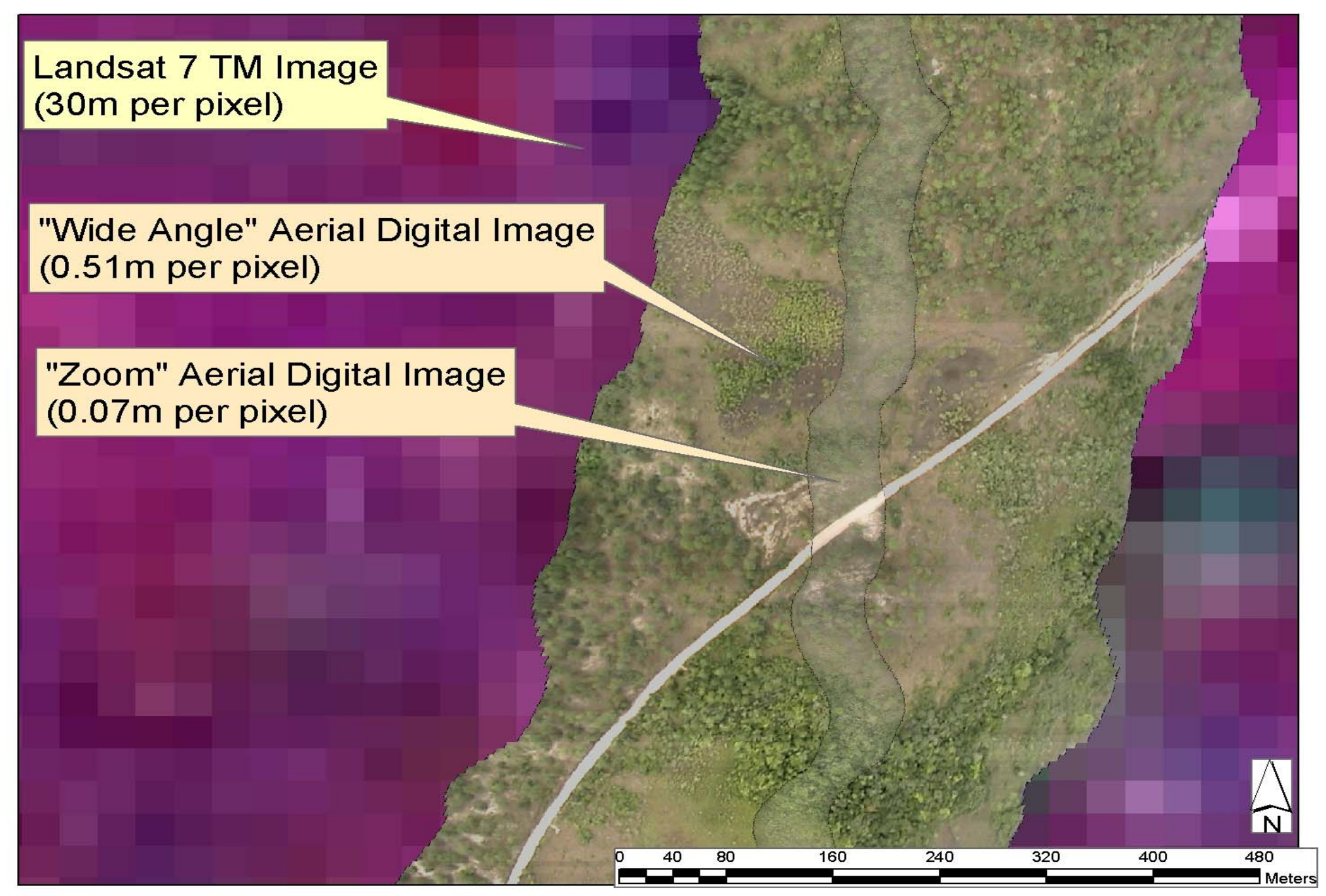


Wide Angle Vs. Zoom Images

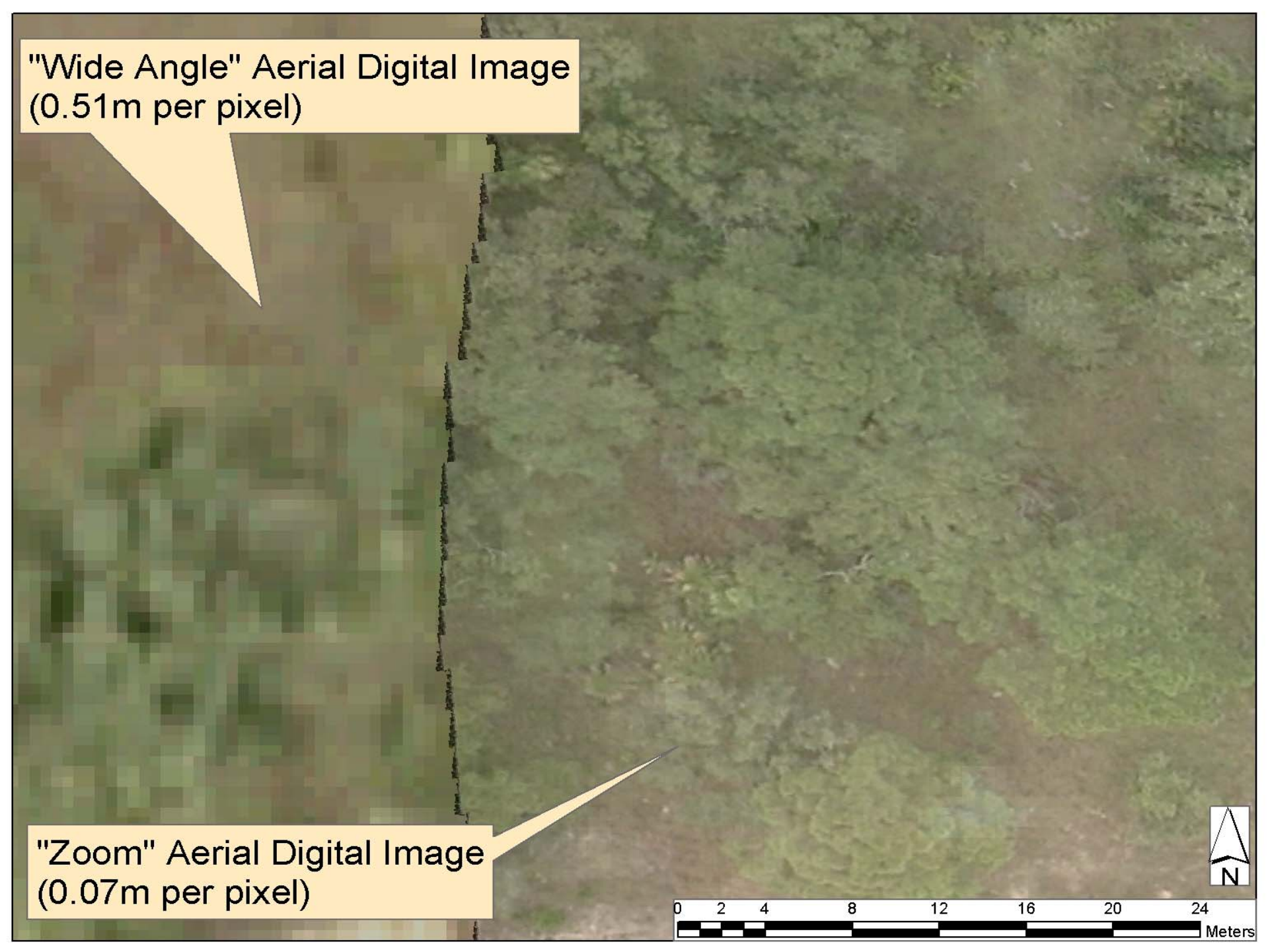




\section{Stereoscopic Image Analysis}

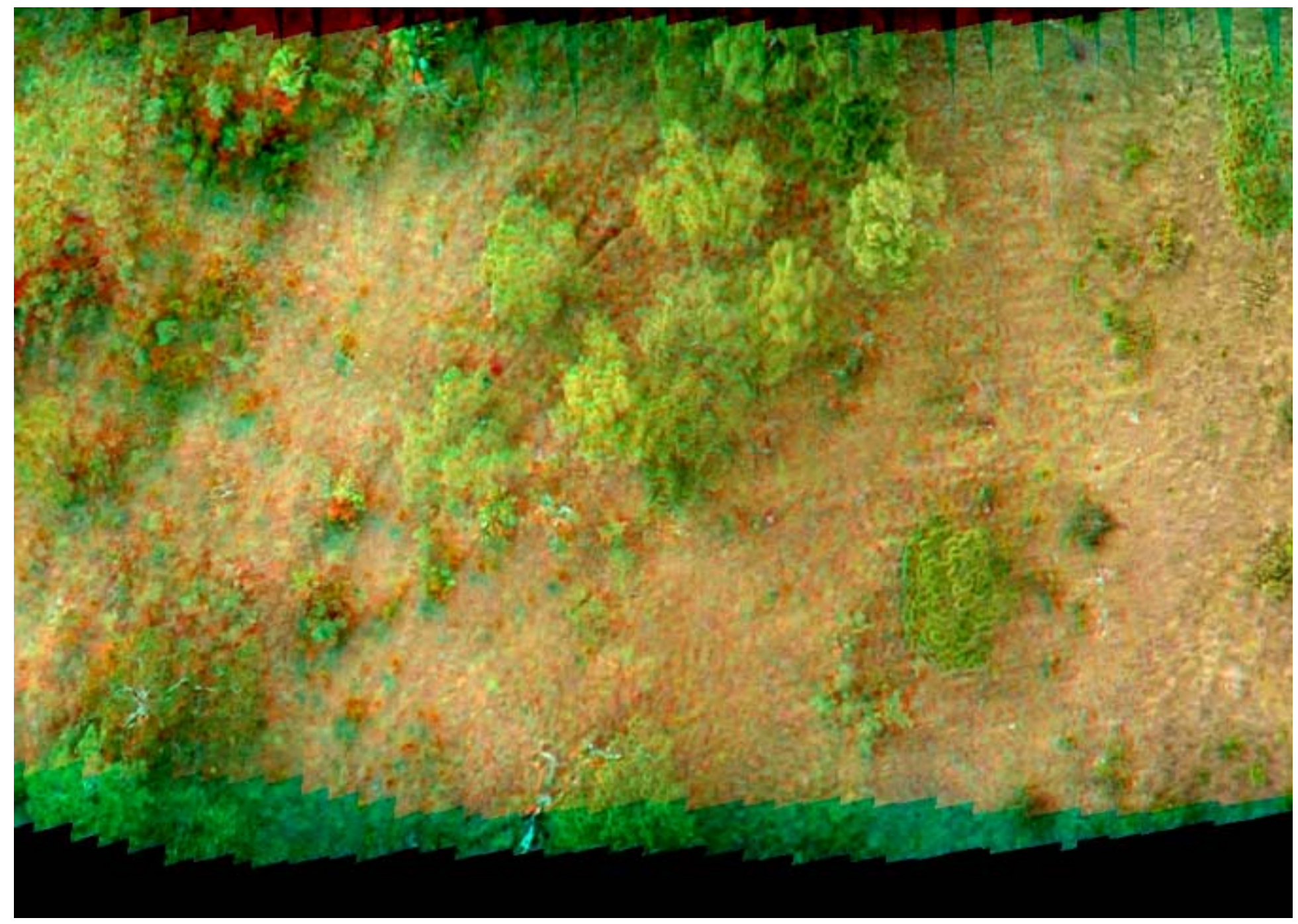




\section{Pine Savannah Classifications}
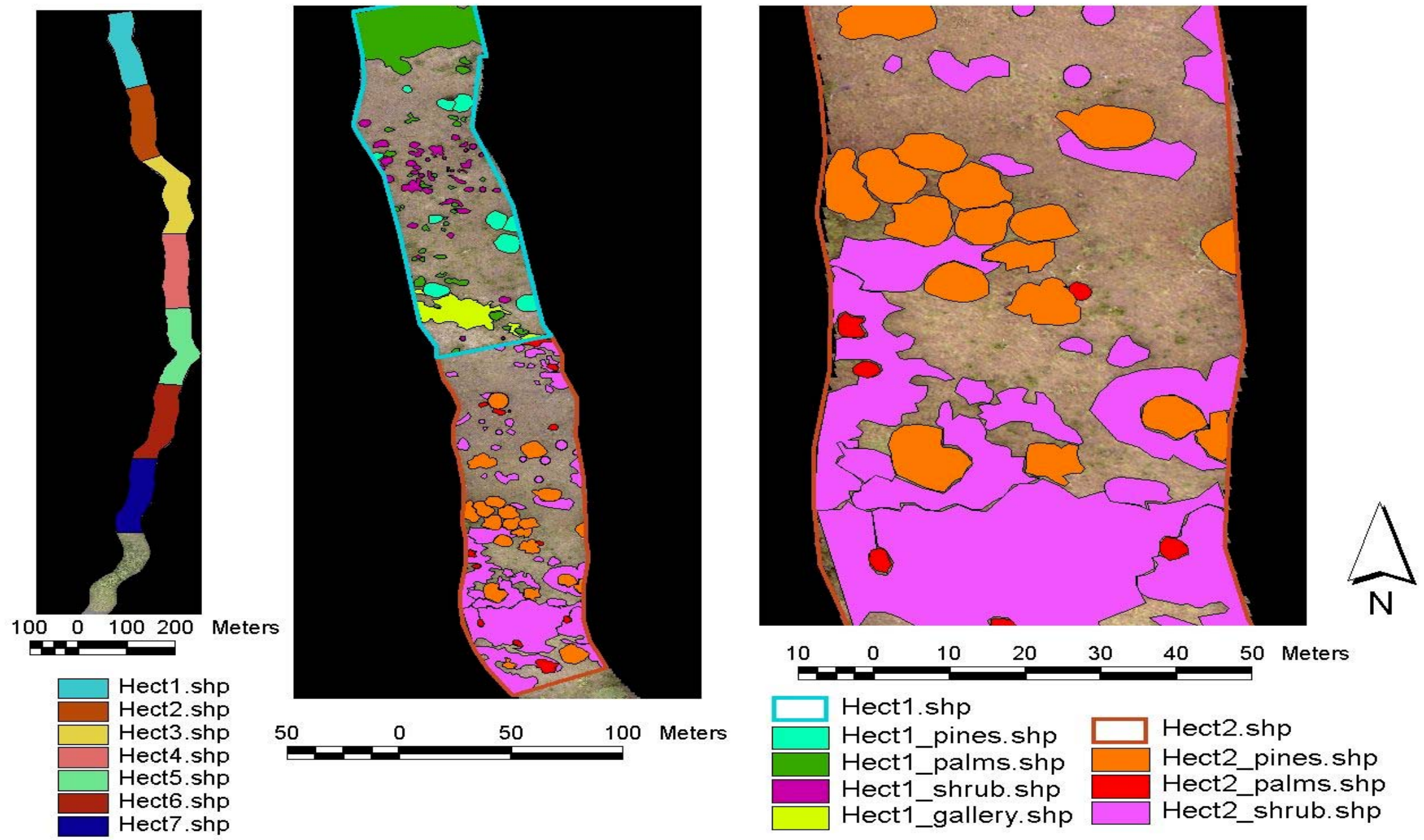

Hect1 shp

Hect1 pines.shp $\square$ Hect2.shp

Hect1 palms.shp $\square$ Hect2_pines.shp

Hect1_shrub.shp $\square$ Hect2_palms.shp Hect1_gallery.shp $\square$ Hect2_shrub.shp 
Sample of Percent Coverage by Study Plot

\begin{tabular}{|l|rr|}
\hline Class & Total Area (sqr meters) & Percent Coverage \\
\hline Plot 1 & 10005.440 & \\
Pines & 521.891 & $5.22 \%$ \\
Palms & 1778.387 & $17.77 \%$ \\
Shrubs & 375.750 & $3.76 \%$ \\
Gallery & 497.756 & $4.97 \%$ \\
Grassland & 6831.656 & $68.28 \%$ \\
\hline \hline Plot 2 & 9932.519 & \\
Pines & 1086.661 & $10.94 \%$ \\
Palms & 186.902 & $1.88 \%$ \\
Shrubs & 2959.365 & $29.79 \%$ \\
Grassland & 5699.591 & $57.38 \%$ \\
\hline \hline Plot 3 & 10204.129 & \\
Pines & 3038.679 & $4.46 \%$ \\
Palms & 454.693 & $28.60 \%$ \\
Shrubs & 2918.798 & $37.16 \%$ \\
Grassland & 3791.959 & \\
\hline \hline Plot 4 & 10039.234 & $3.22 \%$ \\
Pines & 2327.091 & $19.96 \%$ \\
Palms & 323.379 & $53.64 \%$ \\
Shrubs & 2003.385 & \\
Grassland & 5385.379 & \\
\hline
\end{tabular}


Appendix 5.

Kankakee Sands Soil Sampling Coordinates

Project

:

Sampling Site:

Samples taken :

Sampling Date:

\begin{tabular}{lllr} 
Site & $\begin{array}{c}\text { Sample } \\
\text { Type }\end{array}$ & ID \# & \multicolumn{1}{c}{ UTM E } \\
BLP/N & $30 \mathrm{~cm}$ & BLP/N-1 & $16-464303$ \\
BLP/N & $30 \mathrm{~cm}$ & BLP/N-2 & 464297 \\
BLP/N & $30 \mathrm{~cm}$ & BLP/N-3 & 464282 \\
BLP/N & $30 \mathrm{~cm}$ & BLP/N-4 & 464265 \\
BLP/N & $30 \mathrm{~cm}$ & BLP/N-5 & 464251 \\
BLP/N & $30 \mathrm{~cm}$ & BLP/N-6 & 464238 \\
BLP/N & $30 \mathrm{~cm}$ & BLP/N-7 & 464227 \\
BLP/N & $30 \mathrm{~cm}$ & BLP/N-8 & 464204 \\
BLP/N & $30 \mathrm{~cm}$ & BLP/N-9 & 464184 \\
BLP/N & $30 \mathrm{~cm}$ & BLP/N-10 & 464169 \\
BLP/N & $30 \mathrm{~cm}$ & BLP/N-11 & 464161 \\
BLP/N & $30 \mathrm{~cm}$ & BLP/N-12 & 464142 \\
BLP/N & $30 \mathrm{~cm}$ & BLP/N-13 & 464129 \\
BLP/N & $30 \mathrm{~cm}$ & BLP/N-14 & 464113 \\
BLP/N & $30 \mathrm{~cm}$ & BLP/N-15 & 464099 \\
BLP/N & $30 \mathrm{~cm}$ & BLP/N-16 & 464084 \\
BLP/N & $30 \mathrm{~cm}$ & BLP/N-17 & 464068 \\
BLP/N & $30 \mathrm{~cm}$ & BLP/N-18 & 464050 \\
BLP/N & $30 \mathrm{~cm}$ & BLP/N-19 & 464034 \\
BLP/N & $30 \mathrm{~cm}$ & BLP/N-20 & 464015 \\
BLP/N & $30 \mathrm{~cm}$ & BLP/N-21 & 463998 \\
BLP/N & $30 \mathrm{~cm}$ & BLP/N-22 & 463979 \\
BLP/N & $30 \mathrm{~cm}$ & BLP/N-23 & 463969 \\
BLP/N & $30 \mathrm{~cm}$ & BLP/N-24 & 463968 \\
BLP/N & $30 \mathrm{~cm}$ & BLP/N-25 & 463970 \\
BLP/N & $30 \mathrm{~cm}$ & BLP/N-26 & 463976 \\
BLP/N & $30 \mathrm{~cm}$ & BLP/N-27 & 463989 \\
BLP/N & $30 \mathrm{~cm}$ & BLP/N-28 & 464009 \\
BLP/N & $30 \mathrm{~cm}$ & BLP/N-29 & 464029 \\
BLP/N & $30 \mathrm{~cm}$ & BLP/N-30 & 464047 \\
BLP/N & $30 \mathrm{~cm}$ & BLP/N-31 & 464065 \\
BLP/N & $30 \mathrm{~cm}$ & BLP/N-32 & 464072 \\
BLP/N & $30 \mathrm{~cm}$ & BLP/N-33 & 464086
\end{tabular}
North)

23-Jul-02

Kankakee Sands

Restoration Project

BLP/N (Beaver Lake Prairie I

$30 \mathrm{~cm}$, Bulk Density (BD), $1 \mathrm{~m}$ (ESP)

\section{Coordinates}




\begin{tabular}{|c|c|c|c|}
\hline BLP/N & $30 \mathrm{~cm}$ & BLP/N-34 & 464102 \\
\hline BLP/N & $30 \mathrm{~cm}$ & BLP/N-35 & 464120 \\
\hline BLP/N & $1 \mathrm{~m}(\mathrm{ESP})$ & $\begin{array}{l}\text { BLP/N-1 } \\
\text { ESP }\end{array}$ & $16-464303$ \\
\hline BLP/N & $1 \mathrm{~m}(\mathrm{ESP})$ & $\begin{array}{l}\text { BLP/N-3 } \\
\text { ESP }\end{array}$ & 464282 \\
\hline BLP/N & $1 \mathrm{~m}(\mathrm{ESP})$ & $\begin{array}{l}\text { BLP/N-7 } \\
\text { ESP }\end{array}$ & 464227 \\
\hline BLP/N & BD & BLP/N-1 BD & $16-464303$ \\
\hline BLP/N & $B D$ & BLP/N-3 BD & 464282 \\
\hline BLP/N & BD & BLP/N-7 BD & 46422 \\
\hline BLP/N & BD & $\begin{array}{l}\text { BLP/N-11 } \\
\text { BD }\end{array}$ & 4641 \\
\hline BLP/N & $\mathrm{BD}$ & BLP/N-16 BD & 4640 \\
\hline
\end{tabular}

\section{Project : \\ Sampling Site:}

Samples taken :

Sampling Date:

$\begin{array}{ll}\text { Site } & \begin{array}{c}\text { Sample } \\ \text { Type }\end{array} \\ \text { BLP/S } & 30 \mathrm{~cm} \\ \text { BLP/S } & 30 \mathrm{~cm} \\ \text { BLP/S } & 30 \mathrm{~cm} \\ \text { BLP/S } & 30 \mathrm{~cm} \\ \text { BLP/S } & 30 \mathrm{~cm} \\ \text { BLP/S } & 30 \mathrm{~cm} \\ \text { BLP/S } & 30 \mathrm{~cm} \\ \text { BLP/S } & 30 \mathrm{~cm} \\ \text { BLP/S } & 30 \mathrm{~cm} \\ \text { BLP/S } & 30 \mathrm{~cm} \\ \text { BLP/S } & 30 \mathrm{~cm} \\ \text { BLP/S } & 30 \mathrm{~cm} \\ \text { BLP/S } & 30 \mathrm{~cm} \\ \text { BLP/S } & 30 \mathrm{~cm} \\ \text { BLP/S } & 30 \mathrm{~cm} \\ \text { BLP/S } & 30 \mathrm{~cm} \\ \text { BLP/S } & 30 \mathrm{~cm} \\ \text { BLP/S } & 30 \mathrm{~cm} \\ \text { BLP/S } & 30 \mathrm{~cm}\end{array}$

\section{Kankakee Sands Restoration Project BLP/S (Beaver Lake Prairie I South)}

T30N/R09W/SE1/4 of NW1/4 of S2 McClellan Twp, Newton Co, Indiana

$30 \mathrm{~cm}$, Bulk Density (BD), $1 \mathrm{~m}$ (ESP)

24-Jul-02

\section{Coordinates}

\section{ID \#}

BLP/S-1

BLP/S-2

BLP/S-3

BLP/S-4

BLP/S-5

BLP/S-6

BLP/S-7

BLP/S-8

BLP/S-9

BLP/S-10

BLP/S-11

BLP/S-12

BLP/S-13

BLP/S-14

BLP/S-15

BLP/S-16

BLP/S-17

BLP/S-18

BLP/S-19

\section{UTM E UTM N}
4643754547785
4643914547788
4644074547791
4644244547793
4644404547796
4644574547799
4644734547802
4644914547804
4645064547809
4645234547810
4645394547812
4645564547815
4645744547817
4645914547818
4646154547825
4646324547825
4647094547838
4646714547832
4646834547834 


\begin{tabular}{|c|c|c|c|}
\hline BLP/S & $30 \mathrm{~cm}$ & BLP/S-20 & 4647004547836 \\
\hline BLP/S & $30 \mathrm{~cm}$ & BLP/S-21 & 4647064547846 \\
\hline BLP/S & $30 \mathrm{~cm}$ & BLP/S-22 & 4647184547857 \\
\hline BLP/S & $30 \mathrm{~cm}$ & BLP/S-23 & 4647314547870 \\
\hline BLP/S & $30 \mathrm{~cm}$ & BLP/S-24 & 4647424647880 \\
\hline BLP/S & $30 \mathrm{~cm}$ & BLP/S-25 & 4647574647757 \\
\hline BLP/S & $30 \mathrm{~cm}$ & BLP/S-26 & 4647124547819 \\
\hline $\mathrm{BLP} / \mathrm{S}$ & $30 \mathrm{~cm}$ & BLP/S-27 & 4647124547819 \\
\hline BLP/S & $30 \mathrm{~cm}$ & BLP/S-28 & 4648064547844 \\
\hline BLP/S & $30 \mathrm{~cm}$ & BLP/S-29 & 4648164547848 \\
\hline BLP/S & $30 \mathrm{~cm}$ & BLP/S-30 & 4648284547836 \\
\hline BLP/S & $30 \mathrm{~cm}$ & BLP/S-31 & 4648454547832 \\
\hline BLP/S & $30 \mathrm{~cm}$ & BLP/S-32 & 4648124547812 \\
\hline BLP/S & $30 \mathrm{~cm}$ & BLP/S-33 & 4648644547804 \\
\hline BLP/S & $30 \mathrm{~cm}$ & BLP/S-34 & 4648784547793 \\
\hline BLP/S & $30 \mathrm{~cm}$ & BLP/S-35 & 4648244547706 \\
\hline BLP/S & BD & BLP/S-1 BD & 4643754547785 \\
\hline BLP/S & $\mathrm{BD}$ & $\begin{array}{c}\text { BLP/S-10 } \\
\text { BD }\end{array}$ & 4645234547810 \\
\hline BLP/S & BD & $\begin{array}{c}\text { BLP/S-15 } \\
\text { BD }\end{array}$ & 4646154547825 \\
\hline BLP/S & BD & $\begin{array}{c}\text { BLP/S-20 } \\
\text { BD }\end{array}$ & 4647004547836 \\
\hline BLP/S & BD & $\begin{array}{c}\text { BLP/S-30 } \\
\text { BD }\end{array}$ & 4648284547836 \\
\hline BLP/S & $\begin{array}{c}1 \mathrm{~m} \\
(\mathrm{ESP})\end{array}$ & $\begin{array}{c}\text { BLP/S-1 } \\
\text { ESP }\end{array}$ & 4643754547785 \\
\hline BLP/S & $\begin{array}{c}1 \mathrm{~m} \\
(\mathrm{ESP})\end{array}$ & $\begin{array}{c}\text { BLP/S-10 } \\
\text { ESP }\end{array}$ & 4645234547810 \\
\hline
\end{tabular}

Location :

Kankakee Sands Restoration

Project

Sampling Site:

Stoutsburg Savanna

T32N/R06E/SE1/4 of NW1/4 of S2

Wheatfield Twp.,Jasper

Co, IN

Samples

taken :

Sampling

Date:

$\begin{array}{ccc}\text { Site } & \begin{array}{c}\text { Sample } \\ \text { Type }\end{array} & \text { ID \# } \\ \text { Stoutsburg, East } & 30 \mathrm{~cm} & \text { Stoutsburg East-1 } \\ \text { Stoutsburg, East } & 30 \mathrm{~cm} & \text { Stoutsburg East-2 }\end{array}$

\begin{tabular}{cc}
\multicolumn{2}{c}{ Coordinates } \\
UTM E & UTM E \\
492473 & 4557790 \\
492453 & 4557794
\end{tabular}




\begin{tabular}{|c|c|c|c|}
\hline Stoutsburg, East & $30 \mathrm{~cm}$ & Stoutsburg East-3 & 4924324557796 \\
\hline Stoutsburg, East & $30 \mathrm{~cm}$ & Stoutsburg East-4 & 4923984557798 \\
\hline Stoutsburg, East & $30 \mathrm{~cm}$ & Stoutsburg East-5 & 4923714557797 \\
\hline Stoutsburg, East & $30 \mathrm{~cm}$ & Stoutsburg East- 6 & 4923434557800 \\
\hline Stoutsburg, East & $30 \mathrm{~cm}$ & Stoutsburg East-7 & 4923144557801 \\
\hline Stoutsburg, East & $30 \mathrm{~cm}$ & Stoutsburg East-8 & 4922894557800 \\
\hline Stoutsburg, East & $30 \mathrm{~cm}$ & Stoutsburg East-9 & 4922614557803 \\
\hline Stoutsburg, East & $30 \mathrm{~cm}$ & Stoutsburg East-10 & 4922614557806 \\
\hline $\begin{array}{l}\text { Stoutsburg, } \\
\text { Central }\end{array}$ & $30 \mathrm{~cm}$ & Stoutsburg Central-1 & 4919914557800 \\
\hline $\begin{array}{l}\text { Stoutsburg, } \\
\text { Central }\end{array}$ & $30 \mathrm{~cm}$ & Stoutsburg Central-2 & 4919334557796 \\
\hline $\begin{array}{l}\text { Stoutsburg, } \\
\text { Central }\end{array}$ & $30 \mathrm{~cm}$ & Stoutsburg Central-3 & $491899 \quad 455779$ \\
\hline $\begin{array}{l}\text { Stoutsburg, } \\
\text { Central }\end{array}$ & $30 \mathrm{~cm}$ & Stoutsburg Central-4 & 4918604557800 \\
\hline $\begin{array}{l}\text { Stoutsburg, } \\
\text { Central }\end{array}$ & $30 \mathrm{~cm}$ & Stoutsburg Central-5 & 4918584547828 \\
\hline $\begin{array}{l}\text { Stoutsburg, } \\
\text { Central }\end{array}$ & $30 \mathrm{~cm}$ & Stoutsburg Central-6 & 4918614557861 \\
\hline $\begin{array}{l}\text { Stoutsburg, } \\
\text { Central }\end{array}$ & $30 \mathrm{~cm}$ & Stoutsburg Central-7 & 4918664557904 \\
\hline $\begin{array}{l}\text { Stoutsburg, } \\
\text { Central }\end{array}$ & $30 \mathrm{~cm}$ & Stoutsburg Central-8 & 4918694557947 \\
\hline $\begin{array}{l}\text { Stoutsburg, } \\
\text { Central }\end{array}$ & $30 \mathrm{~cm}$ & Stoutsburg Central-9 & 4918754557984 \\
\hline $\begin{array}{l}\text { Stoutsburg, } \\
\text { Central }\end{array}$ & $30 \mathrm{~cm}$ & Stoutsburg Central-10 & 4918814558018 \\
\hline $\begin{array}{l}\text { Stoutsburg, } \\
\text { West }\end{array}$ & $30 \mathrm{~cm}$ & Stoutsburg West-1 & 4917384557784 \\
\hline $\begin{array}{l}\text { Stoutsburg, } \\
\text { West }\end{array}$ & $30 \mathrm{~cm}$ & Stoutsburg West-2 & 4917434557818 \\
\hline $\begin{array}{l}\text { Stoutsburg, } \\
\text { West }\end{array}$ & $30 \mathrm{~cm}$ & Stoutsburg West-3 & 4917484557855 \\
\hline $\begin{array}{l}\text { Stoutsburg, } \\
\text { West }\end{array}$ & $30 \mathrm{~cm}$ & Stoutsburg West-4 & 4917544557895 \\
\hline $\begin{array}{l}\text { Stoutsburg, } \\
\text { West }\end{array}$ & $30 \mathrm{~cm}$ & Stoutsburg West-5 & 4917604557930 \\
\hline $\begin{array}{l}\text { Stoutsburg, } \\
\text { West }\end{array}$ & $30 \mathrm{~cm}$ & Stoutsburg West-6 & 4917674557962 \\
\hline $\begin{array}{l}\text { Stoutsburg, } \\
\text { West }\end{array}$ & $30 \mathrm{~cm}$ & Stoutsburg West-7 & 4917744558000 \\
\hline $\begin{array}{l}\text { Stoutsburg, } \\
\text { West }\end{array}$ & $30 \mathrm{~cm}$ & Stoutsburg West-8 & 4917454558060 \\
\hline $\begin{array}{l}\text { Stoutsburg, } \\
\text { West }\end{array}$ & $30 \mathrm{~cm}$ & Stoutsburg West-9 & 4917404557989 \\
\hline $\begin{array}{l}\text { Stoutsburg, } \\
\text { West }\end{array}$ & $30 \mathrm{~cm}$ & Stoutsburg- West-10 & 4917284557969 \\
\hline
\end{tabular}


Stoutsburg,

$30 \mathrm{~cm}$ Stoutsburg West-11

4917164557944

West

Stoutsburg,

$30 \mathrm{~cm}$ Stoutsburg West-12

4917074557918

West

Stoutsburg,

$30 \mathrm{~cm}$ Stoutsburg, West, 13

4916994557899

West

Stoutsburg,

$30 \mathrm{~cm} \quad$ Stoutsburg West-14

4916854557869

West

Stoutsburg,

$30 \mathrm{~cm} \quad$ Stoutsburg West-15

4916834557854

West

Stoutsburg,

BD Stoutsburg West-1 BD

4917384557784

West

Stoutsburg,

West

Stoutsburg, East

Stoutsburg, East

Stoutsburg,

Central

BD Stoutsburg West-6 BD

4917674557962

BD Stoutsburg East-9 BD

4922614557803

BD Stoutsburg East-4 BD

4923984557798

BD Stoutsburg Central-6

4918614557861

\section{Locati}

on :

Sampling Site: Conrad

Kankakee Sands

Restoration Project

\section{Savanna}

T31N/R09W/SE1/4 of S27

Lake Twp, Newton Co, Indiana

Samples taken : $\quad 30 \mathrm{~cm}$, Bulk Density (BD), $1 \mathrm{~m}$ (ESP)

Sampling Date: 23-Jul-02

$\begin{array}{cccc}\text { Site } & \begin{array}{c}\text { Sample } \\ \text { Type }\end{array} & \text { ID \# } & \text { UTM E UTM N } \\ \text { Conrad } & \begin{array}{c}\text { Cocm } \\ \text { Conrad }\end{array} & \text { Conrad-1 } & 16-4550244 \\ \text { Conrad } & 30 \mathrm{~cm} & \text { Conrad-2 } & 463159 \\ \text { Conrad } & 30 \mathrm{~cm} & \text { Conrad-3 } & 4632004550248 \\ \text { Conrad } & 30 \mathrm{~cm} & \text { Conrad-4 } & 4633914550274 \\ \text { Conrad } & 30 \mathrm{~cm} & \text { Conrad-5 } & 4634824550291 \\ \text { Conrad } & 30 \mathrm{~cm} & \text { Conrad-6 } & 4635204550295 \\ \text { Conrad } & 30 \mathrm{~cm} & \text { Conrad-7 } & 4635254550330 \\ \text { Conrad } & 30 \mathrm{~cm} & \text { Conrad-8 } & 4635294550352 \\ \text { Conrad } & 30 \mathrm{~cm} & \text { Conrad-9 } & 4635774550380 \\ \text { Conrad } & 30 \mathrm{~cm} & \text { Conrad-10 } & 4636124550384 \\ \text { Conrad } & 30 \mathrm{~cm} & \text { Conrad-11 } & 4636294550350 \\ \text { Conrad } & 30 \mathrm{~cm} & \text { Conrad-12 } & 4636374550323\end{array}$




$\begin{array}{lccc}\text { Conrad } & 30 \mathrm{~cm} & \text { Conrad-13 } & 4636414550300 \\ \text { Conrad } & 30 \mathrm{~cm} & \text { Conrad-14 } & 4636404550274 \\ \text { Conrad } & 30 \mathrm{~cm} & \text { Conrad-15 } & 4636384550247 \\ \text { Conrad } & 30 \mathrm{~cm} & \text { Conrad-16 } & 4636274550237 \\ \text { Conrad } & 30 \mathrm{~cm} & \text { Conrad-17 } & 4636174550212 \\ \text { Conrad } & 30 \mathrm{~cm} & \text { Conrad-18 } & 4636134550198 \\ \text { Conrad } & 30 \mathrm{~cm} & \text { Conrad-19 } & 4635854550206 \\ \text { Conrad } & 30 \mathrm{~cm} & \text { Conrad-20 } & 4635364550211 \\ \text { Conrad } & 30 \mathrm{~cm} & \text { Conrad-21 } & 4634814550216 \\ \text { Conrad } & 30 \mathrm{~cm} & \text { Conrad-22 } & 4634284550203 \\ \text { Conrad } & 30 \mathrm{~cm} & \text { Conrad-23 } & 4634014550194 \\ \text { Conrad } & 30 \mathrm{~cm} & \text { Conrad-24 } & 4633754550190 \\ \text { Conrad } & 30 \mathrm{~cm} & \text { Conrad-25 } & 4633414550182 \\ \text { Conrad } & 30 \mathrm{~cm} & \text { Conrad-26 } & 4632884550169 \\ \text { Conrad } & 30 \mathrm{~cm} & \text { Conrad-27 } & 4631364549971 \\ \text { Conrad } & 30 \mathrm{~cm} & \text { Conrad-28 } & 4631834549982 \\ \text { Conrad } & 30 \mathrm{~cm} & \text { Conrad-29 } & 4632194549977 \\ \text { Conrad } & 30 \mathrm{~cm} & \text { Conrad-30 } & 4632504549976 \\ \text { Conrad } & 1 \mathrm{~m} \mathrm{(ESP)} & \text { Conrad-1, ESP } & 16-4550244 \\ & & & 463159 \\ \text { Conrad } & \text { BD } & \text { Conrad-1 BD } & 16-4550244 \\ & & & 463159 \\ \text { Conrad } & \text { BD } & \text { Conrad-2 BD } & 4632004550248 \\ \text { Conrad } & \text { BD } & \text { Conrad-3 BD } & 4632864550274 \\ \text { Conrad } & \text { BD } & \text { Conrad-4 BD } & 4633914550280 \\ \text { Conrad } & \text { BD } & \text { Conrad-5 BD } & 4634824550291\end{array}$

